NBER WORKING PAPER SERIES

\title{
RESERVATION RAISES: \\ THE AGGREGATE LABOR SUPPLY CURVE AT THE EXTENSIVE MARGIN
}

Preston Mui

Benjamin Schoefer

Working Paper 28770

http://www.nber.org/papers/w28770

\author{
NATIONAL BUREAU OF ECONOMIC RESEARCH \\ 1050 Massachusetts Avenue \\ Cambridge, MA 02138 \\ May 2021
}

A 2019 version of this paper was circulated under the title "The Aggregate Labor Supply Curve at the Extensive Margin: A Reservation Wedge Approach." We thank referees of the previous version for constructive feedback, which has greatly improved the paper. We thank Chaoran $\mathrm{Yu}$ for excellent research assistance. We thank Mark Aguiar, Mark Bils, Gabriel Chodorow-Reich, Shigeru Fujita, Adam Guren, Greg Kaplan, Loukas Karabarbounis, Marios Karabarbounis, David Lagakos, Ellen McGrattan, Monika Merz, Luigi Pistaferri, Richard Rogerson, Ayşegül Şahin, Sergio Salgado, and Gianluca Violante for useful comments. We thank seminar participants at Amsterdam/Tinbergen, Bonn, the Central Bank of Chile, Edinburgh, the Federal Reserve Bank of Philadelphia, New York University, Princeton, Stanford/SIEPR, the Virtual Australian Macroeconomics Seminar, UC Berkeley, UC San Diego, and VATT. We thank conference audiences at the Bank of Italy-CEPR Labour workshop, the ifo Conference on Macroeconomics and Survey Data, the NBER Dynamic Equilibrium Models meeting, the NBER Summer Institute Micro Data and Macro Models meeting, the NBER Summer Institute Impulse and Propagation Mechanisms meeting, the Society of Economic Dynamics Annual Meeting, and the West Coast Matching Workshop (Federal Reserve Bank of San Francisco). For financial support of our custom survey, we thank the Clausen Center and the Institute for Research on Labor and Employment at UC Berkeley, and SIEPR at Stanford. We thank the survey design teams of NORC at UChicago, and GSOEP/Kantar. The survey received IRB approval from UC Berkeley (protocol number 2019-02-11815). The views expressed herein are those of the authors and do not necessarily reflect the views of the National Bureau of Economic Research.

NBER working papers are circulated for discussion and comment purposes. They have not been peer-reviewed or been subject to the review by the NBER Board of Directors that accompanies official NBER publications.

(C) 2021 by Preston Mui and Benjamin Schoefer. All rights reserved. Short sections of text, not to exceed two paragraphs, may be quoted without explicit permission provided that full credit, including $(\odot$ notice, is given to the source. 
Reservation Raises: The Aggregate Labor Supply Curve at the Extensive Margin

Preston Mui and Benjamin Schoefer

NBER Working Paper No. 28770

May 2021

JEL No. E24,E32,J22,J64

\begin{abstract}
$\underline{\text { ABSTRACT }}$
We measure extensive-margin labor supply (employment) preferences in two representative surveys of the U.S. and German populations. We elicit reservation raises: the percent wage change that renders a given individual indifferent between employment and nonemployment. It is equal to her reservation wage divided by her actual, or potential, wage. The reservation raise distribution is the nonparametric aggregate labor supply curve. Locally, the curve exhibits large short-run elasticities above 3, consistent with business cycle evidence. For larger upward shifts, arc elasticities shrink towards 0.5 , consistent with quasi-experimental evidence from tax holidays. Existing models fail to match this nonconstant, asymmetric curve.
\end{abstract}

\author{
Preston Mui \\ University of California at Berkeley \\ mui@ berkeley.edu \\ Benjamin Schoefer \\ Department of Economics \\ University of California, Berkeley \\ 530 Evans Hall \#3880 \\ Berkeley, CA 94720-3880 \\ and NBER \\ schoefer@berkeley.edu
}




\section{Introduction}

Business cycle fluctuations in total hours largely reflect employment shifts, i.e., they occur along the extensive margin (see, e.g., Heckman, 1984). Hence, the shape of the short-run aggregate labor supply curve at the extensive margin - the total number of individuals desiring to work as a function of prevailing wages-is a crucial factor in business cycle models. In market-clearing equilibrium models, this curve forms the iron link between wages and employment, with business cycles implying large elasticities, i.e., a large mass of marginal individuals (Hansen, 1985; Rogerson, 1988). In models of wage bargaining and search frictions, the curve enters workers' outside options and reservation wages (Jäger, Schoefer, Young, and Zweimüller, 2020; Koenig, Manning, and Petrongolo, 2020), so that large employment fluctuations again imply a large mass of marginal individuals (Hagedorn and Manovskii, 2008; Ljungqvist and Sargent, 2017). In New Keynesian models, the aggregate labor supply curve shapes the Phillips curves for wages and prices, which imply large elasticities or the presence of frictions (Gali, 2011). The local elasticity of the curve, and hence the mass of marginal individuals, also determines the cyclical amplitude of potential labor market disequilibria and their welfare costs (Shimer, 2009). It also speaks to the employment effects of earnings subsidies (Card and Hyslop, 2005, Kleven, 2019) and tax reforms (Martinez, Saez, and Siegenthaler, 2021). Finally, the short-run, Frisch elasticity is also an upper bound for the Hicksian elasticity (Chetty, 2012), which in turn guides the long-run labor supply effects of taxation (Prescott, 2004: Saez, Slemrod, and Giertz, 2012).

The existing strategies to measure the extensive-margin aggregate labor supply curve are threefold. First, a long literature has structurally estimated specific models with participation choices-making parametric assumptions about functional forms, including the joint distribution of tastes and wages, on the basis of observational data. 1 Second, recent quasi-experimental studies of income tax holidays have disciplined specific arc elasticities-albeit with respect to net-of-tax wage changes an order of magnitude larger than those over business cycles. 2 They may also capture equilibrium, compensated, and frictional effects, rather than purely preferences. Third, a small strand of research has elicited labor supply preferences in surveys-albeit in specific and selected samples such

${ }^{1}$ For examples of structurally estimated labor supply models with participation margins, see, e.g., Heckman and MaCurdy (1980); Chang and Kim (2007); Gourio and Noual (2009); Blundell, Pistaferri, and Saporta-Eksten (2016); Chang and Kim (2006); Park (2020); Attanasio, Levell, Low, and Sánchez-Marcos (2018); Beffy, Blundell, Bozio, Laroque, and To (2019).

${ }^{2}$ For estimates of employment effects of income tax holidays and the implied arc elasticities, see Bianchi, Gudmundsson, and Zoega (2001); Chetty, Guren, Manoli, and Weber (2012); Martinez, Saez, and Siegenthaler (2021); Sigurdsson (2018). 
as of unemployed job seekers or older workers. 3

Yet, no survey evidence exists on the extensive-margin labor supply preferences of a representative sample of individuals from all labor force groups: employed, unemployed, and out of the labor force. Such a comprehensive sample is necessary to measure the aggregate labor supply curve for an entire economy and to discipline macro models.

We fill this gap by eliciting extensive-margin labor supply preferences from a representative sample of individuals from all labor forces groups, and on that basis provide a nonparametric estimate of the global aggregate labor supply curve. As a convenient scalar measure, we capture these preferences in the form of reservation (pay) raises (or cuts): the hypothetical percent shift in an individual's actual/potential labor earnings required to render her indifferent between employment and nonemployment. It equals the ratio of an individual's actual/potential wage to her reservation wage. It is therefore a close cousin of the standard reservation wage (which enters aggregate labor supply, as in Chang and Kim, 2006, 2007). The convenient difference is that, by being normalized by an individual's idiosyncratic actual/potential wage, the reservation raise collapses these two dimensions of heterogeneity into a scalar sufficient statistic. ${ }^{4}$ Reservation raises then give the aggregate labor supply curve as a univariate function: the cumulative distribution function $(\mathrm{CDF})$ of the reservation raises. Its argument is the prevailing aggregate raise, a homogeneous proportionate wage shifter, which stands in for specific experiments such as aggregate productivity shocks or linear tax reforms.

We elicit reservation raises in two representative surveys covering all three labor force groups in the U.S. and Germany. Our first survey covers 2,071 U.S. respondents as part of the AmeriSpeak Omnibus Survey run by NORC at UChicago, in the spring of 2019. Our second survey is a custom questionnaire we integrated into German Socio-Economic Panel (GSOEP) conducted in the fall of 2019, covering 3,510 individuals.

The two surveys yield strikingly congruent aggregate labor supply curves. In each case, the empirical distribution of reservation raises exhibits a large mass around onewhere an individual's reservation wage equals her actual/potential wage. This large mass of marginal individuals generates a large local Frisch elasticity above 3, as implied by

${ }^{3}$ For studies of reservation wages of the unemployed, see Feldstein and Poterba (1984); Krueger and Mueller (2016); Le Barbanchon, Rathelot, and Roulet (2019); Kneip, Merz, and Storjohann (2020). Mas and Pallais (2019) study the employment preferences of job searchers applying to jobs at a call center. Ameriks, Briggs, Caplin, Lee, Shapiro, and Tonetti (2020) do so for the retirement margin of older workers with a focus on job flexibility. Kimball and Shapiro (2008) measure income effects on labor supply to hypothetical wealth shocks in a survey.

${ }^{4}$ Some existing research on reservation wages of the unemployed (Feldstein and Poterba, 1984, Krueger and Mueller. 2016) has used this "reservation wage ratio" as an ad hoc and informal normalization of empirical observations, but not interpreted it through the lens of an economic model or as a sufficient statistic for labor supply preferences. 
business cycle evidence (Hansen, 1985; Rogerson, 1988; Hagedorn and Manovskii, 2008; Ljungqvist and Sargent, 2017).

Globally, however, the empirical curves feature nonconstant arc elasticities, and considerable asymmetries. For wage decreases, the arc elasticities remain high. Here, considerable shares of employed workers require only moderate wage cuts to prefer temporary nonemployment. By contrast, for wage increases - where the curve eats into individuals out of the labor force-arc elasticities drop quickly, to around 0.5 . This low value in this portion of the curve is consistent with the quasi-experimental evidence for small employment responses to large net wage increases following income tax holidays (Bianchi, Gudmundsson, and Zoega, 2001; Chetty, Guren, Manoli, and Weber, 2012; Martinez, Saez, and Siegenthaler. 2021: Sigurdsson, 2018).

Overall, therefore, while isoelasticity is a standard assumption in empirical and modeling practice, our survey strategy reveals that no single constant elasticity would capture the global shape of the aggregate labor supply curve of either country. Both curves feature high local elasticities, which would guide business cycles, and, at the same time, low arc elasticities to large wage increases, which are relevant to, e.g., tax holidays. Moreover, we show that no existing calibrated model generates a curve that comes close to the empirical shape (although any given model could be reverse-engineered to match it).

Our survey-based research design aims to isolate preferences about desired employment status as a function of wage shifts. In the presence of labor market frictions, the labor supply curve need not perfectly guide realized employment changes (analogously to the intensive-margin argument by Keane and Rogerson, 2015; Chetty, 2012). For instance, with frictions, job loss in recessions need not follow the elastic pecking order prescribed by the reservation raise ranking, but may hit high-surplus individuals.

In Section, 2, we define aggregate labor supply on the basis of reservation raises. In Section 3, we describe the surveys, and discuss the empirical labor supply curves. In Section 4, we compare the empirical curves to those of existing macro models with an extensive margin. Section 5 concludes with questions our study leaves open.

\section{Conceptual Framework}

We define the individual-level reservation raise and show that its cumulative distribution function $(\mathrm{CDF})$ gives the aggregate labor supply curve.

Individual-level Employment At the individual level, the extensive-margin (employment) status is binary, $e_{i t} \in\{0,1\}$. For each individual indexed by $i \sim \mathcal{U}(0,1)$ at time $t$, 
desired extensive-margin labor supply can be formulated as a standard reservation wage rule. To abstract from hours choices, we cast the rule in terms of reservation earnings $y_{i t}^{r}$ (as an hourly wage $w$ will be featured in Section 4) compared to her potential earnings $y_{i t}$ :

$$
e_{i t}^{*}=\mathbb{1}\left(y_{i t} \geq y_{i t}^{r}\right)
$$

This standard reservation wage rule characterizes desired employment in rich settings, including those with dynamic considerations, adjustment costs, search frictions, borrowing constraints, or human capital considerations. Hence, besides spot labor markets, it also applies in frictional models, where desired and actual employment status need not coincide (for labor supply under search frictions, see Krusell et al., 2017). This section intentionally does not spell out detailed models; we present a simple spot labor market setup and specific cases thereof in Section 4 .

Aggregate desired employment rate $E_{t}^{*}$ equals the fraction of individuals with $y_{i t} \geq y_{i t}^{r}$ :

$$
\begin{aligned}
E_{t}^{*}(\cdot) & =\int_{i} e_{i t}^{*} d i \\
& =\int_{i} \mathbb{1}\left(y_{i t} \geq y_{i t}^{r}\right) d i \\
& =\int_{y^{r}} \int_{y} \mathbb{1}\left(y \geq y^{r}\right) f^{y \mid y^{r}}\left(y \mid y^{r}\right) f^{y^{r}} g\left(y^{r}\right) d y d y^{r},
\end{aligned}
$$

where an interior employment rate requires heterogeneity in either $y_{i t}$ or $y_{i t}^{r}$, or in both.

We reformulate this standard reservation wage setup by introducing two concepts.

The Aggregate Labor Earnings Shifter First, we define an aggregate prevailing raise $1+\Xi_{t}$. It is a homogeneous labor income shifter of potentially heterogeneous baseline labor earnings $y_{i t}$ - which are always defined gross of this aggregate raise, so that the allocative, net-ofraise potential earnings are $\left(1+\Xi_{t}\right) y_{i t}$. The shifter $1+\Xi_{t}$ operationalizes the question: how much would aggregate labor supply change if all labor earnings shifted by a percent amount given by raise $1+\Xi_{t}$ ? It stands in for specific experiments such as aggregate wage fluctuations, changes in productivity (e.g., Chang and Kim, 2006), or changes in labor taxes. (For convenience, we will refer to multiplier $1+\Xi_{t}$ as the raise, rather than $\Xi_{t}$ ) 
The Reservation (Pay) Raise Second, we define an individual's reservation raise $1+\xi_{i t}^{*}$ as the hypothetical aggregate prevailing raise $1+\Xi_{t}$ that would render her marginal 5

$$
\begin{gathered}
\left(1+\xi_{i t}^{*}\right) y_{i t}=y_{i t}^{r} \\
\Leftrightarrow 1+\xi_{i t}^{*}=\frac{y_{i t}^{r}}{y_{i t}}
\end{gathered}
$$

The reservation raise is a measure of rent, or surplus, from employment as a fraction of the idiosyncratic earnings, and hence the individual's distance from entering or leaving employment (relative to her idiosyncratic potential earnings).

Individual-level labor supply is then a cutoff rule of the reservation vs. the prevailing aggregate raise:

$$
e_{i t}^{*}=\left\{\begin{array}{lll}
0 & \text { if } & 1+\xi_{i t}^{*}>1+\Xi_{t} \\
1 & \text { if } & 1+\xi_{i t}^{*} \leq 1+\Xi_{t} .
\end{array}\right.
$$

Aggregate Labor Supply: the CDF of Reservation Raises Finally, aggregate labor supply can then be reformulated as a univariate function of the aggregate prevailing raise $1+\Xi_{t}$, with the function given by the reservation raise $C D F$, evaluated at aiven aggregate prevailing raise, corresponding to the fraction of individuals for whom $1+\xi_{i t}^{*} \leq 1+\Xi_{t}$ :

$$
\begin{aligned}
E_{t}^{*}\left(1+\Xi_{t} ; F_{t}\right)= & \int 1\left(1+\xi^{*} \leq 1+\Xi_{t}\right) d F_{t}\left(1+\xi^{*}\right) \\
= & \underbrace{F_{t}\left(1+\Xi_{t}\right)}_{\begin{array}{c}
\text { CDF of reservation raises, } \\
\text { evaluated at aggregate } \\
\text { prevailing raise } 1+\Xi_{t}
\end{array}}
\end{aligned}
$$

Comparison to the Reservation Wage The reservation raise of course simply equals the idiosyncratic reservation wage normalized by the idiosyncratic potential wage-thereby collapsing both dimensions of heterogeneity into a scalar sufficient statistic for an individual's desired employment status (to be paired with an aggregate prevailing raise).

The incremental added value of the reservation raise over the standard reservation wage concept is that it provides a standard labor supply curve: a univariate function drawing on the one-dimensional ranking of labor suppliers, that, evaluated at any aggregate prevailing raise, gives the desired aggregate employment rate. By contrast, the

${ }^{5}$ The lower case differentiates the micro reservation raise from the aggregate prevailing raise. The *-symbol denotes indifference, rather than a potential idiosyncratic prevailing micro raise. 
standard reservation wage distribution alone would not sufficiently rank individuals without simultaneous reference to their idiosyncratic potential earnings-encoded in the joint distribution of potential and reservation wages 6 Of course, that joint distribution does contain more information than the reservation raise distribution: the former can give the desired employment rate for any shift in the distribution of potential earnings, whereas the latter does so specifically for a homogeneous percent shift. Lastly, of course, with homogeneous wages, reservation wages are sufficient to characterize extensive-margin labor supply.

Employment Adjustment Employment adjustment to a shift in the aggregate prevailing raise from $\left(1+\Xi_{t}\right)$ to $\left(1+\Xi_{t}^{\prime}\right)$ is driven by the mass of nearly marginal individuals (for whom $\left.1+\Xi_{t}<1+\xi_{i t}^{*} \leq 1+\Xi_{t}^{\prime}\right)$, and amounts to $F_{t}\left(1+\Xi_{t}^{\prime}\right)-F_{t}\left(1+\Xi_{t}\right)$.

Aggregate Arc Elasticities For discrete raise changes, the arc elasticities of extensivemargin labor supply are:

$$
\epsilon_{E_{t},\left(1+\Xi_{t}\right) \rightarrow\left(1+\Xi_{t}^{\prime}\right)}=\frac{F_{t}\left(1+\Xi_{t}^{\prime}\right)-F_{t}\left(1+\Xi_{t}\right)}{F_{t}\left(1+\Xi_{t}\right)} / \frac{\left(1+\Xi_{t}^{\prime}\right)-\left(1+\Xi_{t}\right)}{1+\Xi_{t}} .
$$

For infinitesimal changes in $\left(1+\Xi_{t}\right)$, the elasticity is:

$$
\epsilon_{E_{t}, 1+\Xi_{t}}=\frac{\left(1+\Xi_{t}\right)}{E_{t}} \frac{\partial E_{t}}{\partial\left(1+\Xi_{t}\right)}=\frac{\left(1+\Xi_{t}\right) f_{t}\left(1+\Xi_{t}\right)}{F_{t}\left(1+\Xi_{t}\right)}
$$

For a pre-existing labor-tax-like shifter normalized to $1+\Xi_{t}=1$, the elasticity is the reverse hazard rate (or inverse Mills ratio) at 1, i.e., $f_{t}(1) / F_{t}(1)$ (where any pre-existing tax system can alternatively simply be subsumed into a redefined (net) earnings concept $y_{i t}$ ).

Constant Elasticity We can now also clarify the distributional conditions delivering constant elasticities, a property convenient for calibration and often assumed in modeling practice. Additionally, empirical work often thinks of a single elasticity to be measured, hence taking isoelasticity as the implicit point of departure (e.g., Chetty, Guren, Manoli, and Weber, 2012). We find that isoelasticity requires a power law distribution

\footnotetext{
${ }^{6}$ In this spirit, Chang and Kim (2006) plot model-implied reservation-wage CDFs in their Figures 3-5 (i.e., quarterly earnings), where Figure 5 (the inverse CDF of reservation wages. where the $x$-axis is indeed labeled "participation") in our understanding does not sufficiently pin down the labor supply curve exactly because their model features heterogeneity in idiosyncratic productivity/wages. Chang and Kim (2007) refer to the same concept of reservation wages. Of course, it would be a simple step to compute reservation raises and plot those; the specific aggregate shifter in their model would be the productivity shock. Their actual employment results arise from a simulation that reflects the full joint distribution.
} 
$G_{1+\xi^{*}}\left(1+\xi^{*}\right)=\left(\frac{1+\xi^{*}}{\left(1+\xi^{*}\right)_{\max }}\right)^{\alpha_{1+\xi^{*}}}$ with shape parameter $\alpha_{1+\xi^{*}}$ and maximum $\left(1+\xi^{*}\right)_{\max }{ }^{7}$ All interior arc elasticities of this reservation raise distribution are constant and equal to $\epsilon_{E_{t}, 1+\Xi_{t}}=\alpha_{1+\xi^{*}}$ (using Equation (6)). The arc elasticities mechanically shrink once a pertubation is large enough to cross full nonemployment or full employment.

Heterogeneous Shifters While business cycle or tax reforms studies often consider homogeneous income shifters-which directly map into our setup-, it may also be interesting to study heterogeneous shifters, such as heterogeneous exposure to the business cycle (see, e.g., Guvenen, Schulhofer-Wohl, Song, and Yogo, 2017, for evidence on "worker betas") could be accommodated by partitioning individuals into groups by shock size. Aggregate labor supply is then equal to the weighted average of the group-specific CDFs each evaluated by their respective group-specific prevailing raise, so the argument is a vector of group-specific prevailing raises. We focus on the aggregate curve in this paper, but will make available the underlying micro data of reservation raises and covariates.

\section{Measurement}

We now measure the empirical reservation raise distribution by integrating custom questionnaires into two representative surveys in the United States and in Germany. We follow three steps, mirroring the exposition in Section 2 (i) elicit individual-level reservation raises $1+\xi_{i t}^{*} ;$ (ii) construct and plot their CDF $F_{t}\left(1+\xi^{*}\right)$, the aggregate labor supply curve; (iii) compute arc elasticities from the CDF.

\subsection{Survey Implementation}

We conduct two custom surveys of U.S. and German households comprising all labor force segments (aged 18 and older), of which we ask a tailored question eliciting directly their idiosyncratic reservation raises. To our knowledge, ours is the first attempt to elicit any reservation wage concepts (let alone reservation raises) from non-job-searchers (job

\footnotetext{
${ }^{7}$ Specifically, the distributional assumptions specify a standard power law distribution $F(X)=P(x<$ $X)=a \cdot\left(x / X_{\min }\right)^{-\gamma+1}$ with shape parameter $\gamma>0$. A comparison with our reservation-raise-based power law distribution $G_{1+\xi^{*}}\left(1+\xi^{*}\right)=\left(\frac{1+\xi^{*}}{\left(1+\xi^{*}\right)_{\max }}\right)^{\alpha_{1+\xi^{*}}}$ clarifies that we require the inverse of the reservation raises to follow a power law distribution: $G_{1+\xi^{*}}\left(1+\xi^{*}\right)=P\left(X<1+\xi^{*}\right)=\left(\frac{1+\xi^{*}}{\left(1+\xi^{*}\right)_{\max }}\right)^{\alpha_{1+\xi^{*}}} \Leftrightarrow P\left(\frac{1}{1+\xi^{*}}<\frac{1}{X}\right)=$ $\left(\frac{1}{1+\xi^{*}} / \frac{1}{\left(1+\xi^{*}\right)_{\max }}\right)^{-\alpha_{1+\xi^{*}}}$, which is a power law distribution of $\frac{1}{1+\xi^{*}}$ with minimum $\frac{1}{\left(1+\xi^{*}\right)_{\max }}$, and shape parameter $\gamma=\alpha_{1+\xi^{*}}+1$.
} 
searchers make up a selected section of the population, thereby not providing a lever on the aggregate labor supply curve, as in studies cited in Footnote 3 ).

U.S. Survey: NORC at the University of Chicago AmeriSpeak Survey We integrate reservation-raise questions into a nationally representative survey covering 2,071 respondents in the United States aged 18 and older. Our survey was fielded by NORC at the University of Chicago (henceforth "NORC," formerly the National Opinion Research Center), which, e.g., also runs the General Social Survey. NORC integrated our questionnaire in the AmeriSpeak survey program, a large probability-based panel designed to be representative of the U.S. household population, comprising around 35,000 households in 2019, who are recruited by mail, phone and face-to-face interviews. Dennis (2019) describes the AmeriSpeak sampling, recruitment and survey administration. We integrated our survey into two waves of the AmeriSpeak Omnibus program, conducted on the days following March 19th and April 19th, 2019. Each Omnibus wave draws a nationally representative sample of around 1,000 adults age 18 and older from the AmeriSpeak Panel. Interviews are conducted online and by phone. The Omnibus program is designed for shorter questionnaires such as ours and is, e.g., also used by, e.g., the AP-NORC Center for Public Affairs Research. In this survey, we elicit reservation percent changes in the wage directly, rather than the reservation earnings and actual/potential earnings separately. The survey also contains a limited set of characteristics of the respondent.

German Survey: German Socio-Economic Panel (GSOEP) Our second survey covers 3,527 individuals and is a custom questionnaire we integrated into the 2019 wave of the German Socio-Economic Panel (GSOEP). We did so as part of the SOEP Innovation Sample program, which draws on the GSOEP main sample and permits external researchers to integrate tailored questionnaires, based on an application process and collaborative design and piloting (Richter and Schupp, 2015); it is also used to pilot new permanent questions. The sample design and core fieldwork follow that of the GSOEP overall; Zweck and Glemser (2018) discusses the minor differences of the sampling method. The GSOEP is a maximally representative survey, drawing respondents at an address basis, and implementing multi-month recontact strategies to maximize response rates. The Innovation Sample respondents receive a core questionnaire besides the custom questionnaires proposed by external researchers. Zweck and Glemser (2020) describes details of the 2019 Innovation Sample round, part of which our survey was, with comprehensive information on recruitment and response rates; the full questionnaires and data will be made available by GSOEP. Importantly, the survey was fielded in the fall and winter of 2019, and 
completed before the onset of COVID (with the results shared with the researchers in the summer of 2020) 8 Surveys are conducted by trained interviewers, including in-person interviews, during which answers are recorded by a computer-assisted personal interview equipment. Kantar, a survey company, conducts the field work on behalf of GSOEP, as well as the programming of the survey. Our sample is again workers 18 and older. In this survey, we elicit the reservation earnings and actual/potential earnings separately, and on that basis construct the reservation raise as their ratio. This survey provides a rich set of covariates of the individual and the household, as generally contained in the GSOEP survey.

Ideal Measure of the Reservation Raise To fix ideas, we start with the ideal survey question that tightly mirror the theoretical reservation raise:

You are currently [non]employed. Suppose the following thought experiment: you (and only you) receive an additional temporary linear incremental tax [or subsidy] on your take-home earnings (at whichever positive hours or job you may choose to work). At what incremental tax [or subsidy] rate would you be indifferent between working for this period and not (at whichever positive hours or job would be your best choice at that tax [subsidy] rate)?

This approach invokes an additional tax [subsidy] on top of any potentially pre-existing taxes and frictions, thereby normalizing the exactly marginal individual's reservation raise to one. We thus do not have to take a stance on the level of the baseline already-prevailing aggregate labor tax or tax-like factors $1+\Xi_{t}$, broadly defined, in the data. Formally, we would elicit a normalized reservation raise $1+\widetilde{\xi}_{i t}^{*}$ corresponding to:

$$
1+\widetilde{\xi}_{i t}^{*}=\frac{1+\xi_{i t}^{*}}{1+\Xi_{t}}
$$

Actual Survey Implementation of Reservation Raise Measure The actual questions we implement are the result of piloting in online samples (Amazon Mechanical Turk) and iterations with survey administrators from both NORC and GSOEP. These iterations lead us to formulate relatively concrete hypotheticals compared to the aforementioned ideal question. While the ideal formulation permits job switching and reoptimization (as discussed in Section 4.1), we in practice invoke a "job-constant" perspective for a reference

${ }^{8}$ The main results were obtained between September 17th, 2019 and December, 2019; 82.5\% of the households completed the survey by December, 2019; 97.6\% had done so by February, 2020 (see Table 2 in Zweck and Glemser. 2020). 
job. 9 We specify the frequency of the Frischian wage change to one month-balancing sufficient shortness to induce short-run, plausibly Frischian variation, and sufficient length to still capture a meaningful extensive-margin choice. We detail the questions below, review the results, and then critically discuss limitations in Section 3.3 .

The (Print) Appendix presents our NORC and GSOEP reservation raise questions, separately for NORC and for GSOEP. For GSOEP, we report the English translations; (Online) Appendix A reports the German original text. We specify separate questions for each of the three labor force groups (employed, unemployed, out of the labor force). In each survey, we therefore classify workers based on standard definitions about their employment status as well as their search behavior and availability to work, and on that basis route them into the survey arms.10

We iterated the GSOEP questionnaire in collaboration with the GSOEP/Kantor survey team, and therefore differs slightly from the NORC questions, also permitting us to assess robustness to varying the specific framing, described below as well as in Section 3.3 .

Question for the Employed To keep the scenario sufficiently realistic, we allude to unpaid time off in NORC as well as in our baseline scenario in GSOEP. To avoid confusion associated with job mobility (an insight from piloting), the question permits the worker to be able to return to the original job in this specification. We specify that the worker must not take a second job during this time period, to accurately capture nonemployment vs. employment trade-offs. (We do not differentiate questions for multiple-job holders.)

A potential concern is that we paint an overly specific picture about time off from work; away from spot labor markets, the implied return option may not be realistic. In GSOEP, we therefore randomly assign some employed (and unemployed) workers into a survey arm that does not specify the return option but brings up explicitly that take-up may require quitting (and find similar results, discussed in Section 3.3).

In NORC, the reservation raises for the employed (and the unemployed) are given as

\footnotetext{
${ }^{9}$ Formally, in the setting described in Section 4.1. this yields a job- $j$-specific reservation raise $1+\widetilde{\xi}_{i t, j}^{*}=$ $\frac{v_{i t, j}}{\left(1+\Xi_{t}\right) y_{i t, j} \lambda_{i t}}$ for some reference job $j$.

${ }^{10}$ In NORC, we define the three labor force statuses as follows: we use the variable on employment status ("EMPLOY") to partition respondents into the employed (working as an employee, self-employed, or on temporary layoff), unemployed (not working but looking for work) and out of the labor force (not working for retirement, disability, or other reasons). In GSOEP, we define the three labor force statuses as follows: we use the variable on employment status to partition respondents into the employed ( "PERW" 1-7, including apprentices and part-time); we then split up the nonemployed ("PERW" 9) into the unemployed ("PNERW02" 1-2, i.e., likely or certain to take up work), and the out of the labor force ("PNERW02" 3-4, i.e., sure to not or unlikely to take up work). Our NORC questionnaire features an additional variant of the question for the temporarily laid off that mirrors that of the employed (supposing the respondent is back at the previous job). We do not ask the self-employed, given the missing wage concept.
} 
percent changes of the idiosyncratic potential earnings (which we do not separately elicit). That design does not permit the employed to report negative cuts (raises) - so that their reservation raises $1+\xi_{i t}^{*}$ cannot exceed one. The GSOEP survey design team iterated our questionnaire to separately elicit reservation earnings and actual/potential earnings and (and we then construct the reservation raise as ratio of the former over the latter, as in Equation (2)). As a result, employed GSOEP respondents can report requiring a pay raise not to temporarily separate (e.g., if that opportunity were to not otherwise be feasible, or because they misunderstand the question); we will find that few employed (or unemployed) workers report reservation earnings above their actiual/potential earnings, i.e., reservation raises above one.

Question for the Unemployed While previous work has measured reservation wages of the unemployed, (e.g., Feldstein and Poterba, 1984; Krueger and Mueller, 2016), our comprehensive coverage of all labor force groups requires us to keep the question for the unemployed comparable to the other two groups'. In NORC, we induce a scenario in which a prospective job permits a one-month earlier start date, albeit at a wage reduction for that month. The particular reason is left unspecified, although we clarify that this interim month is to be spent in nonemployment. In GSOEP, we evoke a situation after job acceptance, and ask the respondent to reflect on the question identical to the employed described above (after a short preamble).

Since the unemployed will want to work, we expect the reservation raise-which reflects the desired employment status- to be at most one, as for the employed. In NORC, where as for the employed, the respondents report reservation pay cuts. In GSOEP, we again separately elicit reservation and potential earnings (and take their ratio), and here therefore permit the unemployed to report reservation raises above one (which we again find few unemployed will give).

Question for the Out of the Labor Force By self-classification and revealed preference, the out of the labor force likely have reservation wages exceeding their expected potential wages. So for this group, we ask about the required wage increase to induce a respondent into employment, for a concrete job that they envision they could realistically be offered if they searched and did attempt to take up employment. Crucially, for our Frischian perspective, this wage change is supposed to only occur for a single month. For concreteness and realism, we implement this scenario in the form of a sign-up bonus on top of the first-month salary. We also specify that the employment relationship is to last for at least one month. 
Naturally, the out of the labor force individuals include those least likely to consider taking up employment (including the disabled, the retired, or students), who may hence rarely think about labor markets. However, the out of the labor force do appear to contain some marginal individuals (as evidenced by the worker flows in and out of the labor force, as documented in, e.g., Davis, Faberman, and Haltiwanger, 2006). Moreover, to achieve large employment increases to large responses to, e.g., tax holidays, it is the out of the labor force that would need to be crowded in. The reservation raises identifies those marginal individuals.

Response Rates We have high response rate of $80 \%$ for NORC and $70 \%$ for GSOEP (here defined as respondents giving nonmissing answers out of the participants). Appendix Table A.2 details those numbers, separately by labor force status, for NORC and GSOEP. While the numbers are not directly comparable, the response rates dramatically exceed those in reservation wage surveys of the unemployed, which are around $10 \%$ (see, e.g., Feldstein and Poterba, 1984; Krueger and Mueller, 2016). We discuss residual potential effect of missing information below in Section 3.3 .

Our NORC survey covered 2,071 individuals (minus 13 for whom we were unable to assign a labor force status, so they were not asked any subsequent question). For $82 \%$ $(1,679 ; 809$ in March, and 870 in April) of the NORC participants, we have non-missing reservation raise information.

Our GSOEP questionnaire covered 3,527 individuals (minus 17 respondents without labor force status information). Among those, $70 \%(2,431)$ participants have non-missing reservation raises. (In the vast majority of missing observations, both reservation and actual/potential wages are missing). We further drop 164 individuals for whom survey weights are missing, 11

Covariates and Weighting We present summary statistics for the observations with nonmissing reservation raises in Table 1 . We present the numbers for the total sample, as well as the analysis sample with nonmissing reservation raises.

In NORC, we weight observations within each labor force status using the accompanying sample probability weights (to match the American adult population, although the survey is designed to be representative). We also rescale the weights in each wave to represent the proportion of the total sample obtained from each wave, although those were similar (see above). The raw sample was close to the February 2019 BLS population shares

\footnotetext{
${ }^{11}$ Based on correspondence with the GSOEP survey team, the weights for those survey entrants will become available in 2021 as part of the 2020 data delivery (wave); we will then update our results.
} 
for employment, labor force participation, and unemployment (see Table 1 Panel A); to precisely match that important target of our data, we finally reweight the observations with non-missing reservation raises so that the weighted labor force status proportions precisely match the BLS target 12 In GSOEP, we again use the sampling weights (which made very little difference), and additionally reweight the observations with nonmissing reservation raises to match the shares of the labor force groups in the data in 2019 13

\subsection{Results}

Histograms We present histograms of the empirical reservation raises from the reported reservation raises in Figure 1 Panel (a) for NORC and in Panel (b) for GSOEP. Differential shading separates observations by labor force status.

For both surveys, the empirical histogram of the reservation raise distribution exhibits a large mass around one-where the reservation wage is close to the individual's actual or potential wage, i.e., the location of marginal individuals. To the left, for wage reductions, the employed and unemployed would be crowded into nonemployment; to the right, for wage increases, labor supply would recruit the out of the labor force individuals into employment (strictly so for NORC, and approximately so for GSOEP, discussed above as well as below in Section 3.3.

Globally, however, the distribution is widely dispersed, as most individual derive considerable and tremendously heterogeneous surplus (or, in the case of the out of the labor force, would suffer considerable net disutility) from employment. For visual clarity, we bunch raises above 2.0 into the 2.0 group (on a secondary y-axis in the histogram).

Lastly, the NORC — but not the GSOEP—histogram exhibits some likely spurious mass points at 0.5 and 1.5 , perhaps due to respondents' rounding; we conjecture that smoothing out those bunching points would spread out more evenly would distribute mass towards a locally more elastic and far-away less elastic curve, thereby further accentuating the asymmetries already present. We discuss this and other limitations of the survey in Section 3.3 .

${ }^{12}$ The March 2019 BLS targets give $60.7 \%$ (employed), 2.4\% (unemployed) and 36.9\% (out of the labor force), given by $60.7 \%$ employment to population rate (source: https://fred.stlouisfed.org/series/EMRATIO) and 63.1\% labor force participation rate (source: https:/ / fred.stlouisfed.org/series/CIVPART).

${ }^{13}$ For instance, the 2019 labor force participation rate in Germany was 61.9\% according to OECD statistics (age 15 and up; 18 and up not available); in our GSOEP sample, it is $61.14 \%$ (in the whole dataset) and $61.06 \%$ (among those that were asked our questions). In GSOEP, we have also experimented with dropping low earners, and have found similar aggregate labor supply curves and elasticities. 
Aggregate Labor Supply Curves To trace out the aggregate labor supply curve, we aggregate the micro reservation raises into a cumulative distribution function (CDF) $F(1+$ $\left.\xi^{*}\right)$, plotted in Figure2 2 Panel (a). The curve gives the desired employment rate as a function of any given prevailing raise $1+\Xi$. (The empirical reservation raises are measured as the normalized-around-one baseline raise $1+\widetilde{\xi}^{*}$ defined in Equation (8).)

To facilitate visual inspection with regards to elasticities, we additionally take logs of both axes and normalize the employment rates at the baseline level, thereby plotting changes in desired log employment against changes in $\log (1+\Xi)$. We do so in Panel $(b)$ of Figure 2. This plot zooms into the local range around 0.05 upwards and downwards.

Arc Elasticities We construct a set of arc elasticities over varying aggregate prevailing raise deviations: the share of the population in a given upward or downward distance $\Xi^{\prime}$ from the prevailing unit raise $1+\Xi=1$, following the definition in Equation (6), $\epsilon_{E,(1+\Xi) \rightarrow\left(1+\Xi^{\prime}\right)}=\frac{F\left(1+\Xi^{\prime}\right)-F(1+\Xi)}{F(1+\Xi)} / \frac{\left(1+\Xi^{\prime}\right)-(1+\Xi)}{1+\Xi}$. Appendix B.1 details the calculation and the treatment of marginal individuals. Table 2 reports these arc elasticities (along with the shares of observations). Figure 3 visualizes the resulting arc elasticities (for the range of 0.20 upwards and downwards).

Large Local Elasticities Locally, i.e., for small shifts, we find large elasticities of around 3 , and even higher values for tiny shifts. That is, on both sides, lots of individuals prefer to move in or out of employment in response to small percent wage changes. Considering the NORC results in Table 2, we find that a local 1\% increase in the aggregate prevailing raise crowds in nearly 2.26 percent of additional employment (implying an elasticity of $\left.\frac{d(\mathrm{Emp} / \mathrm{Pop})}{\mathrm{Emp} / \mathrm{Pop}} / 0.01=\frac{0.0226}{0.631} / 0.01=3.72\right)$. A $1 \%$ decrease implies an even larger elasticity of 5.66. Similarly high local elasticities emerge for GSOEP (2.86 and 9.38).

The small shifts upward and downward are those that would drive business cycle fluctuations in employment in equilibrium models, where shifts in labor productivity and hence wages are small (e.g., a quarterly standard deviation of around 2\% as in Hansen, 1985). For this reason, many macro models require large Frisch elasticities (Chetty, Guren, Manoli, and Weber. 2012). Locally, the concentration of marginal individuals paints such a highly elastic picture in the survey, mirroring intuitions from models of indivisible labor and worker homogeneity (Hansen, 1985; Rogerson, 1988).

Nonconstancy: Smaller Elasticites for Large Shifts Nonlocal perturbations, to large wage changes, imply dramatically lower arc elasticities. Compared to the high local elasticities of 3.72 to a $1 \%$ increase, for instance, the arc elasticity falls to 0.96 when 
considering a larger raise of $10 \%$. Downward, the arc elasticity falls from 5.66 for the $1 \%$ wage decrease to 1.68 for a 10\% decrease. For GSOEP, a strikingly similar picture emerges, with elasticities to large changes being even somewhat lower throughout, at 0.41 and 1.22 for a $10 \%$ increase and decrease, respectively. The nonconstant elasticities are salient in the arc elasticities plot in Figure 3. Arc elasticities are largest locally around the baseline prevailing raise, and shrink for larger perturbations.

Asymmetry: Smaller Arc Elasticities Far Upward than Far Downward Not only do the curves exhibit nonconstant arc elasticities, but also an asymmetry: arc elasticities stay relatively high downward, as the labor market continues to find employed workers ready to switch into nonemployment. But upward, the out of the labor force appear hard to recruit into employment. This pattern emerges in NORC, but is if anything more pronounced in GSOEP.

An Implication: External Validity of Specific Arc Elasticity Estimates in the Presence of Nonconstant Elasticities Figure 3 suggests that a constant elasticity would not provide a realistic description of the global aggregate extensive-margin labor supply curve. As one concrete implication, the empirical curve suggests that the small arc elasticities identified by large positive increases in net wages may mask large local elasticities. For example, Chetty, Guren, Manoli, and Weber (2012) infer a 0.42 Frischian extensive-margin labor supply elasticity by interpreting employment responses to the tax holiday in Iceland studied by Bianchi, Gudmundsson, and Zoega (2001), which reduced average tax rates from $14.5 \%$ to $0 \%$ for one year. ${ }^{14}$ In our framework, this experiment corresponds to an increase in $1+\Xi_{t}$ from 1.00 to 1.17 .

Our survey-implied labor supply curves accommodate this estimate, as it features an arc elasticity of 0.60 for that large an upward raise shift in NORC, and even lower in GSOEP. At the same time, however, in the global curves the surveys imply, this small arc elasticity to a large upward shift masks dramatically larger local elasticities 15 Hence,

\footnotetext{
${ }^{14}$ Another quasi-experiment reviewed in Chetty, Guren, Manoli, and Weber (2012) is the Self Sufficiency Program in Canada, studied by Card and Hyslop (2005), which raised average net of tax rates from 0.25 to 0.83 , for 36 months, with an implied employment elasticity of 0.38 .

${ }^{15}$ To some degree, the nonconstant elasticity is of course expected, as the employment rate cannot exceed $100 \%$. A priori, the large macro elasticity benchmarks of around 2.5 cited by Chetty, Guren, Manoli, and Weber (2012) for cyclical macro contexts would, out of a baseline employment rate of $79.2 \%$ in their Icelandic example of a tax holiday, imply employment rates exceeding 100\%, similarly for some of the other case studies with large net-of-tax increases the authors discuss. Of course, in the case studies the empirical employment rates do not reach $100 \%$ in response to the subsidies, and therefore do not actually hit the full-employment constraint. By contrast, Martinez, Saez, and Siegenthaler (2021) also study a large tax holiday, in Switzerland, and find no treatment effects on employment rates, which therefore implies small elasticities across all intermediate arcs.
} 
such low estimated specific arc elasticities with respect to large upward net-of-tax wage increases need not provide tight bounds on the arc elasticities in the local portions of the curve, which are those relevant to business cyclical fluctuations.

More generally, nonconstant arc elasticities also imply a trade-off between statistical power and overcoming adjustment costs (e.g., Chetty et al., 2011; Chetty, 2012), and measuring the local elasticities relevant for smaller shocks-unless one is willing to maintain the pervasive assumption of isoelasticity, which however our survey-implied labor supply curves imply appears counterfactual.

\subsection{Robustness Checks and Limitations}

Response Quality As with contingent valuation surveys more generally, and specifically standard reservation wage measures among the unemployed, our survey measures may not accurately capture preferences. On the one hand, idiosyncratic noise in the responses raises would generate spurious dispersion, and hence bias downward the measured elasticities. On the other hand, local elasticities would be overestimated with spurious bunching around 1. Indeed, the mass points in the NORC survey at 0.5 and 1.5 reflect bunching at semi-round numbers. However, the NORC mass around 1.0 reflects a healthily spread-out mass, making it unlikely that sharp and strict bunching drives the result. Most importantly, the GSOEP does not feature such mass points, while otherwise featuring a similar curve overall. The absence of bunching in the GSOEP may reflect higher quality responses. Or, it may reflect the design difference in that in the GSOEP, we elicit the potential and reservation earnings separately.

Comparison to Existing Evidence from Unemployed Job Seekers The local mass of marginal individuals is qualitatively consistent with existing evidence from surveys of the unemployed. Some empirical studies of the reservation wages of the unemployed have constructed the "reservation wage ratio" as an ad hoc and informal normalization (Feldstein and Poterba, 1984; Krueger and Mueller, 2016). Importantly, that work has not interpreted it through the lens of a model and as a sufficient statistic for labor supply preferences. The results in Feldstein and Poterba (1984); Krueger and Mueller (2016) reveal that the unemployed state on average high reservation wages relative to their wages - which has been interpreted as implausible (see, e.g.. Shimer and Werning, 2007, p. 1160). However, in our setting, such properties need not indicate bugs but may be features consistent with the unemployed comprising mostly marginal individuals. Indeed, Figure 1 Panels (a) and (b) do suggest this pattern. Moreover, recent studies with high-quality survey data on reservation wages and larger samples have clarified that even 
the unemployed report considerable gaps between their reservation wage and the past wage (see, e.g., the histogram in Figure 2 Panel A in Le Barbanchon, Rathelot, and Roulet, 2021). The discrepancy may be due to the fact that the evidence in Feldstein and Poterba (1984); Krueger and Mueller (2016) stems from recessionary periods, and the relatively low response rates of around $10 \%$ or below in those surveys. Moreover, in our survey implementation, we do not use the past wage as a proxy for the reemployment wage, but evoke a scenario that holds fixed a specific, current or prospective, job. An alternative route would be to validate the labor supply preferences by studying covariates or realized previous and future employment behavior in the surveys.

Adjustment Frictions Our baseline survey formulation in particular for the employed evokes a spot-market scenario without adjustment frictions. For the employed, a postnonemployment return to work appears at least implicitly permitted. This scenario may lead employed workers to overstate their reservation raises compared to a scenario in which such return is either not possible or would entail, e.g., losses in wages, skill, or job stability.

We have assessed the relevance of this feature in the GSOEP survey. We have randomly allocated, in a 50/50 proportion, the employed and unemployed into two survey arms: one that deliberately did not specify the return option—and instead leaves to the worker to consider whether the month nonemployed may require quitting and a subsequent job switch. The other half was presented with the baseline formulation. The (Print) Appendix lists the supplementary survey questions; Online Appendix Alists the associated German original text.

In Appendix Figure A.2, we replicate the reservation raise distribution using only one of the two survey arms (and accordingly reweight the employed and unemployed doubly). The curves and associated arc elasticities are strikingly similar. The robust pattern implies that at least in this specification, the evocation of the seemingly frictionless setting does not drive the large mass of marginal individuals. The congruence of the two curves depicted in Appendix Figure A.2 also permits us to pool both survey arms for the employed and unemployed, which, in fact, the GSOEP distributions throughout the paper have done.

Ultimately, beyond the survey, any such discomfort extends to the standard, predominant neoclassical labor supply and spot labor markets more generally, perhaps in favor of approaches that dissect labor-supply-like behavior in search-frictional settings (see, e.g. Hall, 2009; Krusell, Mukoyama, Rogerson, and Sahin, 2017). 
Rationed Labor Supply of the Employed Relatedly, it is conceivable that even some employed respondents are overemployed: they may prefer to be (temporarily) nonemployed in a given month, but adjustment frictions prop up their realized employment status. That is, their reservation raise is above one. In the NORC survey, reservation raises above one are not permitted for the employed (or unemployed), as we phrase their questions explicitly as a wage reduction. Still, the histogram suggests that this concern is of limited relevance: there is no sharp bunching at the maximal values among the employed in NORC, but values below 0.99 remain high. In the GSOEP, we separately elicit reservation earnings for the job, and divide by actual earnings to construct the reservation raise. Hence, employed GSOEP respondents can give raises above 1.0. Inspecting the GSOEP histogram reveals only a small fraction (around 15\%) of the employed (or unemployed) workers giving such answers, with limited spread. If anything, if we were to move those workers into the employed group (and declared them marginal by winsorizing their raises down to 1.0), we would obtain a higher elasticity downward and a faster decline upward, but still a high upward local elasticity given by the marginal individuals out of the labor force. Appendix B.1 presents the detailed discussion of these issues and presents that calibration. Overall, we therefore conclude that our treatment of potentially overemployed respondents does not drive our main results.

Duration We set the duration of the wage perturbation to one month, balancing sufficient shortness to plausibly induce short-run (e.g., Frischian) variation and sufficient length to capture a meaningful extensive-margin choice. An interesting extension would be to study longer-lasting deviations. On the one hand, potential wealth effects grow with duration. (In Section 4, we find that for the calibrated models, uncompensated curves are essentially identical to Frischian ones even for quarter-long durations.) On the other hand, longer durations help overcome adjustment costs (which we however deemphasize).

Missing Observations We can gauge and bound the potential effects of observations with missing reservation raises on measured elasticities by considering three benchmark cases. First, if observations were missing-at-random, all results would stay the samewhich is, implicitly, the assumption we have made by studying the non-missing observations. Second, if all missing individuals were marginal (i.e., have reservation raises within the local range for which we construct arc elasticities), we would of course currently underestimate the local elasticities. Third, since we measure relatively high elasticities, the most interesting alternative case to quantify is the extreme case if all missing observations were perfectly inframarginal. Then, we would currently overestimate local elasticities. We 
can quantify the bound this overestimate as follows. Formally, the latent, population-level distribution $G\left(1+\xi^{*}\right)=(1-m) \cdot F\left(1+\xi^{*}\right)+m \cdot H\left(1+\xi^{*}\right)$ consists of those of non-missing and missing observations, $F\left(1+\xi^{*}\right)$ and $H\left(1+\xi^{*}\right)$, where $m$ denotes the share of missing observations. In the extreme case in which all missings are inframaginal, the density of $H\left(1+\xi^{*}\right)$ is zero in the local intervals we consider. Then, we arrive at the value of the population elasticities by adjusting the measured ones by $1-m$, i.e., one minus the share of missing observations. This adjustment factor $1-m$ would be $80 \%$ for NORC and $70 \%$ for GSOEP (as the shares of missing observations, $m$, are $20 \%$ and $30 \%$ respectively, as discussed above), such that it only moderately compresses the original elasticities. $\sqrt{16}$ Hence, the treatment of missing reservation raise observations cannot drive our main results.

Snapshot Our surveys elicit a snapshot of the labor supply curve for one cross-section representative of the U.S. and German populations each. The shape of the curve may vary over time, so it would be interesting to elicit the reservation raises in many repeated cross sections or even in a panel of workers. Unfortunately, the labor market upheaval following the pandemic prevented meaningful follow-up studies in 2020 and 2021.

\section{Comparison with Model-Implied Curves}

We now show that the aggregate labor supply curves of various macro models do not match the global empirical one. For each model, we (i) construct the individual-level reservation raise $1+\xi_{i t}^{*}$; (ii) compute and plot its (steady state) reservation raise distribution $F_{t}\left(1+\xi^{*}\right)$ (the aggregate labor supply curve), and (iii) compute its arc elasticities. Specifically, we study a representative household with constant Frisch elasticities, a finitely lived atomistic household including an intensive margin, and a heterogeneous agents with wage shocks and incomplete markets.

\subsection{Leading Case: Frischian Labor Supply in Spot Labor Market}

We now specialize the general framework presented in Section 2 to a spot labor market. We consider a Frischian context, because it does not require specifying the temporal dimension of the wage shift, because the Frisch elasticity is a key focus of the literature, and to streamline the exposition.

${ }^{16}$ Appendix Table A.2 also separates the missings by labor force status, additionally permitting the reader to gauge an asymmetric adjustment. 
General Setting The labor supply blocks we study are set in spot labor markets. Consider an individual $i$ with time-separable utility $u_{i}\left(c_{i t}, h_{i t}\right)$ from consumption $c_{i t}$ and hours worked $h_{i t}$, with budget Lagrange multiplier $\lambda_{i t}$, and assets $a_{i t}$ earning interest rate $r_{t-1}$ :

$$
\begin{gathered}
\max _{a_{i t}, h_{i t}, c_{i t}} \mathbb{E}_{t} \sum_{s=t}^{t_{i}^{\max }} \beta^{s-t} u_{i}\left(h_{i s}, c_{i s}\right) \\
\text { s.t. } a_{i s}+c_{i s} \leq a_{i, s-1}\left(1+r_{s-1}\right)+\left(1+\Xi_{s}\right) \theta_{i s}\left(h_{i s}\right) \quad \forall t_{i}^{\max } \geq s \geq t .
\end{gathered}
$$

Gross-of- $\left(1+\Xi_{s}\right)$ earnings at a given hours choice are $\theta_{i t}\left(h_{i t}\right)$, for example, a standard linear wage schedule $\theta_{i t}\left(h_{i t}\right)=w_{i t} h_{i t}$.

Frischian Labor Supply, Indivisible Labor, and Separable Utility We now study the leading case, which will map most closely into the specific models we study below. First, we specialize to separable utility between consumption and labor/leisure, such that $u_{i}\left(h_{i s}, c_{i s}\right)=u_{i}^{c}\left(c_{i s}\right)-u_{i}^{h}\left(h_{i s}\right)$; we discuss nonseparabilities below. Second, labor is indivisible, such that $h_{i t} \in\left\{0, \widetilde{h}_{i t}\right\}$; we permit intensive-margin hours choices below. Third, we study pertubations in the aggregate prevailing wedge that are Frischian, i.e., that leave $\lambda_{i t}$ constant; we permit wealth effects in Section 4.3 .

The discrete employment choice compares costs and benefits of working. Working comes at labor supply disutility $v_{i t}=u_{i}^{h}(0)-u_{i}^{h}\left(\widetilde{h}_{i t}\right) . v_{i t}$ may also include fixed participation costs (Cogan, 1981). On the benefit side, the worker obtains potential earnings $y_{i t}=\theta_{i t}\left(\widetilde{h}_{i t}\right)$ (and zero otherwise, although the monetary opportunity cost may involve, e.g., unemployment insurance. discussed below).

Optimal labor supply assigns each individual $i$ her desired hours $h_{i t}^{*} \in\left\{0, \widetilde{h}_{i t}\right\}$, a binary discrete choice due to indivisible labor, according to a cutoff rule-equivalently, it determines the desired employment status $e_{i t}^{*} \in\{0,1\}$ :

$$
h_{i t}^{*}=\left\{\begin{array}{lll}
0 & \text { if } & \left(1+\Xi_{t}\right) \theta_{i t}\left(\widetilde{h}_{i t}\right) \lambda_{i t}<v_{i t} \\
\widetilde{h}_{i t} & \text { if } & \left(1+\Xi_{t}\right) \theta_{i t}\left(\widetilde{h}_{i t}\right) \lambda_{i t} \geq v_{i t} .
\end{array} \Leftrightarrow e_{i t}^{*}=\left\{\begin{array}{lll}
0 & \text { if } & \left(1+\Xi_{t}\right) y_{i t} \lambda_{i t}<v_{i t} \\
1 & \text { if } & \left(1+\Xi_{t}\right) y_{i t} \lambda_{i t} \geq v_{i t} .
\end{array}\right.\right.
$$

That is, an individual prefers employment if the benefits, $\left(1+\Xi_{t}\right) y_{i t} \lambda_{i t}$, outweigh the cost, $v_{i t}$ (such the post-raise earnings exceed the extensive-margin MRS). For marginal-i.e., indifferent-individuals, the condition holds with equality.

The Frischian Reservation Raise with Indivisible Labor in a Spot Labor Market Here, the Frischian ( $\lambda$-constant) reservation raise $1+\xi_{i t}^{*}$ for individual $i$ captures the hypothetical 
aggregate prevailing raise $1+\Xi_{t}$ that would render her indifferent:

$$
1+\xi_{i t}^{*} \equiv \frac{v_{i t}}{y_{i t} \lambda_{i t}}
$$

Here, the reservation raise encodes three elements: potential labor earnings $y_{i t}$, budget multiplier $\lambda_{i t}$, and labor disutility $v_{i t}$. These elements, in turn, may capture rich modelspecific sources of heterogeneity, such as in wealth, borrowing constraints, skills, hours requirements, job amenities, time endowments, or tastes for leisure.

Intensive Margin The approach accommodates intensive-margin choices. Rather than a binary choice set $h_{i t} \in\left\{0, \widetilde{h}_{i t}\right\}$, suppose now a choice of job $j$ with attributes $\left(y_{i t, j}, v_{i t, j}\right)$ (nesting hours differences only) from a job menu $J_{i t}=\left\{\left(y_{i t, j}, v_{i t, j}\right)\right\}_{j}$. Here, the reservation raise is implicitly defined, as the prevailing raise achieving indifference between working and not—conditional on having reoptimized job choice with respect to that raise ${ }^{17}$

\section{Nonseparable Preferences and Other Components of the Opportunity Cost of Employ-}

ment In principle, the reservation raise accommodates richer preference and market structures, such as unemployment insurance, nonseparable preferences, or even search frictions and long-term jobs. Such additional terms are featured in the opportunity cost of employment in the context of search and matching models in representative households (as in Hall and Milgrom, 2008; Chodorow-Reich and Karabarbounis, 2016). A variant, simplified to a spot labor market setting, applies here even with atomistic households, and would be $\widehat{v}_{i t}=u_{i}\left(0, c\left(0, \lambda_{i t}\right)\right)-u_{i}\left(\widetilde{h}_{i t}, c\left(\widetilde{h}_{i t}, \lambda_{i t}\right)\right)+\lambda_{i t} \cdot\left(b_{i t}-\left(c\left(0, \lambda_{i t}\right)-c\left(\widetilde{h}_{i t}, \lambda_{i t}\right)\right)\right.$, where $c(h, \lambda)$ is the consumption level associated with hours choice $h$ and multiplier $\lambda$, and $b$ is a nonemployment subsidy such as unemployment insurance benefits. The models reviewed below will not feature any such additional properties.

\subsection{Frischian Curves from Specific Macro Models}

We plot the reservation raise CDFs and arc elasticities of specific models (in logs and normalized to 0 in steady state on both axes), along with the empirical ones, in Figure 4 We report arc elasticities for various intervals in Table 2 , as with the survey statistics.

${ }^{17}$ Formally, the "inner loop" gives the optimal intensive-margin job choice conditional on any prevailing raise $1+\Xi_{t}$ while ignoring the participation constraint: $j^{*}\left(1+\Xi_{t}\right)=\operatorname{argmax}_{j \in J_{i t}}\left\{u(\right.$.$\left.) ; s.t. \mathrm{BC} \mid 1+\Xi_{t}\right\}$. Second, the "outer loop" implicitly defines the extensive-margin indifference point $1+\xi_{i t}^{*}=v_{i t, j^{*}\left(1+\xi_{i t}^{*}\right)} /\left(y_{i t, j^{*}\left(1+\xi_{i t}^{*}\right)} \lambda_{i t}\right)$. 
Method Details for each model and the calibrations are in Appendix Section C.1. We parameterize each model so that its steady state employment rate is $60.7 \%$, as in the U.S. $16+$ civilian employment population ratio in February 2019 from the BLS (FRED series EMRATIO), similar to the NORC survey ${ }^{18}$ In each model, we normalize the steady steady prevailing rate raise (including potential taxes) to one. We extract the reservation raise distributions from the steady state equilibrium.

\subsubsection{Representative Household Models with Full Insurance}

A common specification of aggregate labor supply appeals to a large representative household comprised of a unit mass of individual members, with consumption levels and employment statuses assigned by the utilitarian head (Galí, 2011) or by incentive-compatible lotteries (Hansen, 1985; Rogerson, 1988). Full (cross-sectional) insurance and the pooled budget constraint imply homogeneous $\lambda_{i t}=\bar{\lambda}_{t}$. We consider two canonical cases.

Homogeneity (Hansen, 1985) The perfect homogeneity model of Hansen (1985) yields a degenerate reservation raise distribution and hence corner cases of employment out of steady state. Qualitatively, the high local elasticity in the data mirrors these intuitions, but in an attenuated way; away from the local mass, the empirical reservation raises exhibit tremendous heterogeneity and hence lower arc elasticities.

Isoelasticities (MaCurdy, 1981) A convenient specification with heterogeneity is in the employment disutility, specifically in the parametric way that delivers a constant elasticity, as derived by Galí (2011). We include two 0.32 and 2.5 isoelasticity cases, following Chetty, Guren, Manoli, and Weber (2012), who propose 0.32 as the average of quasi-experimental estimates, and 2.5 as that implied by business cycle evidence. For small changes, the empirical arc elasticities are closer to the large isoelasticity. For larger, in particular positive pertubations, the data exhibit smaller arc elasticities towards 0.50 , closer to the 0.32 isoelasticity. Hence, neither isoelastic case-in fact, none-accurately describes the global empirical curve.

\subsubsection{Heterogeneous Agent Model}

In heterogeneous agent models, atomistic individuals with separate budget constraints make individual-level choices. Heterogeneity arises from stochastic wages, which pass

\footnotetext{
${ }^{18}$ Rather than restricting the sample to the prime working age population, we target a fuller population definition because our surveys target individuals 18 and older without an upper age limit.
} 
through into budget constraints under incomplete markets, and thence into assets, consumption, and $\lambda_{i t}$. To study this setting, we introduce indivisible labor into the Huggett (1993) model as in Chang and Kim (2006, 2007), and calibrate the 33-state potentialearnings process to mimic that in Kaplan, Moll, and Violante (2018) (whose model features only intensive-margin labor supply), which in turn approximates the empirical earnings dynamics documented in Guvenen, Karahan, Ozkan, and Song (2015).

Baseline The model generates small local labor supply elasticities (0.12-0.31) upward, but exhibits larger (up to 0.72 ) elasticities downward, albeit quickly settling in below 0.5 for large pertubations towards 0.10 . Yet, quantitatively, the elasticities are too small throughout, although for positive shifts, the arc elasticity gradient asymptotes towards the 0.32 benchmark proposed by Chetty, Guren, Manoli, and Weber (2012).

The Role of Incomplete Insurance Since the equilibrium reservation raise distribution inherits the joint distribution of $\lambda$ and $y$, the curve is inelastic if low earnings realizations are offset by high $\lambda$ values. Incomplete markets generate exactly this negative covariance. To see this, we also plot the curve under complete markets-which generate a homogeneous $\lambda \sqrt{19}$ This curve is dramatically more elastic, especially for large downward perturbations. ${ }^{20}$ This exercise illustrates how the reservation raises can serve as a diagnostic tool for the complex labor-supply implications of richer asset market structures.

\subsubsection{Lifecycle and Intensive Margin}

A model with both intensive and extensive margins is that by Rogerson and Wallenius (2009), which also features lifecycle patterns (studied by Chetty, Guren, Manoli, and Weber, 2012, as a leading macro model with an extensive margin, whose parameterization we largely follow).

Baseline The calibrated economy exhibits a high local elasticity. In the upwards direction, it generates a nearly constant elasticity, mirroring the 2.5 isoelasticity line. Arc elasticities range from 2.60 to 3.20, with local elasticities (from 0.01 raise pertubations)

\footnotetext{
${ }^{19}$ The underlying sparse discrete Markov process (chosen for computation reasons) would render the full-insurance curve choppy, otherwise smoothed by the asset distribution. For visual clarity, we can here (since $\lambda$ is homogeneous) instead plot the reservation raise distribution arising from continuous earnings process (which Kaplan, Moll, and Violante (2018) discretize).

${ }^{20}$ This distributional intuition at the extensive margin differs from incomplete markets attenuating labor supply elasticities at the intensive margin (as in Domeij and Floden, 2006) and from $\lambda$ shifting with wealth shocks in non-Frischian settings (which we find has a small effect below in Section 4.3 ).
} 
between 2.84 and 2.90.21 Qualitatively, the model generates some asymmetry, but quantitatively, the model misses the steep decline towards 0.5 in the elasticities upwards.

The Role of the Intensive Margin To assess the importance of intensive-margin reoptimization on extensive-margin labor supply, as discussed in Section 4.1. we also plot a second curve, which instead holds hours fixed at the baseline optimal choice. Intuitively, intensive-margin reoptimization weakly raises the benefit of working, and so the flexible-hours curve weakly exceeds the fixed-hours one, but not by much.

The Role of the Wage-Age Profile In the model, wages are a triangular function of age, a convenient but consequential choice. To show this, we recalibrate the wage-age gradient around the marginal ages (labor force entry and exit) while targeting a lower Frisch elasticity, by allowing a higher level of peak lifetime productivity and a steeper slope of the wage-age productivity gradient. While the elasticities fall by around half locally, the global fit remains off. Ultimately, as with the other models, matching (reverseengineering) the empirical curve globally would require more complex functional forms.

\subsection{Non-Frischian, Uncompensated Variation}

We finally quantitatively evaluate the divergence between Frischian and uncompensated model curves. For each baseline model, we simulate an unexpected aggregate-raise perturbation lasting for one quarter, a useful horizon for business-cycle frequencies, and permit $\lambda$ adjustments through wealth effects. Computational details are in Appendix Section C.4. Appendix Figure A.4 shows that the uncompensated curves are close to their Frischian counterparts. Larger divergence may arise with richer asset structures such as illiquid assets and adjustment costs therein (as modeled in Kaplan, Violante, and Weidner. 2014; Kaplan, Moll, and Violante, 2018, which feature intensive margins only).

\section{Open Questions}

We close by highlighting two questions beyond the scope of our paper, which has focused on descriptive measurement of employment preferences.

First, our descriptive exercise leaves open which deep sources of heterogeneity or equilibrium mechanisms drive the asymmetric and locally elastic shape of the empirical curve. While specific models can be reverse-engineered to match the empirical curve, and are

\footnotetext{
${ }^{21}$ Consistent with our global clarification, Chetty et al. (2012), who simulate reforms of specific large tax reductions in the model, find it to exhibit large Frisch elasticities.
} 
hence isomorphic from the perspective of aggregate labor supply, observable attributes associated with the micro reservation raises may adjudicate between specific models.

Second, the labor supply curve represents preferences over desired labor supply. In the presence of frictions, even a highly elastic pecking order implied by preferences need not guide realized employment fluctuations. ${ }^{22}$ For some applications, such as predicting the effect of tax reforms, reduced-form elasticities on the basis of realized employment adjustment may be sufficient. Assessing welfare or developing models of the aggregate labor market require the separation of frictions and preferences.

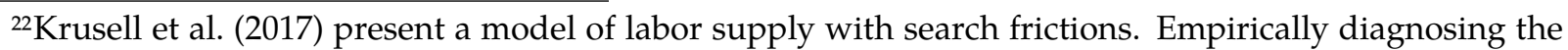
efficiency properties of employment adjustment is challenging (see, e.g., Bils, Chang, and Kim. 2012; Jäger, Schoefer, and Zweimüller. 2021).
} 


\section{References}

Ameriks, John, Joseph Briggs, Andrew Caplin, Minjoon Lee, Matthew Shapiro, and Christopher Tonetti. 2020. "Older Americans Would Work Longer if Jobs Were Flexible." American Economic Journal: Macroeconomics 12 (1):174-209.

Attanasio, Orazio, Peter Levell, Hamish Low, and Virginia Sánchez-Marcos. 2018. "Aggregating Elasticities: Intensive and Extensive Margins of Female Labour Supply." Econometrica 86 (6):2049-2082.

Beffy, Magali, Richard Blundell, Antoine Bozio, Guy Laroque, and Maxime To. 2019. "Labour Supply and Taxation with Restricted Choices." Journal of Econometrics 211 (1):16-46.

Bianchi, Marco, Bjorn Gudmundsson, and Gylfi Zoega. 2001. “Iceland's Natural Experiment in Supply-Side Economics." American Economic Review 91 (5):1564-1579.

Bils, Mark, Yongsung Chang, and Sun-Bin Kim. 2012. "Comparative Advantage and Unemployment." Journal of Monetary Economics 59 (2):150-165.

Blundell, Richard, Luigi Pistaferri, and Itay Saporta-Eksten. 2016. "Consumption Inequality and Family Labor Supply." American Economic Review 106 (2):387-435.

Card, David and Dean Hyslop. 2005. "Estimating the Effects of a Time-Limited Earnings Subsidy for Welfare-Leavers." Econometrica 73 (6):1723-1770.

Chang, Yongsung and Sun-Bin Kim. 2006. "From Individual to Aggregate Labor Supply: A Quantitative Analysis Based on a Heterogeneous Agent Macroeconomy." International Economic Review 47 (1):1-27.

- 2007. "Heterogeneity and Aggregation: Implications for Labor-Market Fluctuations." American Economic Review 97 (5):1939-1956.

Chetty, Raj. 2012. "Bounds on Elasticities with Optimization Frictions: A Synthesis of Micro and Macro Evidence on Labor Supply." Econometrica 80 (3):969-1018.

Chetty, Raj, John Friedman, Tore Olsen, and Luigi Pistaferri. 2011. "Adjustment Costs, Firm Responses, and Micro Vs. Macro Labor Supply Elasticities: Evidence from Danish Tax Records." The Quarterly Journal of Economics 126 (2):749-804.

Chetty, Raj, Adam Guren, Day Manoli, and Andrea Weber. 2012. “Does Indivisible Labor Explain the Difference between Micro and Macro Elasticities? A Meta-Analysis of Extensive Margin Elasticities." NBER Macro Annual 2012.

Chodorow-Reich, Gabriel and Loukas Karabarbounis. 2016. "The Cyclicality of the Opportunity Cost of Employment." Journal of Political Economy 124 (6):1563-1618.

Cogan, John. 1981. "Fixed Costs and Labor Supply." Econometrica :945-963. 
Davis, Steven, Jason Faberman, and John Haltiwanger. 2006. "The Flow Approach to Labor Markets: New Data Sources and Micro-macro Links." Journal of Economic Perspectives 20 (3):3-26.

Dennis, Michael. 2019. “Technical Overview of the AmeriSpeak Panel NORC's ProbabilityBased Household Panel." NORC at the University of Chicago .

Domeij, David and Martin Floden. 2006. "The Labor-Supply Elasticity and Borrowing Constraints: Why Estimates are Biased." Review of Economic Dynamics 9 (2):242-262.

Feldstein, Martin and James Poterba. 1984. “Unemployment Insurance and Reservation Wages." Journal of Public Economics 23 (1-2):141-167.

Galí, Jordi. 2011. "The Return of the Wage Phillips Curve." Journal of the European Economic Association 9 (3):436-461.

Gourio, François and Pierre-Alexandre Noual. 2009. "The Marginal Worker and the Aggregate Elasticity of Labor Supply." Working Paper .

Guvenen, Fatih, Fatih Karahan, Serdar Ozkan, and Jae Song. 2015. "What Do Data on Millions of U.S. Workers Reveal about Life-Cycle Earnings Risk?" Working Paper .

Guvenen, Fatih, Sam Schulhofer-Wohl, Jae Song, and Motohiro Yogo. 2017. “Worker Betas: Five Facts About Systematic Earnings Risk." American Economic Review 107 (5):398-403.

Hagedorn, Marcus and Iourii Manovskii. 2008. "The Cyclical Behavior of Equilibrium Unemployment and Vacancies Revisited." American Economic Review 98 (4):1692-1706.

Hall, Robert. 2009. "Reconciling Cyclical Movements in the Marginal Value of Time and the Marginal Product of Labor." Journal of Political Economy 117 (2):281-323.

Hall, Robert and Paul Milgrom. 2008. "The Limited Influence of Unemployment on the Wage Bargain." American Economic Review 98 (4):1653-1674.

Hansen, Gary. 1985. "Indivisible Labor and the Business Cycle." Journal of Monetary Economics 16 (3):309 - 327.

Heckman, James. 1984. "Comments on the Ashenfelter and Kydland Papers." In CarnegieRochester Conference Series on Public Policy, vol. 21. Elsevier, 209-224.

Heckman, James and Thomas MaCurdy. 1980. "A Life Cycle Model of Female Labour Supply." The Review of Economic Studies 47 (1):47-74.

Huggett, Mark. 1993. "The Risk-Free Rate in Heterogeneous-Agent Incomplete-Insurance Economies." Journal of Economic Dynamics and Control 17 (5-6):953-969.

Jäger, Simon, Benjamin Schoefer, Samuel Young, and Josef Zweimüller. 2020. “Wages and the Value of Nonemployment." The Quarterly Journal of Economics 135 (4):1905-1963. 
Jäger, Simon, Benjamin Schoefer, and Josef Zweimüller. 2021. "Marginal Jobs and Job Surplus: A Test of the Efficiency of Separations." NBER Working Paper .

Kaplan, Greg, Benjamin Moll, and Giovanni Violante. 2018. "Monetary Policy According to HANK." American Economic Review 108 (3):697-743.

Kaplan, Greg, Giovanni Violante, and Justin Weidner. 2014. "The Wealthy Hand-toMouth." Brookings Papers on Economic Activity 2014 (1):77-138.

Keane, Michael and Richard Rogerson. 2015. "Reconciling Micro and Macro Labor Supply Elasticities: A Structural Perspective." Annual Review of Economics 7 (1):89-117.

Kimball, Miles and Matthew Shapiro. 2008. "Labor Supply: Are the Income and Substitution Effects both Large or Both Small?" NBER Working Paper .

Kleven, Henrik. 2019. "The EITC and the Extensive Margin: A Reappraisal." NBER Working Paoer.

Kneip, Alois, Monika Merz, and Lidia Storjohann. 2020. “Aggregation and Labor Supply Elasticities." Journal of the European Economic Association 18 (5):2315-2358.

Koenig, Felix, Alan Manning, and Barbara Petrongolo. 2020. "Reservation Wages and the Wage Flexibility Puzzle." .

Krueger, Alan and Andreas Mueller. 2016. "A Contribution to the Empirics of Reservation Wages." American Economic Journal: Economic Policy 8 (1):142-79.

Krusell, Per, Toshihiko Mukoyama, Richard Rogerson, and Aysegul Sahin. 2017. “Gross Worker Flows over the Business Cycle." American Economic Review 107 (11):3447-3476.

Le Barbanchon, Thomas, Roland Rathelot, and Alexandra Roulet. 2019. "Unemployment Insurance and Reservation Wages: Evidence from Administrative Data." Journal of Public Economics 171:1-17.

— 2021. "Gender Differences in Job Search: Trading Off Commute Against Wage." The Quarterly Journal of Economics 136 (1):381-426.

Ljungqvist, Lars and Thomas Sargent. 2006. “Do Taxes Explain European Employment? Indivisible Labor, Human Capital, Lotteries, and Savings." NBER Macroeconomics Annual 21:181-246.

—_. 2017. "The Fundamental Surplus." American Economic Review 107 (9):2630-65.

MaCurdy, Thomas. 1981. "An Empirical Model of Labor Supply in a Life-Cycle Setting." Journal of Political Economy 89 (6):1059-1085.

Martinez, Isabel, Emmanuel Saez, and Michael Siegenthaler. 2021. "Intertemporal Labor Supply Substitution? Evidence from the Swiss Income Tax Holidays." American Economic Review 111 (2):506-46. 
Mas, Alexandre and Amanda Pallais. 2019. "Labor Supply and the Value of Non-Work Time: Experimental Estimates from the Field." American Economic Review: Insights $1(1): 111-26$.

Park, Choonsung. 2020. "Consumption, Reservation Wages, and Aggregate Labor Supply." Review of Economic Dynamics 37:54-80.

Prescott, Edward. 2004. "Why Do Americans Work So Much More Than Europeans?" Federal Reserve Bank of Minneapolis Quarterly Review 28 (1):2-13.

Richter, David and Jürgen Schupp. 2015. "The SOEP Innovation Sample (SOEP IS)." Schmollers Jahrbuch: Journal of Applied Social Science Studies/Zeitschrift für Wirtschafts-und Sozialwissenschaften 135 (3):389-400.

Rogerson, Richard. 1988. "Indivisible Labor, Lotteries and Equilibrium." Journal of Monetary Economics 21 (1):3-16.

Rogerson, Richard and Johanna Wallenius. 2009. "Micro and Macro Elasticities in a Life Cycle Model With Taxes." Journal of Economic Theory 144 (6):2277-2292.

Saez, Emmanuel, Joel Slemrod, and Seth Giertz. 2012. "The Elasticity of Taxable Income with Respect to Marginal Tax Rates: A Critical Review." Journal of Economic Literature $50(1): 3-50$.

Shimer, Robert. 2009. "Convergence in Macroeconomics: The Labor Wedge." American Economic Journal: Macroeconomics 1 (1):280-97.

Shimer, Robert and Ivan Werning. 2007. "Reservation Wages and Unemployment insurance." The Quarterly Journal of Economics 122 (3):1145-1185.

Sigurdsson, Jósef. 2018. “Labor Supply Responses and Adjustment Frictions: A Tax-Free Year in Iceland." Working Paper.

Zweck, Bettina and Axel Glemser. 2018. "SOEP-IS 2016-Methodenbericht zum Befragungsjahr 2016 des SOEP-Innovationssamples." SOEP Survey Papers .

. 2020. "SOEP-IS 2019: Survey Report on the 2017 SOEP Innovation Sample." SOEP Survey Papers . 


\section{Print Appendix A: NORC at UChicago Survey Questions}

Question for the Employed The following is a hypothetical situation we ask you to think about regarding your current job, so please read [listen] carefully and try to think about what you would do if presented with this choice.

Suppose, for reasons unrelated to you, your employer offers you the following choice: Either you take unpaid time off from work for one month, or you stay in your job for that month and only receive a fraction of your regular salary. No matter what choice you take, after the month is over, your salary will return to normal.

In this hypothetical scenario, you cannot take an additional job to make up for the lost income during that month.

Assume this choice is real and you have to make it. At what point would the cut in your salary be just large enough that you would choose the unpaid month of time off over working for the month at that lower salary?

For example, an answer of 5\% means that a $5 \%$ wage cut would be the point where you would choose to take unpaid time off for the month instead of working for $5 \%$ lower pay during that month. But if the wage cut was less than $5 \%$, you would instead choose to work for that than take unpaid time off. Choose any percentage between $1 \%$ to $100 \%$, where the cut wage cut is just large enough that you would prefer to not work at all for no pay than work at reduced pay for that month.

Question for the Unemployed The following is a hypothetical situation we ask you to think about a potential job you may be looking for, so please read [listen] carefully and try to think about what you would do if presented with this choice.

Suppose you have found the kind of job you are looking for and the employer would like to hire you. The regular start date for the job is one month away. As an alternative, your employer offers you the option to start working immediately, rather than waiting a month.

However, if you chose to start work immediately, for that first month, you will only receive a fraction of the regular salary. The job is otherwise exactly the same. No matter what choice you take, after the month is over, the salary will then resume at the regular salary.

In this hypothetical scenario, you cannot take an additional job to make up for the lost income during that month.

Assume this choice is real and you have to make it. At what point would the cut in your salary be just large enough that you would choose the waiting a month without working and without the salary over starting the job immediately for the first month at that lower salary?

For example, an answer of $5 \%$ means that a $5 \%$ wage cut would be the point where you would choose to wait a month without working instead of working for \% lower pay during that month. But if the wage cut was less than $5 \%$, you would instead choose to work at that wage than wait a month without working. Choose any percentage between 
$1 \%$ to $100 \%$, where the cut wage cut is just large enough that you would prefer to not work at all for no pay than work at reduced pay for that month.

Question for the Out of the Labor Force The following is a hypothetical situation that may not have anything to do with your actual situation, but please read [listen] carefully and try to think about what you would do if presented with this choice.

Think of the range of jobs that you would realistically be offered if you searched for jobs (even if you currently are not looking for a job and may not accept any of these potential jobs).

Suppose you had such job offers in hand. Currently you would likely not take such jobs, at least not at the usual salary. However, suppose the employer were nevertheless trying hard to recruit you, specifically by offering an additional sign-up bonus. The requirement to receive the bonus is that you will work for at least one month. The bonus comes as a raise of the first month's salary. This sign-up bonus will only be paid in the first month (on top of the regular salary that month), afterwards the salary returns to the regular salary.

Assume this choice is real and you have to make it. We would like to learn whether there is a point at which the bonus in the first month is just high enough that you would take the job.

$5 \%$ means you would take the job if your employer paid a bonus of just $5 \%$ of the regular salary in the first month. 100\% means you would require a bonus as large as the regular salary. $500 \%$ would mean you require a bonus equal to five times as large as the regular salary.

Choose any percentage bonus that would be just high enough that you would take the job. You can enter a high number (e.g., 100,000\%) if you think you would not take any job, even if it paid a lot. 


\section{Print Appendix B: German Socio-Economic Panel Survey Questions (English Translations)}

The questions below are the (authors') English translations; the German original text is in (Online) Appendix A.

\section{Questions for the Employed}

Potential (Here: Actual) Earnings (Q434) How high was your labor income [salary] in the last month?

If you had special payments, e.g., vacation pay or retroactive payments, please do not include such payments in your calculations. By contrast, do include overtime pay. In case you are self-employed: Please estimate your monthly profit before and after taxes.

Please report if possible both:

- the gross salary, that is, the wages or the salary before deducting taxes and social insurance

- the net salary, that is, the wages or the salary after deducting taxes and contributions to pension, unemployment and health insurances.

[We use "pnett", i.e., the net salary.]

Baseline: Reservation Earnings Please imagine the following hypothetical scenario: Your employer cuts, for instance because of a situation of reduced demand, your salary for one month.

After that month, your salary will return to its normal level.

How high would the net salary have to be for that month, for you to still go to work at that reduced salary, rather than preferring to take unpaid vacation?

Variant: Reservation Earnings [Identical to baseline question except for the last sentence:]

How high would the net salary have to be for that month, for you to still go to work at that reduced salary, rather than preferring to interrupt your job, e.g., by taking vacation days or by giving up the job, e.g., by quitting?

Calculation of Reservation Raise We calculate the reservation raise as the ratio of the reservation earnings over the actual earnings.

\section{Questions for the Unemployed}

Potential Earnings You have responded that you are currently do not have a job, but are open to accepting a job.

Please now imagine a job that would be realistic for you and that appropriate for your qualifications.

How high would your monthly net salary be, if you were to accept such a job? 
Baseline: Reservation Earnings Now please imagine the following hypothetical scenario:

You have found this job and accepted it.

In the course of the job, your employer cuts, for instance because of a situation of reduced demand, your salary for one month.

After that month, your salary will return to its normal level (that is, [the number the responded gave above as the salary in this job]).

How high would the net salary have to be for that month, for you to still go to work at that reduced salary, rather than preferring to take unpaid vacation?

Variant: Question Giving Reservation Earnings [Identical to baseline question except for the last sentence:]

How high would the net salary have to be for that month, for you to still go to work at that reduced salary, rather than preferring to interrupt your job, e.g., by taking vacation days or by giving up the job, e.g., by quitting?

Calculation of Reservation Raise We calculate the reservation raise as the ratio of the reservation earnings over the anticipated potential earnings.

\section{Questions for the Out of the Labor Force}

Potential Earnings You have responded [in a previous labor force status question] that you are currently not employed and are also not looking for a job.

Please now nevertheless imagine a job that could be realistic for you and would be appropriate for your qualifications.

Additionally, imagine which salary would be realistic for such a job.

What do you estimate: what would be your monthly net salary for such a job?

Reservation Earnings Now please imagine the following hypothetical scenario:

Right now, we know that you [rough translation of the highly contextual German filler word "ja"] would likely not accept this job.

However, please imagine now that the employer would, for this job, guarantee a one-time special payment as a sign-up bonus at the end of the first month. Now please imagine the following hypothetical scenario:

Following the first month, the salary falls back to the normal level (that is, [the number the responded gave above as the salary in this job]).

How high would this one-time special payment need to be, for you to accept this job and at least work for the full first month?

Calculation of Reservation Raise We calculate the reservation raise as the ratio of the reservation earnings (which are the sum of the estimated potential earnings plus the reservation level of the sign-up bonus) over the anticipated potential earnings. 


\section{Tables}

Table 1: Summary Statistics of Survey and Sub-samples of Survey

\begin{tabular}{|c|c|c|c|c|}
\hline & \multicolumn{2}{|c|}{ GSOEP (German) } & \multicolumn{2}{|c|}{ NORC (U.S.) } \\
\hline & Survey & Analysis Sample & Survey & Analysis Sample \\
\hline Employed $^{1}$ & $58.0 \%$ & $58.5 \%$ & $62.1 \%$ & $60.7 \%$ \\
\hline Unemployed & $8.8 \%$ & $8.4 \%$ & $5.2 \%$ & $2.4 \%$ \\
\hline Out of Labor Force & $32.6 \%$ & $33.1 \%$ & $31.9 \%$ & $36.9 \%$ \\
\hline Age (Mean) & 52.1 & 51.1 & 47.4 & 48.1 \\
\hline Age (Median) & 53 & 52 & 47 & 48 \\
\hline Age (Std. Dev) & 18.3 & 17.5 & 17.8 & 17.6 \\
\hline Pctg. Female & $51.9 \%$ & $50.7 \%$ & $51.6 \%$ & $50.8 \%$ \\
\hline Partnered & $62.9 \%$ & $65.2 \%$ & $57.8 \%$ & $59.6 \%$ \\
\hline H.S. Diploma & $19.7 \%$ & $18.1 \%$ & $28.6 \%$ & $28.9 \%$ \\
\hline Some College & $\mathrm{N} / \mathrm{A}$ & $\mathrm{N} / \mathrm{A}$ & $28.2 \%$ & $29.3 \%$ \\
\hline Vocational & $58.1 \%$ & $59.2 \%$ & $\mathrm{~N} / \mathrm{A}$ & $\mathrm{N} / \mathrm{A}$ \\
\hline College or Higher & $22.2 \%$ & $22.8 \%$ & $32.3 \%$ & $33.4 \%$ \\
\hline Annual Household Income ${ }^{2}$ & $37,554.04$ & $37,930.80$ & $62,181.58$ & $62,951.76$ \\
\hline Number of Respondents & 3,346 & 2,431 & 2,071 & 1,679 \\
\hline
\end{tabular}

Note: The table reports summary statistics (means and standard deviations) for the NORC (U.S.) survey and the GSOEP (German) survey. "Survey" refers to the summary statistics of all respondents in the survey that were asked our questions. "Sample" refers to the subset of respondents for which we have nonmissing reservation raise statistics. All statistics use survey weights (with the exception of the "Respondents" row), with the "Sample" column reweighted to replicate overall proportions of labor force groups in the whole survey (for GSOEP, in turn mirroring the OECD numbers for 2019) or 2019 BLS labor force status statistics (in NORC).

${ }^{1}$ For GSOEP, the weights on the three labor force groups in the "Survey" column do not add up to 100\% because a small number of respondents do not cleanly fall into any of the labor force statuses.

${ }^{2}$ For GSOEP, household income figure is net household income, reported monthly in Euros and multiplied by 12 to achieve annual net household income. For NORC, the household income figure is gross, and reported in bins. We calculate the mean household income using the bottom of these bins; (for example, a respondent in the $\$ 50,000$ to $\$ 60,000$ bin is treated as having $\$ 50,000$ in gross annual income). The average household income in the table is therefore likely an underestimate. 
Table 2: Mass of Marginal Agents and Local Arc Elasticities: Reservation Raise Distribution Around 1.00 for Surveys and Calibrated Models

\begin{tabular}{|c|c|c|c|c|}
\hline & \multicolumn{2}{|c|}{ Increase in Raise $\left(1+\Xi^{\prime}>1\right)$} & \multicolumn{2}{|c|}{ Decrease in Raise $\left(1+\Xi^{\prime}<1\right.$} \\
\hline & $\frac{d \text { Emp }}{\text { Pop }} \times 100$ & Elasticity & $\frac{d \text { Emp }}{\text { Pop }} \times 100$ & Elasticity \\
\hline Survey or Model & \multicolumn{4}{|c|}{ Panel A: Raise Interval: $\mathbf{0 . 0 1}$} \\
\hline Data: U.S. (NORC) & 2.26 & 3.72 & 4.61 & 7.59 \\
\hline Data: Germany (GSOEP) & 1.70 & 2.86 & 5.56 & 9.38 \\
\hline Hansen & 100.0 & $\infty$ & 100.0 & $\infty$ \\
\hline Constant: 0.32 & 0.20 & 0.32 & 0.20 & 0.32 \\
\hline Constant: 2.5 & 1.53 & 2.52 & 1.51 & 2.48 \\
\hline Heterogeneous Agent & 0.11 & 0.18 & 0.43 & 0.72 \\
\hline Rogerson-Wallenius & 1.73 & 2.84 & 1.76 & 2.90 \\
\hline \multicolumn{5}{|c|}{ Panel B: Raise Interval: 0.03} \\
\hline Data: U.S. (NORC) & 2.31 & 1.27 & 5.55 & 3.05 \\
\hline Data: Germany (GSOEP) & 1.90 & 1.07 & 5.80 & 3.26 \\
\hline Hansen & 100.0 & $\infty$ & 100.0 & $\infty$ \\
\hline Constant: 0.32 & 0.58 & 0.32 & 0.59 & 0.32 \\
\hline Constant: 2.5 & 4.66 & 2.56 & 4.45 & 2.44 \\
\hline Heterogeneous Agent & 0.42 & 0.23 & 1.04 & 0.58 \\
\hline Rogerson-Wallenius & 5.01 & 2.79 & 5.40 & 2.96 \\
\hline \multicolumn{5}{|c|}{ Panel C: Raise Interval: 0.05} \\
\hline Data: U.S. (NORC) & 4.11 & 1.35 & 14.36 & 4.73 \\
\hline Data: Germany (GSOEP) & 2.13 & 0.72 & 6.00 & 2.02 \\
\hline Hansen & 100.0 & $\infty$ & 100.0 & $\infty$ \\
\hline Constant: 0.32 & 0.96 & 0.32 & 0.99 & 0.33 \\
\hline Constant: 2.5 & 7.87 & 2.59 & 7.31 & 2.41 \\
\hline Heterogeneous Agent & 0.93 & 0.31 & 1.52 & 0.51 \\
\hline Rogerson-Wallenius & 8.30 & 2.74 & 9.18 & 3.02 \\
\hline \multicolumn{5}{|c|}{ Panel D: Raise Interval: $\mathbf{0 . 1 0}$} \\
\hline Data: U.S. (NORC) & 5.81 & 0.96 & 22.35 & 3.68 \\
\hline Data: Germany (GSOEP) & 2.43 & 0.41 & 7.22 & 1.22 \\
\hline Hansen & 100.0 & $\infty$ & 100.0 & $\infty$ \\
\hline Constant: 0.32 & 1.89 & 0.31 & 2.02 & 0.33 \\
\hline Constant: 2.5 & 16.33 & 2.69 & 14.06 & 2.32 \\
\hline Heterogeneous Agent & 1.39 & 0.23 & 2.70 & 0.45 \\
\hline Rogerson-Wallenius & 15.85 & 2.61 & 19.37 & 3.19 \\
\hline
\end{tabular}

Note: The table presents shares and arc elasticities of the reservation raise distributions for the data (U.S. (NORC) as well as German (GSOEP) discussed in Section 3), as well as for the models presented in the model meta-analysis in Section 4 The associated aggregate labor supply curves and arc elasticities are plotted in Figure 4. The left columns present the share of marginal agents (those with reservation raise levels around one) for various intervals around one, above one, ("+", e.g., 1.00 and 1.01), and below one ("-", e.g., 0.99 and 1.00). The right columns present the implied local arc elasticities for each interval. 


\section{Figures}

\section{Figure 1: Empirical Distribution of Reservation Raises}

(a) U.S. (NORC)

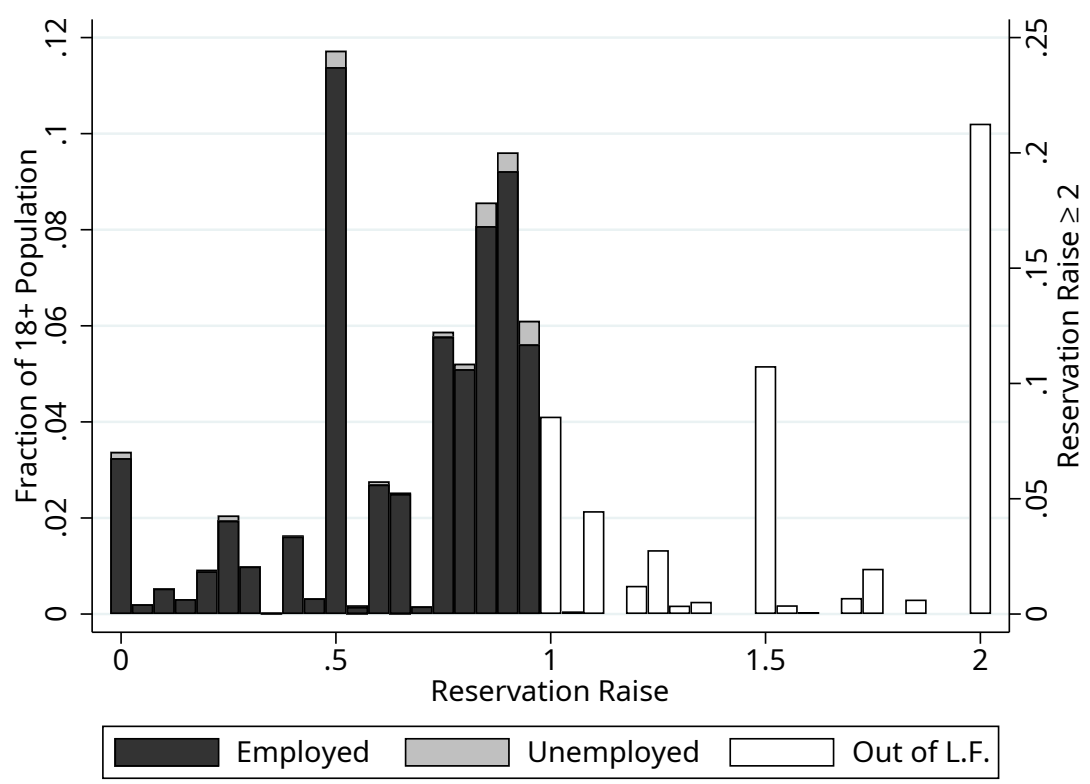

(b) Germany (GSOEP)

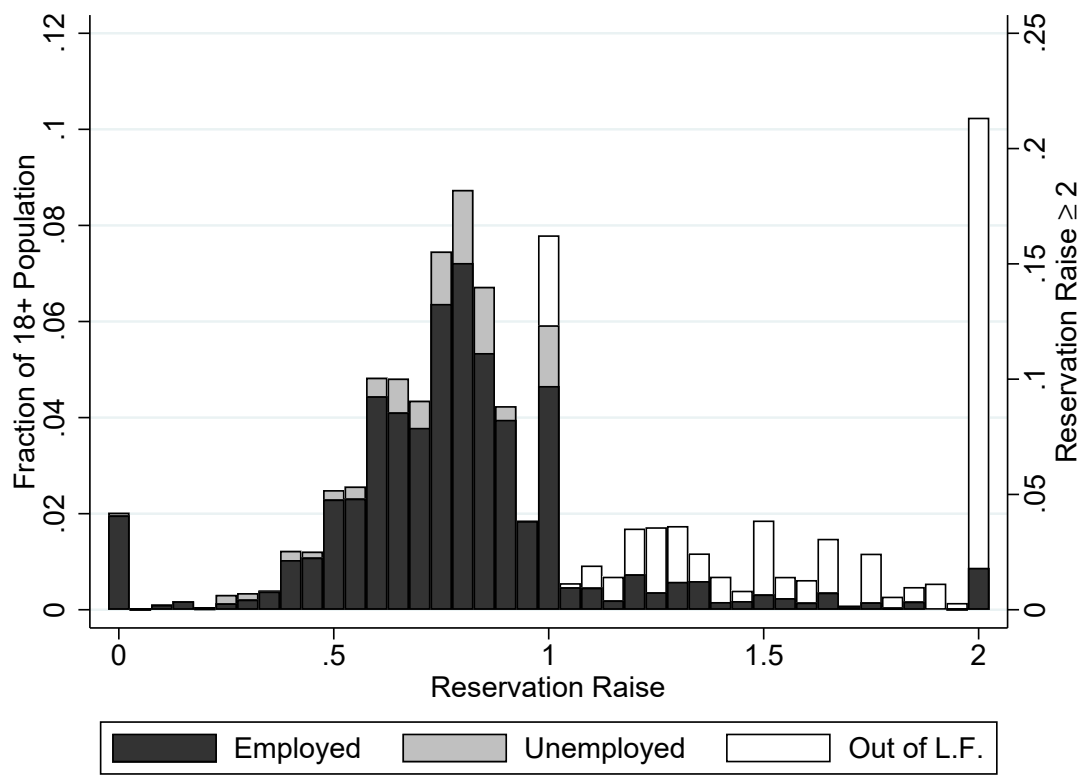

Note: The figure plots histograms of the empirical distribution of reservation raises in a representative sample of the U.S. population (NORC) in Panel (a), as well as of the German population (GSOEP) in Panel (b). Both histograms separate out the observations by their labor force status. For visual clarity, the histograms bunch raises above 2.0 into the 2.0 group, and report this share on the secondary y-axis. 
Figure 2: Empirical Distribution of Reservation Raises

(a) Full Cumulative Distribution Functions = Global Aggregate Labor Supply Curves

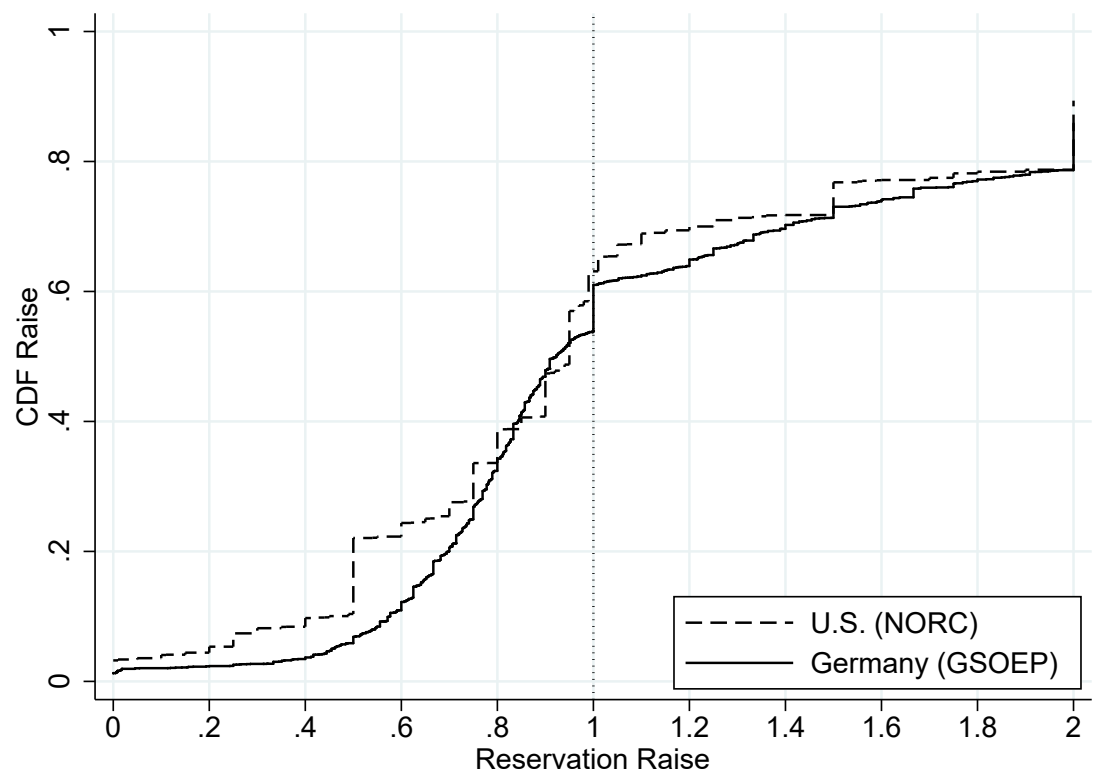

(b) Zoomed-in Version: Local Behavior

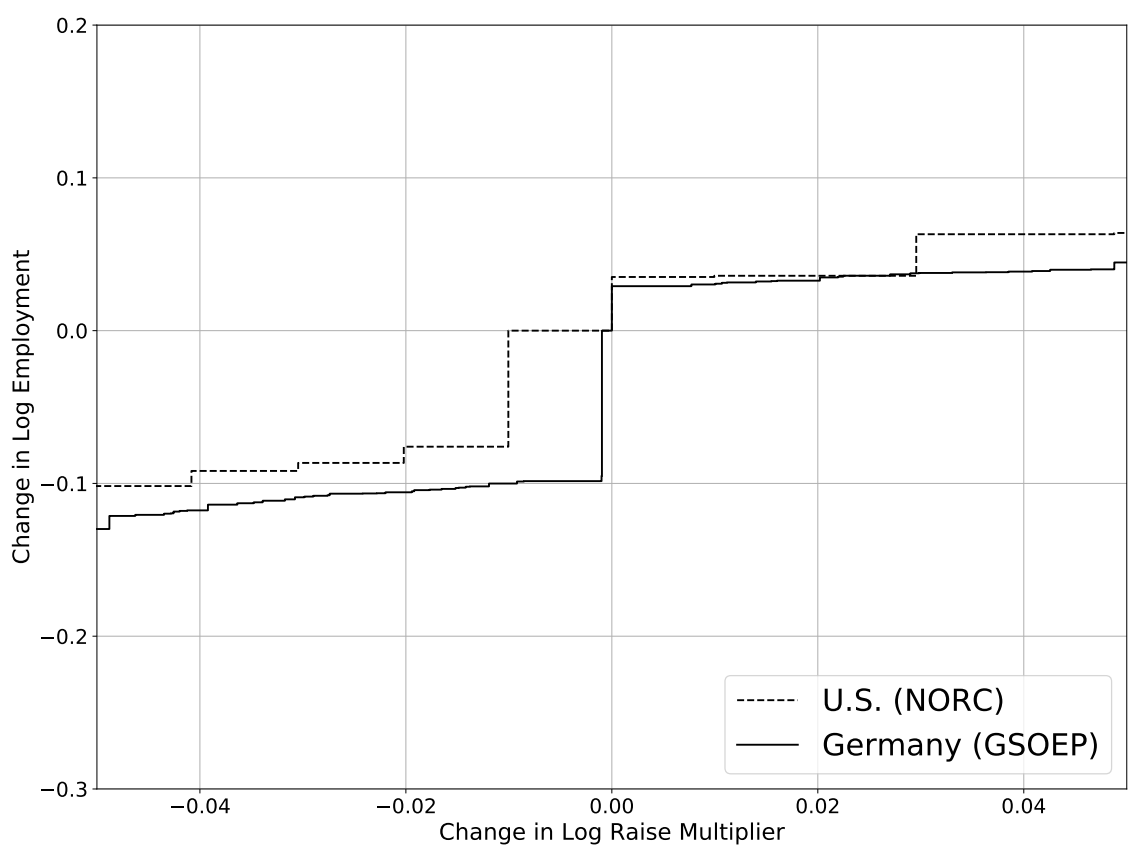

Note: The figure plots cumulative distribution functions of the empirical distribution of reservation raises in a representative sample of the U.S. population (NORC) by the dashed line, as well as of the German population (GSOEP) by the solid line. Panel (a) does so for the full CDF. This CDF is (when evaluated at the cutoff set to the prevailing aggregate raise) the aggregate labor supply curve at the extensive margin. For visual clarity, the CDFs bunch raises above 2.0 into the 2.0 group. Panel (b) takes logs on both sides and zooms into a 0.05 range of the aggregate prevailing raise. 
Figure 3: Empirical Arc Elasticities

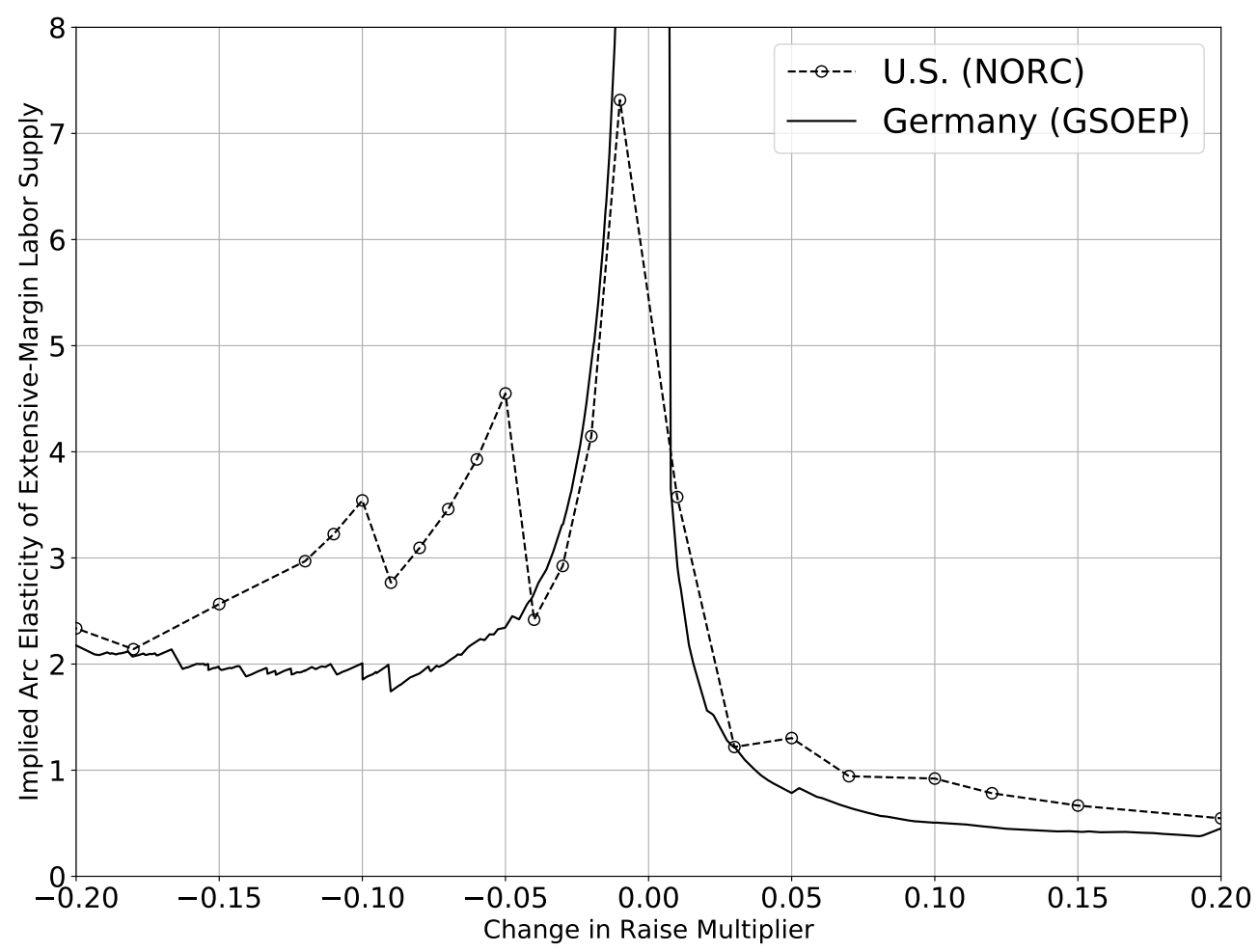

Note: The figure compares the arc elasticities of aggregate desired labor supply in a representative sample of the U.S. population (NORC) (in hollow circles denoting increments with observations) by a dashed line, as well as of the German population (GSOEP) by a solid line. Since the GSOEP permits, and features, mass points of exactly marginal respondents with a reservation raise of exactly one, the elasticity is infinite at this point (so we cap the y-axis), and drops to a finite level at the first non-unit observation. We linearly interpolate the elasticities between points with empirical observations. 
Figure 4: Comparing Models and the Data

(a) Aggregate Labor Supply Curves (CDFs of Reservation Raises)

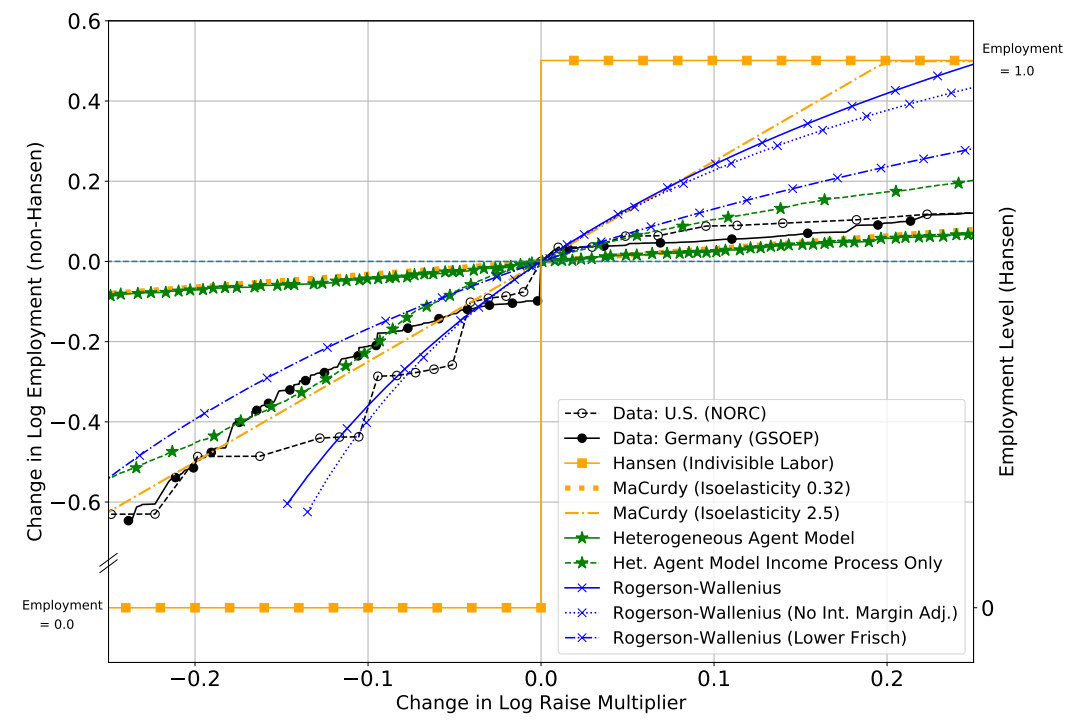

(b) Arc Elasticities

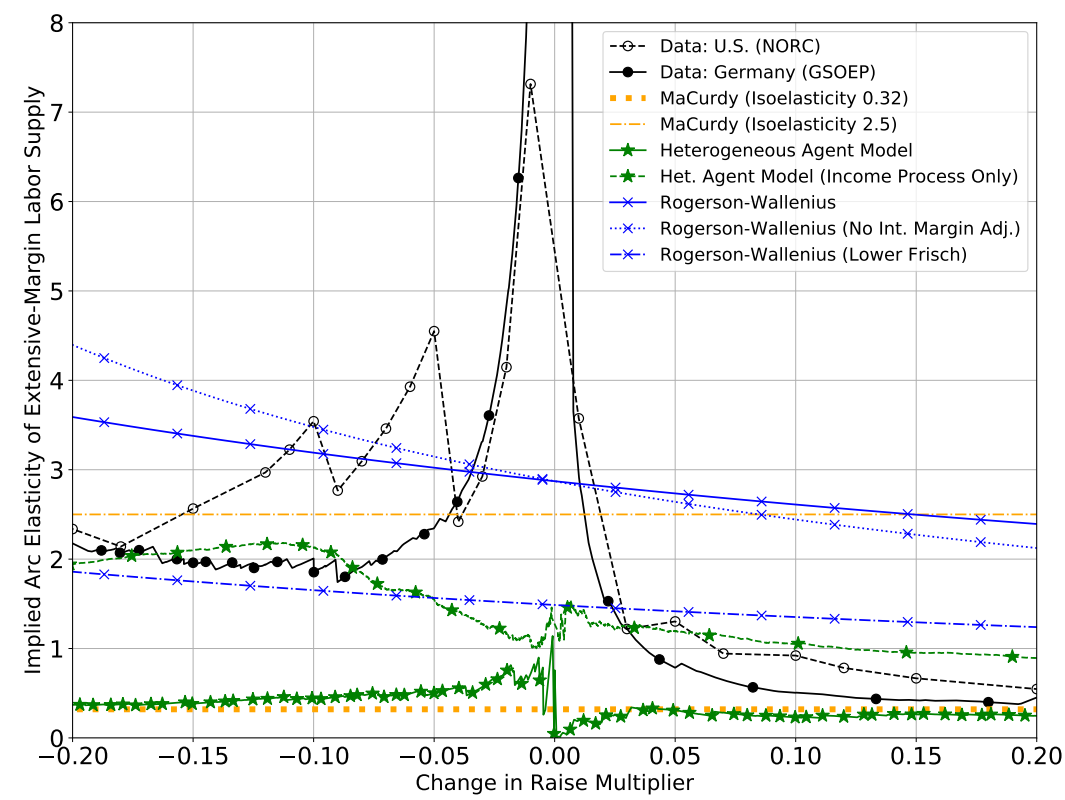

Note: The figure compares the empirical and model-implied aggregate labor supply curves at the extensive margin building on our reservation raise approach. Panel (a) plots the labor supply curve as follows: it plots the deviation in the log (desired) employment rate (y-axis) against deviations in the aggregate prevailing raise (x-axis). Hence, it corresponds to the CDFs of the reservation raise distribution, logging both axes, and plotting deviations from baseline levels (a unit reservation raise and the employment levels harmonized across models by calibration). The Hansen indivisible labor model is plotted on a secondary y-axis denoting the employment level (rather than in log deviations). Panel (b) plots arc elasticities of the employment rate with respect to deviations of the aggregate prevailing raise $1+\Xi$, for range of deviations of the raise around the baseline level (the $\mathrm{x}$-axis). The arc elasticities are calculated as $\frac{d \mathrm{Emp}}{\operatorname{Emp}} / \frac{d(1+\Xi)}{1+\Xi}$, from the baseline employment level (harmonized across models by calibration) and from a corresponding baseline net of raise rate $1+\Xi$ normalized to 1.0 . 


\section{Online Appendix: Reservation Raises: The Aggregate Labor Supply Curve at the Extensive Margin Preston Mui and Benjamin Schoefer}

\section{Table of Appendix Contents}

A German Socio-Economic Panel Survey Questions: German Original Text

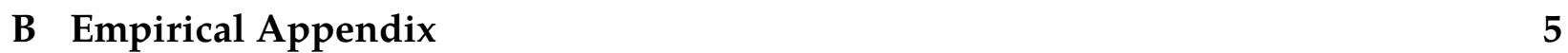

\begin{tabular}{|l|l|}
\hline C Theoretical Appendix for Model Meta-Analysis & 11
\end{tabular}

\section{Index of Tables}

A.1 Shares of Exactly and Nearly Marginal Respondents . . . . . . . . . . . . . 7

A.2 Missing Observations . . . . . . . . . . . . . . . . . . 9 9

A.3 Parameters of Macro Models with an Extensive-Margin of Labor Supply . . 13

\section{Index of Figures}

A.1 Rationed Labor Supply of the Employed and Unemployed: Winsorizing Reservation Raise Above 1 (GSOEP) . . . . . . . . . . . . . . . . . 8

A.2 The Role of Adjustment Frictions: The Reservation Raise Distribution, Baseline vs. Variant (GSOEP) . . . . . . . . . . . . . . . . . . 10

A.3 Further Details on Model Reservation Raises Distributions . . . . . . . . . . 12

A.4 Frischian vs. Uncompensated Quarter-Long Deviation in the Aggregate Prevailing Raise: Extensive-Margin Aggregate Labor Supply Responses in Three Calibrated Models . . . . . . . . . . . . . . . . . . . 23 


\section{A German Socio-Economic Panel Survey Questions: Ger- man Original Text}

The questions below are the German original text; the English translations are in the in Print Appendix 5 .

\section{Questions for the Employed}

Potential (Actual) Earnings (Q434w) Wie hoch war Ihr Arbeitsverdienst im letzten Monat? // Wenn Sie im letzten Monat Sonderzahlungen hatten, z.B. Urlaubsgeld oder Nachzahlungen, rechnen Sie diese bitte nicht mit. Entgelt für überstunden rechnen Sie dagegen mit. // Falls Sie selbständig sind: Bitte schätzen Sie Ihren monatlichen Gewinn vor und nach Steuern. // Bitte geben Sie nach Möglichkeit beides an: // -den Bruttoverdienst, das heißt Lohn oder Gehalt vor Abzug der Steuern und Sozialversicherung // -und den Nettoverdienst, das heißt den Betrag nach Abzug von Steuern und Beiträgen zur Renten-, Arbeitslosen- und Krankenversicherung. //

[We use "pnett", i.e., the net salary.]

Baseline: Question Giving Reservation Earnings Stellen Sie sich bitte nun folgendes hypothetisches Szenario vor:

Ihr Arbeitgeber kürzt beispielsweise aufgrund einer verringerten Auftragslage für einen Monat lang Ihr Gehalt.

Im Anschluss an diesen Monat geht Ihr Gehalt wieder auf sein normales Niveau zurück. Wie hoch müsste der Nettoverdienst in diesem Monat mindestens sein, damit Sie auch zu diesem gekürzten Gehalt weiterhin arbeiten gehen statt lieber unbezahlten Urlaub zu nehmen?

Variant: Question Giving Reservation Earnings [Identical to baseline question except for the last sentence:]

Wie hoch müsste der Nettoverdienst in diesem Monat mindestens sein, damit Sie auch zum gekürzten Gehalt weiterhin arbeiten gehen statt lieber Ihre Stelle zu unterbrechen, z.B. durch Urlaub nehmen, oder aufzugeben, z.B. durch Kündigen?

\section{Question for the Unemployed}

Question Giving Reservation Earnings Sie haben angegeben, dass Sie derzeit keine Arbeitsstelle haben, sich aber vorstellen können, eine Stelle anzutreten.

Stellen Sie sich bitte nun eine Arbeitsstelle vor, die für Sie realistisch wäre und Ihren 
Qualifikationen entspräche.

Was meinen Sie: Wie hoch wäre Ihr monatliches Nettogehalt, wenn Sie eine solche Stelle annehmen würden?

Baseline: Question Giving Reservation Earnings Stellen Sie sich bitte nun folgendes hypothetisches Szenario vor:

Sie haben die Stelle gefunden und angenommen.

Im Verlauf des Arbeitsverhältnisses kürzt Ihr Arbeitgeber beispielsweise aufgrund einer verringerten Auftragslage für einen Monat lang Ihr Gehalt.

Im Anschluss an diesen Monat geht Ihr Gehalt wieder auf sein normales Niveau zurück (also XXX).

Wie hoch müsste der Nettoverdienst in diesem Monat mindestens sein, damit Sie auch zum gekürzten Gehalt weiterhin arbeiten gehen statt lieber unbezahlten Urlaub zu nehmen?

Variant: Question Giving Reservation Earnings Stellen Sie sich bitte nun folgendes hypothetisches Szenario vor:

Sie haben die Stelle gefunden und angenommen.

Im Verlauf des Arbeitsverhältnisses kürzt Ihr Arbeitgeber beispielsweise aufgrund einer verringerten Auftragslage für einen Monat lang Ihr Gehalt.

Im Anschluss an diesen Monat geht Ihr Gehalt wieder auf sein normales Niveau zurück (also XXX).

Wie hoch müsste der Nettoverdienst in diesem Monat mindestens sein, damit Sie auch zum gekürzten Gehalt weiterhin arbeiten gehen statt lieber Ihre Stelle zu unterbrechen, z.B. durch Urlaub nehmen, oder aufzugeben, z.B. durch Kündigen?

\section{Question for the Out of the Labor Force}

Question Giving Potential Earnings Sie haben angegeben, dass Sie derzeit nicht berufstätig sind und auch keine Arbeitsstelle suchen.

Stellen Sie sich nun bitte trotzdem eine Stelle vor, die für Sie realistisch sein könnte und Thren Qualifikationen entspräche.

Stellen Sie sich auch vor, welches Gehalt für eine solche Stelle realistisch wäre.

Was meinen Sie: Wie wäre Ihr monatliches Nettogehalt für eine solche Stelle?

Question Giving Potential Earnings Stellen Sie sich bitte nun folgendes hypothetisches Szenario vor:

Derzeit würden Sie diese Stelle ja wahrscheinlich nicht annehmen. Stellen Sie sich nun 
aber vor, dass der Arbeitgeber für diese Stelle am Ende des ersten Monats eine einmalige Sonderzahlung als Einstiegsbonus garantiert. Im Anschluss an den ersten Monat fällt das Gehalt wieder auf das normale Niveau zurück (also XXX).

Wie hoch müsste diese einmalige Sonderzahlung sein, damit Sie diese Arbeitsstelle annehmen und zumindest für den ganzen ersten Monat lang arbeiten würden? 


\section{B Empirical Appendix}

\section{B.1 Calculation of Arc Elasticities}

In the main text, we construct the arc elasticity for non-infinitesimal changes in the aggregate raise as:

$$
\epsilon_{E_{t},\left(1+\Xi_{t}\right) \rightarrow\left(1+\Xi_{t}^{\prime}\right)}=\frac{F_{t}\left(1+\Xi_{t}^{\prime}\right)-F_{t}\left(1+\Xi_{t}\right)}{F_{t}\left(1+\Xi_{t}\right)} / \frac{\left(1+\Xi_{t}^{\prime}\right)-\left(1+\Xi_{t}\right)}{1+\Xi_{t}} .
$$

Our empirical analog of the arc elasticity (normalized so that the prevailing aggregate raise is $1-\Xi_{t}=1$ ) is:

$$
\hat{\epsilon}_{E_{t},(1) \rightarrow\left(1+\Xi_{t}^{\prime}\right)}=\frac{\tilde{F}_{t}\left(1+\Xi_{t}^{\prime}\right)-\tilde{F}_{t}(1)}{\tilde{F}_{t}(1)} / \Xi_{t}^{\prime} .
$$

We now discuss how we construct the the CDF at which we evaluate the counterfactual employment level $\tilde{F}_{t}\left(1+\Xi_{t}^{\prime}\right)$, and then discuss the baseline employment level $\tilde{F}_{t}(1)$.

Breaking Ties We have two tie-breaking choices to make at points of indifference. Formally, our tie-breaking rule depends on the direction of the shift (whether $1+\Xi_{t}^{\prime}>1,<1$, or $=1$ ) as follows:

$$
\tilde{F}_{t}\left(1+\Xi_{t}^{\prime}\right)= \begin{cases}\sum_{i=1}^{n} \omega_{i} \mathbb{1}_{\left(1+\xi_{i t}<1+\Xi_{t}^{\prime}\right)} & \text { if } 1+\Xi_{t}^{\prime}<1 \\ \sum_{i=1}^{n} \omega_{i} \mathbb{1}_{\left(1+\xi_{i t} \leq 1+\Xi_{t}^{\prime}\right)} & \text { if } 1+\Xi_{t}^{\prime}>1 \\ \text { given by labor force status (see below) } & \text { if } 1+\Xi_{t}^{\prime}=1,\end{cases}
$$

where $\omega_{i}$ is the survey weight on respondent $i$ (in NORC, the sampling weights and the labor force weights as described in the main text; in GSOEP, the labor force weights as described in the main text).

First, we determine how to allocate workers exactly indifferent at the original prevailing aggregate raise, i.e., for whom $1+\xi_{i t}^{*}=1$. The empirical analog of desired employment at the prevailing raise $\left(\tilde{F}_{t}(1)\right)$-and therefore the mass of individuals crowded into employment or nonemployment depending on the direction of the pertubation-depends on the survey used. For the U.S. (NORC) survey, $\tilde{F}_{t}(1)$ is simply the (weighted) fraction of respondents that choose a reservation raise less than than 1 (by survey construction, all employed and unemployed respondents are restricted to reporting a reservation raise lower than 1 , so there is no empirical difference between less than or less than equal with 
this survey). For the German (GSOEP) survey, survey respondents are not prevented from reporting $1+\xi_{i t}^{*}=1$; that is, they can report being exactly indifferent to employment or non-employment. Economically speaking, a respondent with $1+\xi_{i t}^{*}=1$ is exactly indifferent, and so the exact level of desired aggregate labor supply is undefined if there is a mass of respondents with $1+\xi_{i t}^{*}=1$. To break this tie, we use labor force status: we calculate $\tilde{F}_{t}(1)$ as including the exactly marginal $\left(1+\xi_{i t}^{*}=1\right)$ employed or unemployed workers, but not the exactly marginal out-of-the-labor force respondents. This implies that for upward perturbations $1+\Xi_{t}^{\prime}>1$, there is a mass of out of the labor force (those with $1+\xi_{i t}^{*}=1$ being crowded into employment (plus the nearly marginal other respondents); conversely, the exactly marginal employed and unemployed respondents will be crowded into nonemployment for any downward perturbation $1+\Xi_{t}^{\prime}<1$ (plus the nearly marginal other respondents).

Second, we need to break ties for how to treat respondents that are exactly marginal at the new aggregate prevailing wedge $1+\xi_{i t}^{*}=1+\Xi_{t}^{\prime}$, to compute the counterfactual employment level in the numerator $F_{t}\left(1+\Xi_{t}^{\prime}\right)$ (an issue largely present in NORC due to the percentage point increments). In words, the above formula clarifies that when calculating downwards elasticities, we count individuals who report indifference at the perturbation, i.e., for whom $1+\xi_{i t}^{*}=1+\Xi_{t}^{\prime}$, as being induced into nonemployment out of employment; when calculating upward elasticities, we count such individuals as being induced into employment out of nonemployment.

Winsorizing the (Un-)Employed In Table A.1, we report the proportions of exactly and nearly marginal respondents by labor force status for each survey. Across all three each labor force groups, there is a substantial proportion of respondents who report being exactly or nearly marginal, especially for the employed. In NORC, by design these respondents are bunched at the lowest increment below $1.0(0.99)$ for those in the labor force, and above 1.00 (1.01) for those out of the labor force. In GSOEP, the mass of exactly marginal individuals is permitted to occur at exactly 1.00 (when workers' reservation earnings equal the actual earnings). For the employed, the nearly (but not exactly) marginal respondents are predominantly below 1.0, consistent with our decision to allocate these workers to desiring employment.

Figure A.1 Panel (a) plots the alternative CDF and Panel (b) shows the corresponding arc elasticities that would arise if we winsorized the employed and unemployed with reservation raises above 1 to exactly 1 (and for the arc elasticities treat them following the tie-breaking rule described above). Of course, this procedure dramatically raises local elasticities downward, and somewhat attenuates upward elasticities. Of course, some of those answers may reflect measurement error (e.g., the employed may report their 
actual earnings noisily or have another number in mind when then giving the reservation earnings), so that some of these observations need not be exactly marginal.

Table A.1: Shares of Exactly and Nearly Marginal Respondents

\begin{tabular}{l|ccccc} 
L.F. Status & \multicolumn{5}{c}{ Reservation Raises } \\
\hline \multicolumn{7}{c}{$[0.99,1.00)$} & 1.00 & $(1.00,1.01]$ & $>1.01$ \\
\hline Empl. & $<0.99$ Panel A: NORC \\
Unempl. & $56.26 \%$ & $4.44 \%$ & $0.00 \%$ & $0.00 \%$ & $0.00 \%$ \\
OOLF & $2.23 \%$ & $0.17 \%$ & $0.00 \%$ & $0.00 \%$ & $0.00 \%$ \\
\hline \multicolumn{7}{c}{ Panel A: GSOEP } \\
\hline Empl. & $0.00 \%$ & $0.00 \%$ & $0.00 \%$ & $2.26 \%$ & $34.64 \%$ \\
Unempl. & $46.52 \%$ & $0.28 \%$ & $4.10 \%$ & $0.05 \%$ & $7.56 \%$ \\
OOLF & $7.15 \%$ & $0.00 \%$ & $1.26 \%$ & $0.00 \%$ & $0.00 \%$ \\
& $0.00 \%$ & $0.00 \%$ & $1.70 \%$ & $0.00 \%$ & $31.37 \%$
\end{tabular}

Note: The table presents respondents that are exactly and nearly marginal by employment status. The reported percentages are the (weighted) percentages of the whole sample. 
Figure A.1: Rationed Labor Supply of the Employed and Unemployed: Winsorizing Reservation Raise Above 1 (GSOEP)

(a) CDFs of Reservation Raises

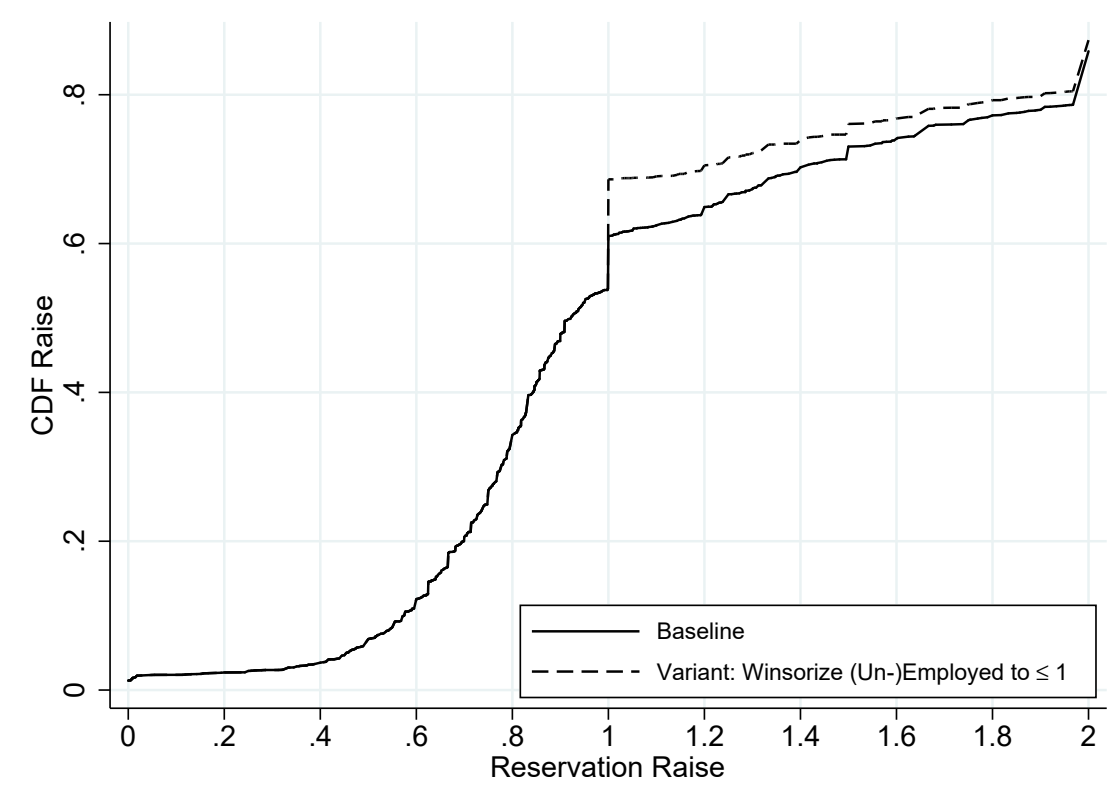

(b) Arc Elasticities

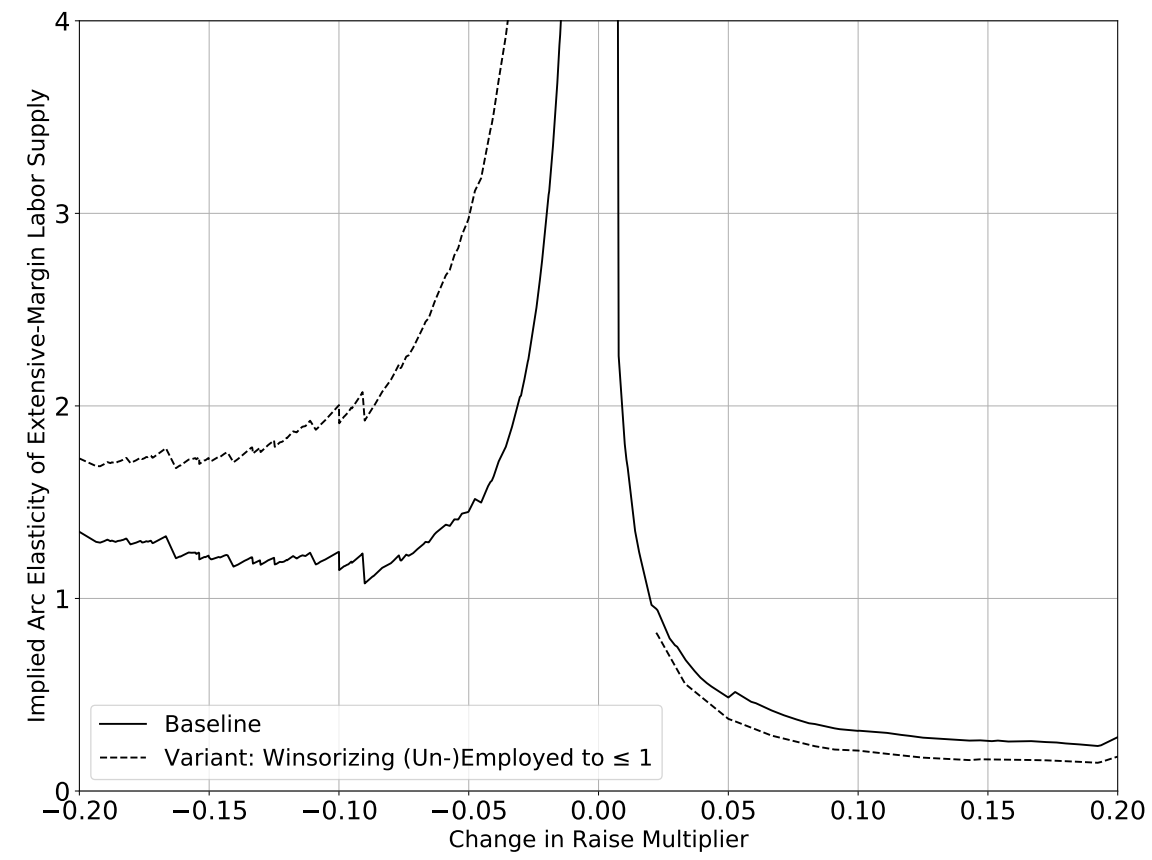

Note: The figure compares the GSOEP reservation raise distributions (CDF in Panel (a), arc elasticities in Panel (b)) under our baseline treatment of the employed versus treating those who are employed (or unemployed) and report a reservation raise greater than 1 as exactly marginal, i.e., we winsorize those observations and reassign them a value of exactly 1. 


\section{B.2 Missing Observations}

\section{Table A.2: Missing Observations}

Panel A: U.S. (NORC)

\begin{tabular}{|c|c|c|c|c|}
\hline L.F. Status & \multicolumn{2}{|c|}{ Missing Reservation Raise } & \multicolumn{2}{|c|}{ Total (Incl. Nonmissing) } \\
\hline Employed & \multicolumn{2}{|c|}{247} & \multicolumn{2}{|c|}{1284} \\
\hline Unemployed & \multicolumn{2}{|c|}{10} & \multicolumn{2}{|r|}{83} \\
\hline OOLF & \multicolumn{2}{|c|}{122} & \multicolumn{2}{|r|}{691} \\
\hline Any L.F. & \multirow{2}{*}{\multicolumn{2}{|c|}{392}} & \multicolumn{2}{|r|}{2,058} \\
\hline Missing L.F. Status & & & \multicolumn{2}{|r|}{13} \\
\hline \multicolumn{5}{|c|}{ Panel B: Germany (GSOEP) } \\
\hline L.F. Status & Missing Res. Raise & Missing Salary & Missing Res. Salary & $\begin{array}{l}\text { Total, incl. non-missing } \\
\text { (Fraction of Total) }\end{array}$ \\
\hline Employed (Baseline) & $194(22.1 \%)$ & $58(6.3 \%)$ & $148(18.7 \%)$ & $933(29.4 \%)$ \\
\hline Employed (Variant) & $174(19.2 \%)$ & $60(6.5 \%)$ & $148(16.2 \%)$ & $926(28.7 \%)$ \\
\hline Unemployed (Baseline) & $39(22.2 \%)$ & $31(17.4 \%)$ & $36(18.4 \%)$ & $144(4.6 \%)$ \\
\hline Unemployed (Variant) & $39(25.0 \%)$ & $32(20.2 \%)$ & $39(24.9 \%)$ & $129(4.2 \%)$ \\
\hline OOLF & $618(47.0 \%)$ & $482(36.1 \%)$ & $605(46.1 \%)$ & $1,360(32.7 \%)$ \\
\hline Any L.F. & $1,062(29.6 \%)$ & $662(27.2 \%)$ & $991(17.3 \%)$ & $3,493(99.5 \%)$ \\
\hline Missing L.F. status & & & & $17(0.46 \%)$ \\
\hline Missing Weight & & & & 164 \\
\hline
\end{tabular}

Note: The table presents the fraction of respondents with missing information on reservation raises (and for GSOEP, separately for potential and reservation earnings), by employment status. 


\section{B.3 Robustness and Alternative Specifications (GSOEP)}

Figure A.2: The Role of Adjustment Frictions: The Reservation Raise Distribution, Baseline vs. Variant (GSOEP)

(a) CDFs of Reservation Raises

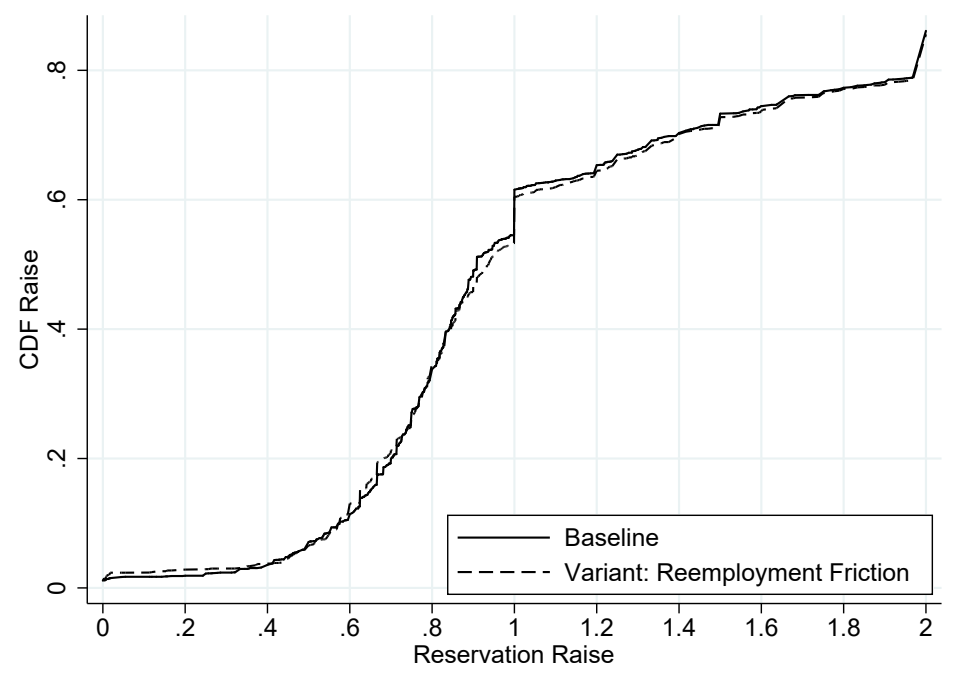

(b) Arc Elasticities

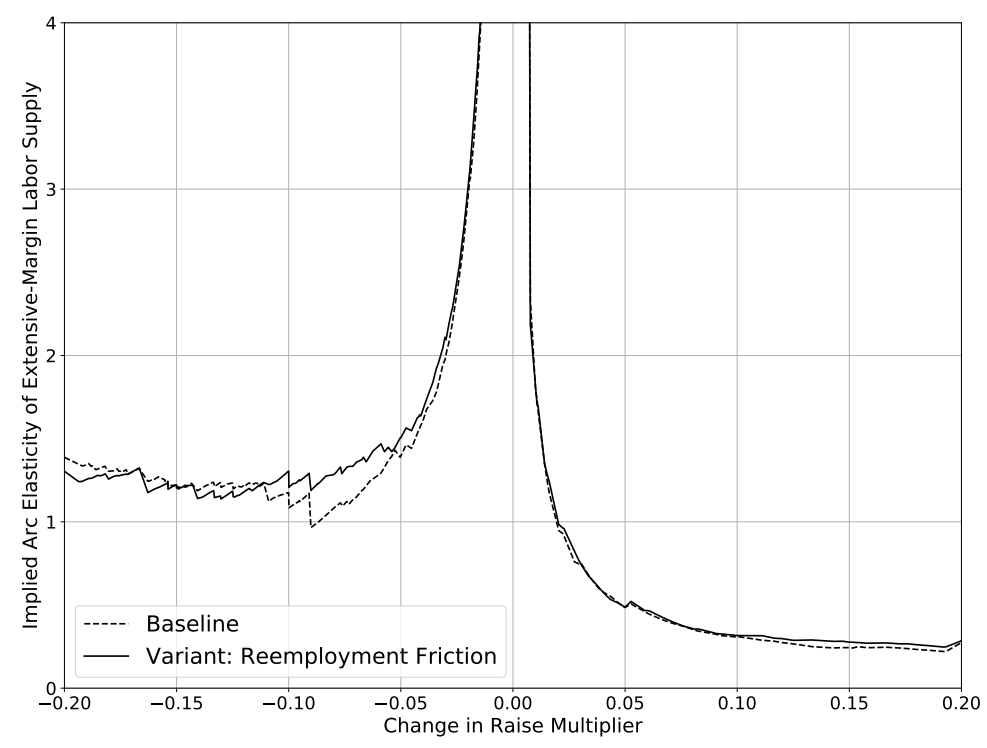

Note: The figure compares the GSOEP reservation raise distributions (CDF in Panel (a), arc elasticities in Panel (b)) under the baseline question (which evokes frictionless labor supply adjustment during the nonemployment month, akin to a vacation) and the variant question (which explicitly eludes to the possibility that a quit from the job may be necessary to achieve that month in nonemployment). The scenarios apply to the employed and unemployed. The resulting graphs reweight the employed and unemployed to match their shares in the full sample. 


\section{Theoretical Appendix for Model Meta-Analysis}

We detail each model's derivations, and then cover computational details.

\section{C.1 Detailed Derivation and Discussion}

We now present a detailed model-by-model meta-analysis applying the reservation-raise approach as a unifying bridge between structurally different labor supply blocks. The parameters for our calibrated models in this meta-analysis are in Appendix Table A.3. Appendix Figure A.3 plots additional model-specific reservation raise histograms and supplementary items.

\section{C.1.1 Representative Household: Full Insurance and "Command" Labor Supply}

A common specification appeals to a large representative household, comprised of a unit mass of individual members, which we explicitly index by $i \in[0,1]$. Micro utility $u_{i}\left(c_{i t}\right)-e_{i t} v_{i t}$ is separable, where $e_{i t} \in\{0,1\}$ is an employment indicator. Potential earnings are $y_{i t}$. There is potentially some uncertainty over the path of wages and interest rates. The large household has a pooled budget constraint and assigns consumption levels and employment statuses to its individual members: 2

$$
\begin{gathered}
\max _{\left\{c_{i t}, e_{i t}\right\}_{i}, A_{t}} \mathbb{E}_{t} \sum_{s=t}^{\infty} \beta^{s-t} \int_{0}^{1}\left[u_{i}\left(c_{i s}\right)-e_{i s} v_{i s}\right] d i \\
\text { s.t. } A_{s}+\int_{0}^{1} c_{i s} d i \leq A_{s-1}\left(1+r_{s-1}\right)+\int_{0}^{1}\left(1+\Xi_{s}\right) y_{i s} e_{i s} d i+T_{s} \quad \forall s \geq t .
\end{gathered}
$$

Full (cross-sectional) insurance implies that the marginal utility of consumption is optimally set homogeneous across households, equal to the multiplier on the pooled budget constraint,

$$
\bar{\lambda}_{t}=\frac{\partial u_{i}\left(c_{i t}\right)}{\partial c_{i t}} \forall i
$$

${ }^{23}$ We take a perspective, as, e.g., Galí (2011), that the household head directly assigns allocations. Hansen (1985) and Rogerson (1988) present incentive-compatible lotteries. The Hansen (1985) set-up is equivalent to a representative household with utility function $U\left(c_{t}, E_{t}\right)=\log \left(c_{t}\right)-\bar{v} E_{t}$, with intratemporal first-order condition $\bar{\lambda}_{t} \bar{w}_{t}=\bar{v}$. 

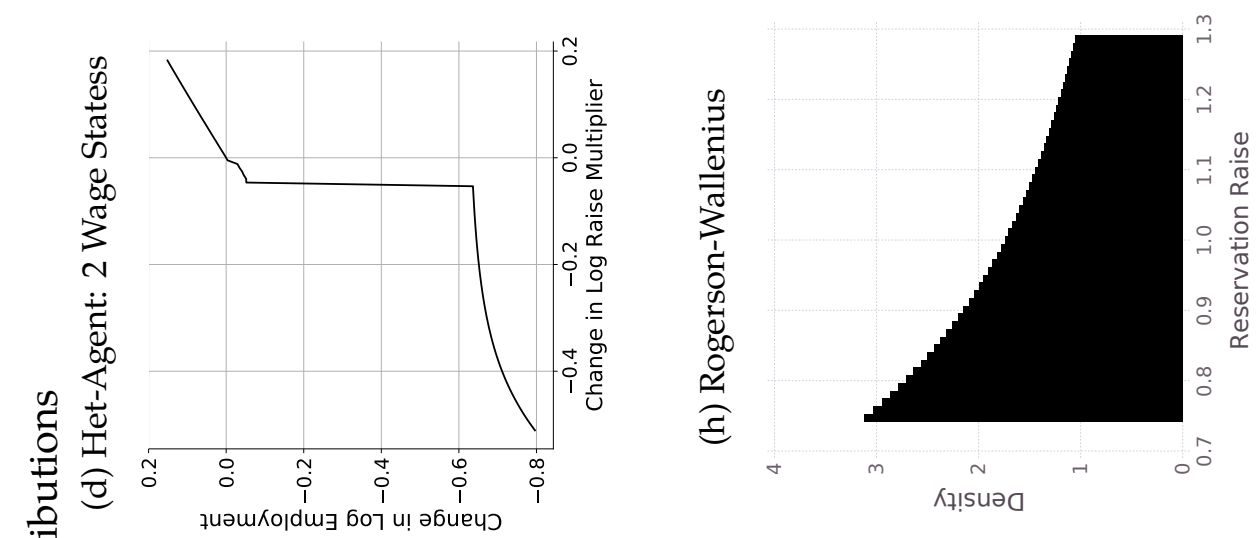

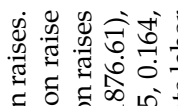

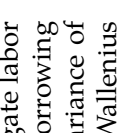

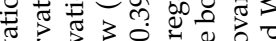

屯

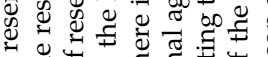
क छ 政

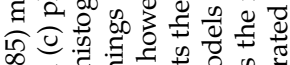

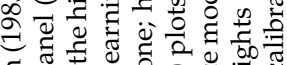
둥 0 \%

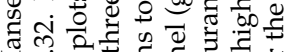

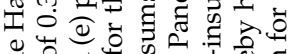

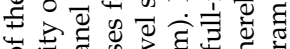

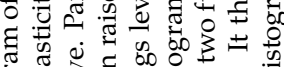

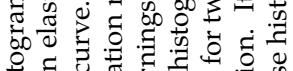
की

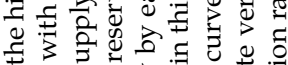
so bo

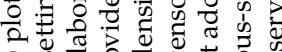
(ब)

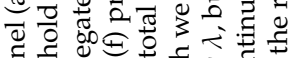

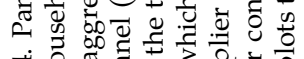
iㅓ웡 ᄃำ 记 马 ⿷匚⿱ क

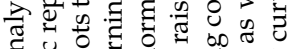

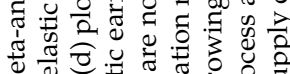
छ

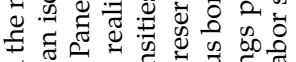

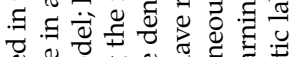

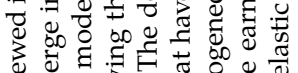
过 学 可

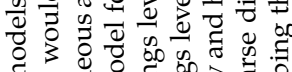

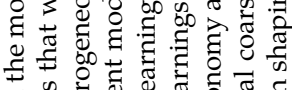

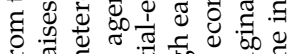

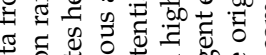

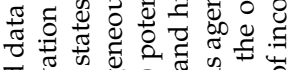
च्ट

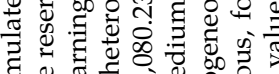

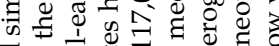

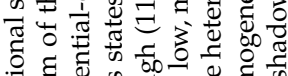
要 क

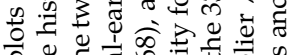

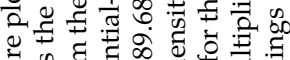

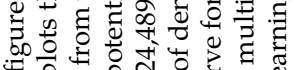

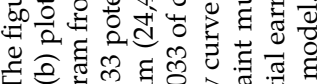

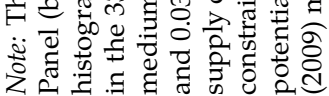


Table A.3: Parameters of Macro Models with an Extensive-Margin of Labor Supply

\begin{tabular}{|c|c|c|c|}
\hline Parameter & Symbol & \multicolumn{2}{|c|}{ Value (by Variant) } \\
\hline \multicolumn{4}{|c|}{ Panel A: Hansen (Indivisible Labor) } \\
\hline Employment disutility & $\overline{\bar{v}}$ & & 1.0 \\
\hline Potential earnings & $\bar{y}$ & & 1.0 \\
\hline MUC & $\bar{\lambda}$ & & 1.0 \\
\hline \multicolumn{4}{|c|}{ Panel B: MaCurdy (Isolesticity) } \\
\hline & & Low Frisch $(0.32)$ & High Frisch (2.50) \\
\hline CRRA cons. param. & $\sigma$ & 1.00 & \\
\hline Potential earnings & $\bar{y}$ & 1.00 & $"$ \\
\hline $\begin{array}{l}\text { Shape parameter of labor } \\
\text { disutility distutility }\end{array}$ & $\alpha_{v}$ & 0.32 & 2.50 \\
\hline Max. labor disutility & $v_{\max }$ & 4.759 & 1.221 \\
\hline \multicolumn{4}{|c|}{ Panel C: Heterogeneous Agent Model } \\
\hline & & Toy Model & HANK Earnings Process \\
\hline Potential-earnings states & & {$\left[y_{1}, y_{2}\right]=[0.0797,0.15]$} & 33-State Markov process from \\
\hline Transition probabilities & & {$\left[\lambda_{12}, \lambda_{21}\right]^{2}=[0.1,0.2]$} & Kaplan, Moll, and Violante (2018)* \\
\hline CRRA cons. param. & $\gamma$ & 2.0 & 2.0 \\
\hline Interest rate & $r$ & 0.03 & 0.03 \\
\hline Discount rate & $\beta$ & 0.95 & 0.97 \\
\hline Labor disutility & $\bar{v}$ & 3.0 & $2.083 \times 10^{-5}$ \\
\hline UI benefit/nonemp. payoff & $b$ & 0.06 & 0.00 \\
\hline $\begin{array}{l}\text { Asset grid: min. assets } \\
\text { (\& borrowing limit) }\end{array}$ & $a_{\min }$ & -0.02 & -1.775 \\
\hline Asset grid: max. assets & $a_{\max }$ & 0.75 & $5,000,000$ \\
\hline \multicolumn{4}{|c|}{ Panel D: Rogerson-Wallenius } \\
\hline & & Baseline & Low-Frisch Variant \\
\hline Interest rate & $r$ & 0.0 & \\
\hline CRRA cons. param. & $\sigma$ & 1.0 & $"$ \\
\hline Labor disutility shifter & $\Gamma$ & 42.492 & 40.000 \\
\hline Minimum hours & $\bar{h}$ & 0.258 & 0.272 \\
\hline Maximum prod. & $\hat{w}_{0}$ & 1.000 & 1.112 \\
\hline Prod.-age slope & $\hat{w}_{1}$ & 0.851 & 1.320 \\
\hline Intensive-margin & $\gamma$ & 0.5 & $"$ \\
\hline Frisch elasticity & & & \\
\hline Tax rate & $\tau$ & $26.0 \%$ & $"$ \\
\hline
\end{tabular}

Note: The table presents the parameters for the models with an extensive margin of labor supply presented in the model meta-analysis Section 4 , generating the calibrated aggregate labor supply curves plotted in Figure 4 *: We describe the 33-state earnings process in Appendix Section C.4.3.

which eliminates $\lambda$ as a source of cross-sectional variation in reservation raises even with heterogeneity in consumption utility function $u_{i}(\cdot)$. Due to spot jobs, expectations and intertemporal aspects are subsumed in $\overline{\lambda_{t}}$. Going forward, $\bar{x}_{t}$ denotes idiosyncratic variables $x_{i t}$ that are homogeneous in the cross-section.

First, we define the allocative micro reservation raise in this large-household structure, here rendering the household head indifferent between sending that marginal member $i$ to employment rather than nonemployment, where we can index an individual $i$ by her 
disutility-earnings type $v y$ :

$$
1+\xi_{i t}^{*}=\frac{v_{i t}}{\bar{\lambda}_{t} y_{i t}}=1+\xi_{v y t}^{*}
$$

Second, we trace out the aggregate labor supply curve from the distribution of the reservation raises, which in turn subsumes the detailed heterogeneity in wages and labor supply disutilities:

$$
\begin{aligned}
E_{t}\left(1+\Xi_{t}\right) & =F_{t}\left(1+\Xi_{t}\right)=P\left(1+\xi_{i t} \leq 1+\Xi\right)=P\left(\frac{v_{i t}}{y_{i t} \bar{\lambda}_{t}} \leq 1+\Xi_{t}\right)=P\left(\frac{v_{i t}}{y_{i t}} \leq\left(1+\Xi_{t}\right) \bar{\lambda}_{t}\right) \\
& =\int_{-\infty}^{\infty} \int_{-\infty}^{\infty} \mathbb{1}\left[\frac{v}{y} \leq\left(1+\Xi_{t}\right) \bar{\lambda}_{t}\right] d G_{t}(v, y),
\end{aligned}
$$

where $G_{t}(v, y)$ is the CDF of the joint distribution of $v$ and $y$.

Third, the arc elasticities follow the definition in Equation (6) and depend on the joint distributions of $v$ and $y$.

Below we review specific cases of this representative-household class of labor supply model block, to study more concrete curves.

Hansen (1985) The setup nests the model of indivisible labor and homogeneous households by Hansen (1985), where specifically $\bar{y}_{t}=\tilde{h} w_{i t}$ and $v_{i t}=\bar{v} \forall i$ (which in the original paper is $\left.A \ln \left(1-h_{i t}\right)\right)$, with one exogenous hours option $h_{i t} \in\{0, \widetilde{h}>0\}$.

First, all individuals have the same reservation raise - i.e., all are exactly marginal:

$$
1+\xi_{i t}^{*}=1+\bar{\xi}_{t}^{*}=\frac{\bar{v}}{\bar{\lambda}_{t} \bar{y}_{t}}
$$

Second, the reservation raise distribution (Appendix Figure A.3 Panel (a)), is degenerate.

Third, the Frisch elasticity is locally infinite at $1+\Xi_{t}$. Interior solutions are obtained through $\lambda_{t}$ (decreasing marginal utility from consumption).

Heterogeneity Only in Disutility of Labor We now maintain wage homogeneity, but disutility of labor $v$ is distributed between individuals according to CDF $G_{t}^{v}(v)$. First, each 
individual $i$ is now characterized by their type $v(i)$, and the household head maximizes:

$$
\begin{gathered}
\max _{\left\{c_{v t}, e_{v t}\right\}, A_{t}} \mathbb{E}_{t} \sum_{s=t}^{\infty} \beta^{s-t} \int\left[u\left(c_{v s}\right)-e_{v s} v_{s}\right] g(v) d v \\
\text { s.t. } A_{s}+\int c_{v s} g(v) d v \leq A_{s-1}\left(1+r_{s-1}\right)+\left(1+\Xi_{s}\right) y_{s} \int e_{v s} g(v) d v+T_{s} \quad \forall s \geq t .
\end{gathered}
$$

First, we define each individual's reservation raise ,characterized by their type $v(i)$ :

$$
1+\xi_{i t}^{*}=\frac{v_{i t}}{\bar{y}_{t} \bar{\lambda}_{t}}=1+\xi_{v t}^{*}
$$

Second, aggregate labor supply, i.e., distribution of $1+\xi_{i t}^{*}$, will follow directly from $G_{t}^{v}(v)$ since consumption and wages are homogeneous. The household head sends off members with $1+\xi_{i t}^{*}<1+\Xi_{t}$ to employment, and all others to nonemployment:

$$
E_{t}\left(1+\Xi_{t}\right)=F_{t}\left(1+\Xi_{t}\right)=P\left(1+\xi_{i t}^{*} \leq 1+\Xi_{t}\right)=P\left(v_{i t} \leq \frac{1+\Xi_{t}}{\bar{y}_{t} \bar{\lambda}_{t}}\right)=G_{t}^{v}\left(\frac{1+\Xi_{t}}{\bar{y}_{t} \bar{\lambda}_{t}}\right) .
$$

Alternatively, pointwise optimization would lead to a disutility cutoff rule $v_{t}^{*}=(1+$ $\left.\Xi_{t}\right) \bar{y}_{t} \bar{\lambda}_{t}: v_{i t} \geq v_{t}^{*}$ types work, $v_{i t}<v_{t}^{*}$ types stay at home.

Third, the elasticity is given by $\left[\left(1+\Xi_{t}\right) g_{t}^{v}\left(\frac{1+\Xi_{t}}{\bar{y}_{t} \bar{\lambda}_{t}}\right)\right] /\left[1-G_{t}^{v}\left(\frac{1+\Xi_{t}}{\bar{y}_{t} \bar{\lambda}_{t}}\right)\right]$.

MaCurdy (1981) Isoelastic Preferences A common representative household setup (pooled budget constraint and homogeneous wages) applies the familiar isoelastic intensive-margin MaCurdy (1981) preferences to the extensive margin:

$$
\frac{C_{t}^{1-\sigma}}{1-\sigma}-\Psi \frac{E_{t}^{1+1 / \eta}}{1+1 / \eta}
$$

We now reverse-engineer a distribution of disutility $G_{t}^{v}(v)$ that delivers this labor supply specification. The micro reservation raise is again given by (A13). Suppose $v$ follows a power law distribution $G_{t}^{v}(v)=\left(\frac{v}{v_{\max }}\right)^{\alpha_{v}}$ with shape parameter $\alpha_{v}$ over support $\left[0, v_{\max }\right]$. Then, aggregate employment is (building on Section 2 , assuming positive nonemployment by all types): 


$$
E_{t}\left(1+\Xi_{t}\right)=F_{t}\left(1+\Xi_{t}\right)=P\left(\frac{v_{i t}}{\bar{y}_{t} \bar{\lambda}_{t}} \leq 1+\Xi_{t}\right)=G_{t}^{v}\left(\left(1+\Xi_{t}\right) \bar{y}_{t} \bar{\lambda}_{t}\right)=\left(\frac{\left(1+\Xi_{t}\right) \bar{y}_{t} \bar{\lambda}_{t}}{v_{\max }}\right)^{\alpha_{v}}
$$

The reservation raise distribution then too is a power law distribution inheriting shape parameter $\alpha_{v}$-giving the constant extensive margin Frisch elasticity:

$$
\epsilon_{E_{t}, 1+\Xi_{t}}=\frac{\left(1+\Xi_{t}\right) F_{t}\left(1+\Xi_{t}\right)}{F_{t}\left(1+\Xi_{t}\right)}=\frac{\left(1+\Xi_{t}\right) \alpha_{v}\left(1+\Xi_{t}\right)^{-1}\left(\frac{\left(1+\Xi_{t}\right) \bar{y}_{t} \bar{\lambda}_{t}}{v_{\max }}\right)^{\alpha_{v}}}{\left(\frac{\left(1+\Xi_{t}\right) \bar{y}_{t} \bar{\lambda}_{t}}{v_{\max }}\right)^{\alpha_{v}}}=\alpha_{v} .
$$

Hence, the representative household can be written with MaCurdy preferences, by simply rearranging the aggregate labor supply curve (A16):

$$
v_{\max } E_{t}^{\frac{1}{\alpha_{v}}}=\left(1+\Xi_{t}\right) \bar{y}_{t} \bar{\lambda}_{t}
$$

which is the FOC of objective function (A15) for $\eta=\alpha_{v}$ and $\Psi=v_{\max }{ }^{24}$

In Appendix Figure A.3 Panel (b), we plot the density of reservation raises for a MaCurdy model with potential earnings $\bar{y}$ and marginal utility of consumption $\bar{\lambda}$ are normalized to one, and the Frisch elasticity is 0.32 . The maximum micro labor supply disutility is set to $0.607^{-1 / 0.32}$ for an equilibrium employment rate at $60.7 \%$.

Heterogeneous (Sticky) Wages and Isoelasticity (Gali, 2011) The New Keynesian model presented in Galí (2011) (which also microfound the isoelasticity) additionally features wage heterogeneity. Individuals are a unit square indexed by $(l, n) \in[0,1] \times[0,1] . l$ denotes the type of labor, paid wage $y_{l t}$, which may diverge across types due to wage

${ }^{24}$ Alternatively, we can directly derive total disutility of labor $V\left(E_{t}\right)$ from employment rate $E_{t} \in[0,1]$, where the head optimally sorts the members by their disutility of labor up until $v=\mu\left(E_{t}\right)$, a threshold defined as the disutility of working of the marginal individual for total employment $E_{t}=G^{v}\left(\mu\left(E_{t}\right)\right)=\left(\frac{\mu\left(E_{t}\right)}{v_{\max }}\right)^{\alpha_{v}}$, which gives quantile function $\mu\left(E_{t}\right)=v_{\max } E_{t}^{1 / \alpha_{v}}$, and hence:

$$
V\left(E_{t}\right)=\int_{0}^{\mu\left(E_{t}\right)} v d G_{t}^{v}(v)=\frac{\alpha_{v}}{v_{\max } \alpha_{v}} \int_{0}^{\mu\left(E_{t}\right)}(v)^{\alpha_{v}} d v=\left.\frac{\alpha_{v}}{v_{\max } \alpha_{v}} \frac{v^{1+\alpha_{v}}}{1+\alpha_{v}}\right|_{0} ^{\mu\left(E_{t}\right)}=v_{\max } \frac{E_{t}^{1+1 / \alpha_{v}}}{1+1 / \alpha_{v}},
$$

which again mirrors MaCurdy utility function A15 for $\eta=\alpha_{v}$ and $\Psi=\bar{v}$. 
stickiness. $n$ indexes labor disutility, $n^{1 / \eta}$. The household head maximizes:

$$
\begin{aligned}
& \max _{c_{t},\left\{E_{l t}\right\}_{l}} \mathbb{E}_{t} \sum_{s=t}^{\infty} \beta^{s-t}(\frac{c_{s}^{1-\sigma}-1}{1-\sigma}-\Psi \int_{0}^{1} \overbrace{\int_{0}^{E_{l n}} n^{1 / \eta}}^{E_{l t}^{1+1 / \eta} /(1+1 / \eta)} d n d l) \\
& \text { s.t. } A_{t}+\int_{0}^{1} c_{l t} d l \leq A_{t-1}\left(1+r_{t-1}\right)+\left(1+\Xi_{t}\right) y_{l t} E_{l t}+T_{t} \quad \forall s \geq t,
\end{aligned}
$$

where the $l$-specific employment rate is $E_{l t}=\int_{0}^{1} e_{l t} d l$.

We now cast this setting into the reservation raise framework. First, we define the micro reservation raise, characterizing individual $i$ by type $n l$ :

$$
1+\xi_{n l t}^{*}=\frac{\Psi n^{\eta}}{y_{l t} \bar{\lambda}_{t}}
$$

Second, $1+\xi_{n l t}^{*}$ follows (with some nonemployment within each wage-type $l$ ), a power law distribution with maximum $\Psi\left(\left(\int_{0}^{1} y_{l t} \eta d l\right)^{1 / \eta} \bar{\lambda}_{t}\right)$ and shape parameter $\eta t^{25}$ This implies the following aggregate labor supply curve:

$E_{t}\left(1+\Xi_{t}\right)=F_{t}\left(1+\Xi_{t}\right)=P\left(\frac{\Psi_{s}^{1 / \eta}}{y_{l t} \bar{\lambda}_{t}} \leq 1+\Xi_{t}\right)=\int_{0}^{1}\left(\frac{\left(1+\Xi_{t}\right) y_{l t} \bar{\lambda}_{t}}{1 / \eta}\right)^{\eta} d l=\left(\frac{\left(1+\Xi_{t}\right)}{\Psi /\left(\left(\int_{0}^{1} y_{l t}^{\eta} d l\right)^{1 / \eta} \bar{\lambda}_{t}\right)}\right)^{\eta}$.

Third, the elasticity is again precisely $\eta$.

${ }^{25}$ Intuitively, the distribution of the reservation raise is power law distributed with the same parameter within each labor type. As a result, changes in $1+\Xi_{t}$ elicit the same proportional employment changes from each labor type, and the aggregate employment elasticity inherits that homogeneous elasticity. Our expression holds for $1+\Xi_{t}$ small enough that $1+\xi_{n l t}^{*}>1+\Xi_{t}$ holds for some $n$ within all labor types $l$, i.e., the aggregate net of raise rate must be high enough that some workers in each labor type are nonemployed. Otherwise, there is full employment from some labor types, and the labor response from those labor types is zero, so the aggregate Frisch elasticity is lower than $\eta$, and the CDF (labor supply curve) is:

$$
E_{t}\left(1+\Xi_{t}\right)=F_{t}\left(1+\Xi_{t}\right)=P\left(n \leq\left(\frac{\left(1+\Xi_{t}\right) y_{l t} \bar{\lambda}_{t}}{\Psi}\right)^{\eta}\right)=\int_{0}^{1} \min \left\{\left(\frac{\left(1+\Xi_{t}\right) y_{l t} \bar{\lambda}_{t}}{\Psi}\right)^{\eta}, 1\right\} d l
$$




\section{C.2 Heterogeneous Agent Models}

We now move to heterogeneous agent models, where atomistic households make labor supply and consumption decisions with separate budget constraints potentially facing incomplete markets. These class of models can feature heterogeneity in $\lambda_{i t}$, which is determined in equilibrium.

A useful classification of heterogeneity is whether it is permanent or transitory.

Permanent Heterogeneity With atomistic agents with separate budget constraints but permanent heterogeneity, a mass point of marginal individuals endogenously emerges. Specifically, in this setting individuals choose a lifetime fraction of working $l_{i}$, or equivalently a probability of working in a given period $\phi_{i t}$ s.t. $\int_{t=0}^{\infty} \phi_{i t}=l_{i}$, as in the timeaveraging approach of Ljungqvist and Sargent (2006). Permanent heterogeneity in tastes, endowments or wages affects the average employment probability, yet at each given point in time, these "interior" households are marginal. This local mass of marginal actors makes up one minus the fraction of households that either never or always work—implying an empirically uninteresting locally infinite elasticity ${ }^{26}$

We therefore next move to more realistic models with time-varying heterogeneity, starting with stochastic wages below, then moving to deterministically time-varying wageage profile in Appendix Section C.3

Time-Varying Heterogeneity: Stochastic Wages (Huggett, 1993) We now consider the popular case where the heterogeneity between households arises from stochastic productivity. Incomplete financial markets mean that income shocks pass through into budget constraints, and thence into consumption/savings policies, assets, consumption, and $\lambda_{i t}$. To study this setting through the lens of the reservation raise framework, we introduce indivisible labor into the Huggett (1993) model as in Chang and Kim (2006, 2007).

${ }^{26}$ To see how permanent heterogeneity can generate trivial reservation raise dispersion (in continuous time), consider a household (indexed by $i \in[0,1]$ ) characterized by disutility $v_{i}$, initial endowments $a_{0 i}$, and wages $w_{i}$ (and consumption tastes $u_{i}\left(c_{i t}\right)$ ), with stable interest rates $r=\rho$ and no borrowing constraint. So the household's problem is $\max _{c_{i t}, e_{i t}, a_{i t}} \mathbb{E}_{t} \int_{s=t}^{\infty} e^{-\rho(s-t)}\left[u_{i}\left(c_{i s}\right)-v_{i} e_{i s}\right] d s$ subject to a lifecycle budget constraint $\dot{a}_{i s}=\left(1+\Xi_{s}\right) y_{i} e_{i s}+r a_{i s}-c_{i s}+\mathbb{1}(s=t) \cdot a_{i t} \forall s \geq t \Leftrightarrow \int_{s=t}^{\infty} e^{-r(s-t)} c_{i s} d s=\int_{s=t}^{\infty} e^{-r(s-t)}\left(1+\Xi_{s}\right) y_{i} e_{i s} d s+a_{i t}$. First, labor supply is an employment policy $e_{i t}^{*}$ characterized by a constant-over-the-lifecycle reservation raise $1+\xi_{i t}^{*}=\frac{v_{i}}{\lambda_{i} y_{i}}=1+\xi_{i}^{*}$. Second, the distribution of the reservation raise (labor supply curve) is $E_{t}\left(1+\Xi_{t}\right)=F\left(1+\Xi_{t}\right)=\int_{i} \mathbb{1}\left[1+\xi_{i}^{*} \leq 1+\Xi_{t}\right] d i$. The constant raise structure implies that for a given prevailing raise $1+\Xi_{t}$, there are three reservation raise regions. Two inframarginal regions denote workers that do not work even for (small) net of raise rate increases, as well as those that always work even for small net of raise rate declines. The third set is the set of marginal individuals, who endogenously are exactly indifferent, and hence will all drop out of work for small net of raise rate declines, and all move into employment for small net of raise rate increases. Hence, if there is a mass point of these marginal individuals at the prevailing raise, the labor supply curve will exhibit an infinite Frisch elasticity at the extensive margin. 
There is a continuum of infinitely lived individuals, in discrete time. Assets $a_{i t}$ earn interest $r_{t}$. An individual chooses consumption $c_{i t}$ and indivisible labor supply $e_{i t} \in\{0,1\}$. Potential earnings $y_{i t}$ follow an exogenous Markov process. She faces borrowing limit $a_{\min }<0$ (set so that positive consumption is always feasible if working even at the lowest earnings level and when at the borrowing constraint), with discount factor $\beta \leq 1$ :

$$
\begin{array}{ll} 
& \max _{c_{i t}, e_{i t}, a_{i t}} \mathbb{E}_{t} \sum_{s=t}^{\infty} \beta^{s-t}\left[\frac{c_{i s}^{1-\sigma}}{1-\sigma}-\bar{v} e_{i s}\right] \\
\text { s.t. } \quad a_{i, s} & =\left(1+\Xi_{s}\right) y_{i s} e_{i s}+\left(1+r_{s}\right) a_{i, s-1}-c_{i s} \quad \forall s \geq t \\
& a_{i s} \geq a_{\min } \forall s \geq t .
\end{array}
$$

First, we calculate the reservation raise by individual, indexed by states $a$ and $y$ :

$$
1+\xi_{a y}^{*}=\frac{\bar{v}}{\lambda_{a y} y} .
$$

Second, we calculate the reservation raise distribution (CDF) from the joint distribution of assets and productivities, yielding the labor supply curve:

$$
E_{t}\left(1+\Xi_{t}\right)=F_{t}\left(1+\Xi_{t}\right)=\sum_{y \in Y} \int_{a_{\min }}^{\infty} \mathbb{1}\left[1+\xi_{a y}^{*} \leq 1+\Xi\right] g_{t}(a, y) d a,
$$

where $g(a, y)$ is the density of agents with assets $a$ and potential earnings $y$.

Third, the arc elasticities follow Equation (6), and depend on the joint distributions of $\lambda$ and $y$.

Below we assess these properties with two concrete earnings processes. We solve for consumption and labor supply rules, as well as the joint distribution of assets and productivity states, for an exogenous and constant interest rate $r_{s}=r \quad \forall s \geq t$.

Two-State Potential-Earnings Process We start by describing a simple economy with a two-state Markov process for potential earnings, jumping from $y_{1}$ to $y_{2}>y_{1}$ ( $y_{2}$ to $y_{1}$ ) with probability $\lambda_{12}\left(\lambda_{21}\right)$. Our goal here is to convey intuitions, and to illustrate the complexity of aggregate labor supply already with only two wage states-and how reservation raises can unveil and organize the obscure labor supply curve. The parameters are not picked to match any empirical moments, except for an equilibrium employment rate of $60.7 \%$ when $1+\Xi_{t}=1$. We plot the distribution of the reservation raises in Appendix Figure A.3 Panel (c).

In the model, for both wage levels, $1+\xi_{a y}^{*}$ is increasing in assets, since $\lambda_{a y}$, the 
individual's budget multiplier, is decreasing in assets. As expected, $1+\xi_{a y_{2}}^{*}<1+\xi_{a y_{1}}^{*}$ for any given asset level $a$, since higher wages raise consumption and the opportunity cost of not working. For $1+\Xi_{t}=1$, all high earners work for any holdings in the asset grid (i.e., $\left.1+\xi_{a y_{2}}^{*}<1 \forall a \in\left[a_{\min }, a_{\max }\right]\right)$. Low earners work if assets (and consumption) are below threshold $a_{y_{1}}^{*}$ s.t. $1+\xi_{a_{y_{1} y_{1}}^{*}}^{*}=1$.

The implied labor supply curve is plotted in Appendix Figure A.3 Panel (d), and exhibits complex behavior even with only two wage types, due to the asset distribution. When the labor raise is at $1+\Xi_{t}=1$, the marginal individual is a low-wage worker with a relatively high asset level. As $1+\Xi_{t}$ falls, low-earners drop out of employment in descending order of their assets holdings, with lower and lower density. At some point, the marginal individual is a low-wage earner with assets at the borrowing limit. Since there is a mass of such individuals, the labor supply curve is locally infinitely elastic at that point (echoing locally the logic in the models of homogeneity of Hansen, 1985; Rogerson, 1988). As $1+\Xi_{t}$ falls further, all low-wage individuals become nonemployed, and the marginal individual is now a high earner (and again the pecking order is given by asset holdings).

Realistic Earnings Process We now apply a realistic 33-state potential-earnings process, mimicking that in Kaplan, Moll, and Violante (2018) (whose model features only intensivemargin labor supply), which in turn approximates the empirical patterns documented in Guvenen, Karahan, Ozkan, and Song (2015). We detail the construction of that variant in Appendix Section C.4.3. The computational details for the full model are again described in Appendix Section C.4.2, and the full set of parameters are in Appendix Table A.3.

We plot the distribution of the reservation raises in Appendix Figure A.3 Panel (e). To further illustrate the compositional origins of the reservation raise distribution, Panel (f) plots the reservation raise distribution for three particular out of the 33 total values of potential-earnings states. High-potential-earnings individuals tend to have lower reservation raises, as expected, but the states themselves are not completely informative without reference to the Markov process that guides expected earnings dynamics and equilibrium assets distributions, further highlighting the benefit of the reservation raises as the sufficient statistic.

Overall, in the heterogeneous agent model calibrated to a realistic earnings process, the reservation raise distribution is widely dispersed. Specifically and as a result, the model generates a small local Frisch elasticity. For a 0.01 pertubation, the downward arc elasticity is 0.72 on the high side, but much smaller upwards (0.18). For large pertubations towards 0.10 , the elasticities quickly settle in below 0.5 . The equilibrium reservation raise distribution and hence labor supply curve inherit the joint distribution of $\lambda$ and $y$, so that 
the curve is particularly inelastic if low earnings realizations are offset by associated high $\lambda$ values.

\section{C.3 Intensive and Extensive Margins, and Lifecycle Dynamics: the Rogerson and Wallenius (2009) Model}

As in the general intensive-margin case in Section 4.1. permitting hours choices preserves the reservation raise logic. A leading model with both margins is that by Rogerson and Wallenius (2009), which also features lifecycle patterns (and the Frischian behavior of which Chetty, Guren, Manoli, and Weber, 2012, studied as a leading macro model with an extensive margin). We discuss our parameterization in Appendix Section C.4.4. largely following the paramaterization choices of Chetty, Guren, Manoli, and Weber (2012), but we change the tax rate and apply a $60.7 \%$ employment rate target for consistency with all our models and the survey, all hence matching our U.S. 2019 broad population benchmark.

The overlapping generations economy is set in continuous time and has a unit mass of individuals born at every instant, denoted by $i$, and each lives for a length of time equal to one. Age at time $t$ is denoted by $d_{i t} \in(0,1)$. (In our calibration, we will set the discount rate to zero, and individuals can save and borrow at zero interest rate.) The individual freely chooses hours worked $h_{i t}$ and consumption $c_{i t}$ at some utility $u\left(c_{i s}\right)$, which is separable from disutility of hours, here following the MaCurdy isoelastic sturcture with $v\left(h_{i t}\right)=\Gamma \frac{h_{i t}^{1+1 / \gamma}}{1+1 / \gamma}$. Earnings $\theta_{i s}\left(h_{i s}\right)$ depend on hours subject to a nonconvexity and age, as we discuss below. The optimization problem at time $t$ for individual $i$ of age $d$ (with remaining lifetime $1-d_{i t}$ ) is:

$$
\begin{aligned}
\max _{c_{i t}, h_{i t}} \mathbb{E}_{t} \int_{s=t}^{t+\left(1-d_{i t}\right)} e^{-\rho(s-t)}\left[u\left(c_{i s}\right)-v\left(h_{i s}\right)\right] d s \\
\quad \text { s.t. } c_{i s}+\dot{a}_{i s}=r_{s} a_{i s}+\left(1+\Xi_{s}\right) y_{i s} \quad \forall t+\left(1-d_{i t}\right) \geq s \geq t .
\end{aligned}
$$

Earnings $\theta_{i s}\left(h_{i s}\right)$ are structured as follows. Hourly wages $w_{i t}=w_{d_{i t}}$ are a triangular, single-peaked function of age $d$, generating lifecycle aspects. Moreover, rather than $y=$ $h w$, to generate an extensive margin, $\theta_{i s}\left(h_{i s}\right)$ features a nonconvexity of earnings in hours, in form of fixed hours cost: labor hours are productive, and hence are paid wages $w_{d}$, only above hours threshold $\underline{h}$ :

$$
\theta_{i t}\left(h_{i t}\right)=w_{d_{i t}} \cdot \max \left\{h_{i t}-\underline{h}, 0\right\}
$$

Absent this fixed cost, the marginal disutility at $h=0$ hours is zero, and so everyone works positive hours (provided positive wages) —eliminating the extensive margin, as in 
our intensive-margin example in Section 4.1 .

First, in a given period $t$, heterogeneity in reservation raises solely reflect heterogeneity in age $d$, so we can write reservation raises and choices indexed by age types $d$. Hours choices $h_{d t}^{*}\left(1+\Xi_{t}\right)$ are given by $\left(1+\Xi_{t}\right) w_{d} \lambda_{d t}=\Gamma\left[h_{d t}^{*}\left(1+\Xi_{t}\right)\right]^{1 / \gamma}$. Since our context features an intensive margin, this reservation raise is implicitly defined as a fixed point, as in our general job-choice case in Section 4.1 .

$$
1+\xi_{d t}^{*}=\frac{v\left(h_{d t}^{*}\left(1+\xi_{d t}^{*}\right)\right)}{\lambda_{d t} \theta_{d t}\left(h_{d t}^{*}\left(1+\xi_{d t}^{*}\right)\right)}=\frac{\frac{\Gamma}{1+\frac{1}{\gamma}}\left(\frac{\lambda_{d t}\left(1+\xi_{d t}^{*}\right) w_{d}}{\Gamma}\right)^{\gamma+1}}{\lambda_{d t} w_{d}\left(\left[\frac{\lambda_{d t}\left(1+\xi_{d t}^{*}\right) w_{d}}{\Gamma}\right]^{\gamma}-\underline{h}\right)} .
$$

That is, individuals work when the (hourly) wage is above some threshold $w^{*}{ }^{27}$ Also, setting $\underline{h}=0$ nests the MaCurdy intensive-margin-only setting, with $1+\xi_{d t}^{*}=0$ for all workers and ages, as in our general intensive-margin job choice in Section 4.1 .

Second, Appendix Figure A.3 Panel (h) plots the histogram of the reservation raise distribution, which also gives the aggregate labor supply curve:

$$
E_{t}\left(1+\Xi_{t}\right)=P\left(\frac{\Gamma(\underline{h}(1 / \gamma+1))^{1 / \gamma}}{\lambda_{d t} w_{d}} \leq 1+\Xi_{t}\right)=P\left(\frac{1}{w_{d}} \leq \frac{1+\Xi_{t}}{\Gamma(\underline{h}(1 / \gamma+1))^{1 / \gamma} / \lambda_{d t}}\right) .
$$

In the nonstochastic steady state, the budget constraint (A31) reduces into a lifecycle budget constraint, generating a homogenous $\lambda$, so the distribution of reservation raises solely inherits that of $1 / w_{d}$, a feature we discuss in detail below.

Third, we compute the extensive-margin arc elasticities. The Frisch arc elasticities range from 2.60 to 3.20 in this particular calibration, with local elasticities (from 0.01 net of raise rate pertubations) between 2.84 and 2.90 .28

\section{C.4 Further Computational Details}

We describe additional details of the models discussed in Section 4 and above.

${ }^{27}$ In fact, without uncertainty and perfect capital markets and hence a lifetime budget constraint $\bar{\lambda}$, we could then solve for the age-specific reservation raise explicitly as $1+\xi_{d}^{*}=\frac{\Gamma(\underline{h}(1 / \gamma+1))^{1 / \gamma}}{\bar{\lambda} w_{d}}$, and therefore also solve for the reservation wage and hence marginal ages.

${ }^{28}$ In principle, we could obtain the elasticity analytically from the reservation raise distribution. Our method to measure the arc elasticities on the basis of the reservation raise distribution complements the construction of the Frisch elasticity by Chetty, Guren, Manoli, and Weber (2012), who simulate a small, shortlived one percentage point tax change, which requires repeatedly solving the model for each generation, may include non-Frischian features, and only isolates one arc elasticity. 


\section{C.4.1 The Representative Household: A Short-Lived, Uncompensated Shock}

Here we describe how we model and quantify the uncompensated labor supply response of a representative household with MaCurdy-style convex labor supply disutility and shared consumption, depicted in Appendix Figure A.4.

Figure A.4: Frischian vs. Uncompensated Quarter-Long Deviation in the Aggregate Prevailing Raise: Extensive-Margin Aggregate Labor Supply Responses in Three Calibrated Models

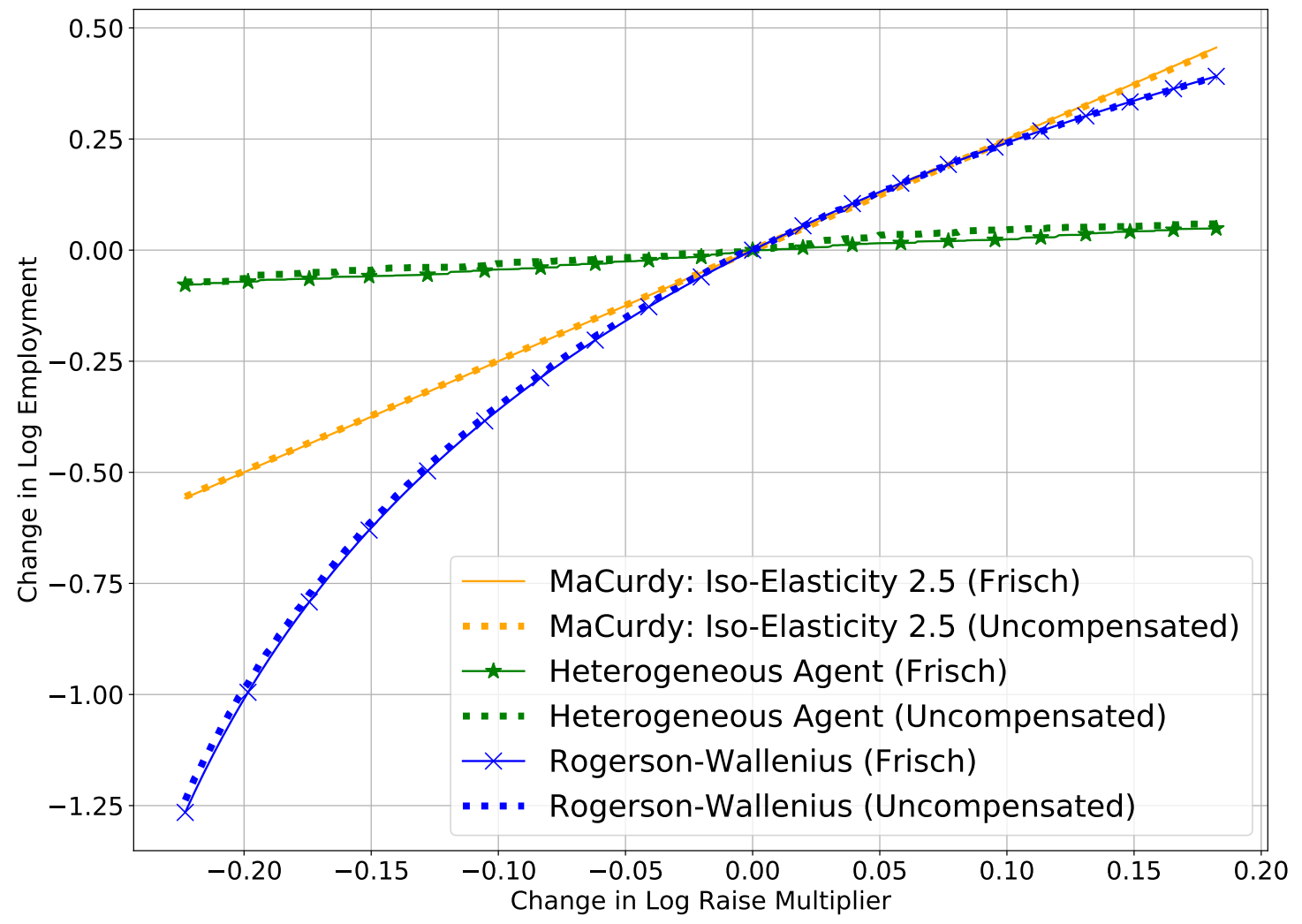

Note: The figure compares aggregate labor supply curves that are purely Frischian (from our reservation raise distributions) and from non-Frischian, uncompensated pertubations in the aggregate prevailing raise that are short-lived and last one quarter in each model. The three curves are output from simulating three of the models we discuss in detail in Section 4 a representative household model with an isoelasticity of 2.5, a heterogeneous agent mode with a realistic 33-state earnings process, and the Rogerson-Wallenius model with lifecycle aspects and an intensive-margin hours choice. The specific quantitative experiments are detailed in Appendix Section C.4 for each model. Model parameters are in Appendix Table A.3. 
We consider a household that maximizes

$$
\begin{array}{r}
\max _{C_{s}, E_{s}} \sum_{s=t}^{\infty} \beta^{s-t} \frac{C_{s}^{1-\sigma}}{1-\sigma}-\Psi \frac{E_{s}^{1-\eta}}{1-\eta} \\
\text { s.t. } \sum_{s=t}^{\infty} \frac{1}{1+r} C_{s} \leq \sum_{s \geq t}^{\infty} \frac{1}{1+r}\left(1+\Xi_{s}\right) y_{s} E_{s},
\end{array}
$$

so that wages are constant at $y_{t}=y \forall t$. We also consider the case were $\beta(1+r)=1$ so that $C_{t}=C \forall t$. We also have assumed that initial assets $A_{0}$ are zero, which implies the largest wealth effect among the range of nonnegative initial asset holdings, thereby providing the largest difference between the Frischian and uncompensated setting (away from the representative household being borrowing-constrained, a setting covered by our heterogeneous agent model).

We study partial equilibrium, i.e., hold aggregate equilibrium variables (interest rates, net of aggregate prevailing raise potential earnings/wages) fixed. We first construct the employment baseline for the unperturbed setting. Denote $\bar{E}$ and $\bar{C}$ as the employment and consumption levels in a stable setting in which $1+\Xi_{t}=1 \forall t$. The intratemporal substitution condition and the budget constraint imply, respectively $y \bar{C}^{-\sigma}=\Psi \bar{E}^{1 / \eta}$ and $\bar{C}=y \bar{E}$. Solving these conditions for $\bar{E}$ delivers $\bar{E}=\left[\frac{y^{1-\sigma}}{\Psi}\right]^{\frac{\eta}{1+\eta \sigma}}$.

Second, we turn to labor supply under a pertubation of the raise of size $1+\Xi$ lasting $T$ periods. In our uncompensated experiment, we set the baseline aggregate prevailing raise $1+\Xi_{t}=1+\Xi$ for $t=1, \ldots, T$, potentially diverging at a constant level from the baseline raise subsequently reset to unity at $1+\Xi_{t}=1$ for $t>T$. The labor response we plot is labor supply in period 1 under the initial raise level $1+\Xi_{t}=1+\Xi$.

Let $E^{\prime}$ and $E^{\prime \prime}$ denote labor supply when $1+\Xi_{t}=1+\Xi$ and $1+\Xi_{t}=1$ respectively. Then, optimal intratemporal labor supply implies

$$
\begin{aligned}
y C^{-\sigma} & =\Psi E^{\prime \prime 1 / \eta} \\
(1+\Xi) y C^{-\sigma} & =\Psi E^{\prime \prime 1 / \eta} .
\end{aligned}
$$

Hence, initial equals eventual labor supply times the Frisch-elasticity-scaled raise:

$$
\Longrightarrow E^{\prime}=(1+\Xi)^{\eta} E^{\prime \prime}
$$


The budget constraint then implies for consumption $C$ in this raise series (or for $\lambda$ ):

$$
\begin{aligned}
\sum_{t=T+1}^{\infty}\left(\frac{1}{1+r}\right)^{t} y E^{\prime \prime}+\sum_{t=1}^{T}\left(\frac{1}{1+r}\right)^{t}(1+\Xi) w E^{\prime} & =\sum_{t=0}^{\infty}\left(\frac{1}{1+r}\right)^{t} C \\
\sum_{t=T+1}^{\infty}\left(\frac{1}{1+r}\right)^{t} y E^{\prime \prime}+\sum_{t=1}^{T}\left(\frac{1}{1+r}\right)^{t}(1+\Xi)^{1+\eta} w E^{\prime \prime} & =\frac{1+r}{r} C \\
\frac{1+r}{r} y E^{\prime \prime}-\sum_{t=1}^{T}\left(\frac{1}{1+r}\right)^{t}\left(1-(1+\Xi)^{1+\eta}\right) y E^{\prime \prime} & =\frac{1+r}{r} C \\
y E^{\prime \prime}-\frac{r}{1+r} \sum_{t=1}^{T}\left(\frac{1}{1+r}\right)^{t}\left(1-(1+\Xi)^{1+\eta}\right) y E^{\prime \prime} & =C \\
& {\left[1-\frac{r}{1+r} \sum_{t=1}^{T}\left(\frac{1}{1+r}\right)^{t}\left(1-(1+\Xi)^{1+\eta}\right)\right] y E^{\prime \prime} }
\end{aligned}
$$

Let $m(T, 1+\Xi) \equiv\left[1-\frac{r}{1+r} \sum_{t=1}^{T}\left(\frac{1}{1+r}\right)^{t}\left(1-(1+\Xi)^{1+\eta}\right)\right]$. Combining the above with the intratemporal substitution condition (A38), one can solve for $L^{\prime}$ in particular as a function of baseline employment level $\bar{E}$ in the unperturbed setting, duration of the pertubation $T$, and raise deviation $1+\Xi$ :

$$
E^{\prime}=\left[(1+\Xi)^{\eta} m(T, 1+\Xi)^{-\sigma \eta /(1+\sigma \eta)}\right]\left(\frac{y^{1-\sigma}}{\Psi}\right)^{\frac{\eta}{1+\sigma \eta}}=\left[(1+\Xi)^{\eta} m(T, 1+\Xi)^{-\sigma \eta /(1+\sigma \eta)}\right] \bar{E} .
$$

The model is calibrated so that the period length corresponds to one month, so this experiment simulates a one-quarter shift in the prevailing aggregate labor raise by implementing a three-period duration of the shift. The quarterly interest rate is set to $0.764 \%$ (implying an annual discount factor of 0.97 ).

\section{C.4.2 The Heterogeneous Agent Model with Extensive-Margin Labor Supply}

We describe the model the solution algorithm, and how we simulate the short-lived uncompensated shock. We also describe the 33-state potential-earnings process.

The Model In this section we describe our modification to Huggett (1993), with endogenous labor supply, which occurs along the extensive margin only. 
Individuals solve

$$
\begin{array}{ll} 
& \max _{c_{i t}, e_{i t} \in\{0,1\}, a_{i t}} \mathbb{E}_{t} \sum_{s=t}^{\infty} \beta^{s-t}\left[\frac{c_{i s}^{1-\sigma}}{1-\sigma}-\bar{v} e_{i s}\right] \\
\text { s.t. } \quad a_{i, s}=\left(1+\Xi_{s}\right) y_{i s} e_{i s}+b\left(1-e_{i s}\right)+\left(1+r_{s}\right) a_{i, s-1}-c_{i s} \quad \forall s \geq t \\
a_{i s} \geq a_{\min } \forall s \geq t,
\end{array}
$$

where $y_{i, t}$ follows the Markov process described in Appendix Section C.4.3 below. Households endogenously choose their labor supply $e_{i t}$, which is restricted to 0 or 1 . As described in the main text, since individuals within the same asset and productivity levels face the same problem, consumption and labor supply decisions (and hence reservation raises) can be written as a function of assets and productivity.

The first-order condition on consumption is, as in the standard case,

$$
u_{c}\left(c^{*}(a, y), e^{*}(a, y)\right)=V_{a}(a, y)
$$

where $V$ is the value function for someone at asset level $a$ and earnings state $y$. The optimality condition on labor supply is

$$
e^{*}(a, w)= \begin{cases}1 & \text { if } V_{a}(a, y) y>\bar{v} \\ 0 & \text { if } V_{a}(a, y) y<\bar{v}\end{cases}
$$

A similar optimality condition solves the problem at the binding constraint $a_{\min }$ :

$$
e^{*}\left(a_{\min }, y\right)= \begin{cases}1 & \text { if } \frac{(y+r a)^{1-\sigma}}{1-\sigma}-v>\frac{(r a)^{1-\sigma}}{1-\sigma} \\ 0 & \text { otherwise }\end{cases}
$$

If $a_{\min }<0$, individuals at the borrowing constraint hence are always employed.

Solution Algorithm We solve the model with parameters $\sigma=2, r=0.03, \beta=0.97$, and unemployment insurance $b=0$. We set the borrowing constraint at $a_{\min }=-z_{1} r+0.001$, so that positive consumption is possible at the lowest productivity and asset levels if the individual works. We choose the labor supply disutility shifter $\bar{v}$ to match the equilibrium employment rate $60.7 \%$.

We use a grid of assets comprising a discrete set of asset levels $A$ with minimum $a_{\min }$ and maximum $a_{\max }=50000000$. We place fifty asset levels equally spaced between $a_{\min }$ and 0, 450 levels between 0 and 1000000, and 500 levels between 1000000 and 5000000 . We 
solve the consumption and labor supply rules using value function iteration:

$$
V^{n+1}(a, y)=\max _{a^{\prime} \in A, e \in\{0,1\}}\left\{u\left(y e+(1+r) a-a^{\prime}\right)+\beta \sum_{y^{\prime}} T_{y, y^{\prime}} V\left(a^{\prime}, y^{\prime}\right)\right\},
$$

where $T_{y, y^{\prime}}$ is the transition probability between productivity levels $y$ and $y^{\prime}$. Consumption is given by $c(a, y)=y e^{*}(a, y)+(1+r) a-a^{\prime *}(a, y)$, where $e^{*}$ and $a^{\prime *}$ are the solutions to the maximization problem in (A52) for an individual characterized by asset and productivity states $(a, y)$.

Consumption and labor supply rules solved for, we calculate the equilibrium joint distribution of $a$ and $y, g(a, y)$, by solving the system of equations:

$$
g(a, y)=\sum_{\tilde{y}} \sum_{\tilde{a} \text { s.t. } a^{\prime *}(\tilde{a}, \tilde{y})=a} g(\tilde{a}, \tilde{y}) T_{\tilde{y}, y} .
$$

With the joint distribution of assets and productivity assets, value functions, and consumption choices, we can solve for the distribution of reservation raises, and therefore the labor supply curve.

A Short-Lived, Uncompensated Shock We describe how we obtain the uncompensated labor supply curve in response to a quarter-long raise pertubation depicted in Appendix Figure A.4. The purpose of this exercise is to simulate the aggregate extensive-margin labor supply response of a heterogeneous agent economy under an uncompensated (nonFrischian) one-period change in the benefit of working i.e., the prevailing aggregate labor raise. We study partial equilibrium, i.e., hold aggregate equilibrium variables (interest rates, potential earnings) fixed.

Consider an individual with assets $a$ and productivity $y$. That individual faces a temporary prevailing aggregate raise $1+\Xi_{s}=1+\Xi$ during some period $s$, which then returns to a raise of level $1+\Xi_{t}=1$ for $t>s$. Then, that individual solves

$$
\begin{gathered}
\max _{c, e \in\{0,1\}}\left\{u(c, e)+\beta \sum_{y^{\prime}} T_{y, y^{\prime}} V\left(a^{\prime}, y^{\prime}\right)\right\} \\
\text { s.t. } a^{\prime}=(1+r) a-c+e y,
\end{gathered}
$$

where $u(c, e)=\frac{c^{1-\sigma}}{1-\sigma}-\bar{v} e$, and where $V$ is the value function from the solution to the equilibrium with the baseline unit raise in all periods.

For a given prevailing labor raise, the solution is easily found by maximizing the 
utility over a grid of consumption points under employment and nonemployment, since the problem is not recursive. We then measure the labor supply response as the difference in the measure of individuals who choose employment under the temporary first-periodonly labor raise $1+\Xi$ versus the measure of individuals who choose employment in the baseline economy with the unit raise.

The model is calibrated so that the period length corresponds to one quarter, so this experiment simulates a one-quarter shift in the prevailing aggregate raise.

\section{C.4.3 The Potential Earnings Process}

We now apply a realistic 33-state potential-earnings process, mimicking that in Kaplan, Moll, and Violante (2018) (whose model features only intensive-margin labor supply), which in turn approximates the empirical patterns documented in Guvenen, Karahan, Ozkan, and Song (2015). Our Markov process represents an underlying process modeled as the sum of two independent components $\log y_{i t}=\log y_{1, i t}+\log y_{2, i t}$, with the $\log$ of each component $y_{j, i t}$ evolving according to a jump-drift process. Jumps arrive at a Poisson rate $\gamma_{j}$, and trigger new draws of the earnings component from a mean-zero normal distribution. Between jumps, the process drifts toward zero at rate $\beta_{j}{ }_{20}^{29}$ Kaplan, Moll, and Violante (2018) implement this process as two finite-state continuous time Markov processes for each independent component. In our application, we do so as a single discrete-time Markov process in which the income states are hence combinations of the states of the two income processes ${ }^{30}$ We discretize the continuous time transition rates between states by using the matrix exponential; i.e., the discrete time transition matrix for income component $j$ is calculated as $T^{j, d}=\exp T^{j, c}=\sum_{k=0}^{\infty} \frac{1}{k !}\left(T^{j, d}\right)^{k}$, where $T^{j, c}$ is the continuous time transition matrix for component $j$. The continuous time transition rates are measured with quarters as the unit of time, so the discrete time transition matrix is also in quarters. Then, we collapse the discrete time transition matrices for the two components into a single transition matrix between one-dimensional income states. $T_{y, y^{\prime \prime}}^{d}$ the transition probability between the single-dimension income state $y$ to $y^{\prime}$ for which $\log y=\log y_{1}+\log y_{2}$ and $\log y^{\prime}=\log y_{1}^{\prime}+\log y_{2}^{\prime}$, is then equal to $T_{y_{1}, y_{1}^{\prime}}^{1, d} T_{y_{2}, y_{2}^{\prime}}^{2, d}$. (For this process and the income levels chosen, conveniently each $y$ state is uniquely defined by one $\left(y_{1}, y_{2}\right)$ combination.)

\footnotetext{
${ }^{29}$ Of course, in our model not all individuals will work; we do not estimate a latent potential earnings process such that the modeled realized earnings, taking into account labor supply decisions, would generate realized empirical earnings dynamics.

${ }^{30}$ Inconsequential for quantities, we normalize the earnings state levels so that the average steady-state potential earnings are equal to the 2015 U.S. average personal income.
} 


\section{C.4.4 The Rogerson and Wallenius (2009) Model}

We describe the solutions, and the simulations of the shock.

Parameterizing the Baseline Model The original Rogerson and Wallenius (2009) distribution of the hourly wage $w_{d}$ (labor efficiency) arises from a uniform age distribution and a triangular wage-age gradient (single-peaked at $d=1 / 2$ with $w_{d=1 / 2}=\hat{w}_{0}$ as the maximum wage level, and generally $\left.w(d)=\hat{w}_{0}-\hat{w}_{1}|d-0.5|\right)$. We approximate the continuum of generations with 1,000,000 equally spaced discrete generations, and solve the model following the Technical Appendix of Chetty, Guren, Manoli, and Weber (2012). We choose the utility function parameters $(\Gamma$, the labor disutility shifter, $\gamma$, the labor supply intensive-margin elasticity), effective labor supply parameters $(\bar{h}$, the minimum number of hours worked, and $\hat{w}_{1}$, the slope of the wage-age gradient) and the tax rate at which the model equilibrium is calculated. We assume CRRA log consumption utility $(\sigma=1)$. We set the initial tax (raise) rate at $26 \%$, which was the average net tax rate faced by an average single worker in 2017. We set the labor supply intensive-margin elasticity to 2.0. From this point, we conduct two paramaterizations. In the first, we choose the remaining three parameters, $\Gamma, \bar{h}$, and $\hat{w}_{1}$, to match three equilibrium targets, as in Chetty, Guren, Manoli, and Weber (2012): the employment rate (60.7\%, as in the other model exercises), the maximum intensive-margin hours choice (0.45), and the ratio of the lowest wage to the highest wage received over the lifecycle (0.5). This paramaterization sets $\Gamma=42.492$, $\bar{h}=0.258$, and $\hat{w}_{1}=0.851$.

For each generation/age, indexed by $d$, we calculate hours at each age, $h_{d^{*}}^{*}$ and then calculate the reservation raises using $1+\xi_{d}^{*}=\frac{(1-\tau) w_{d}\left(h_{d}^{*}-\bar{h}\right) u^{\prime}\left(c_{d}\right)}{v\left(h_{d}^{*}\right)}$. This formulation of the reservation raise is "normalized" so that the relevant wage is the after-tax wage, and so the indifferent worker is that of the age $d$ such that $1+\xi_{d}^{*}=1$.

This, combined with the (uniform) distribution of age, gives the distribution of reservation raises, from which we can compute the arc elasticities.

Low-Frisch Elasticity Parameterization Second," we also set the peak of the wage-age profile to target a lower extensive-margin Frisch elasticity. This paramaterization sets $\Gamma=40.000, \bar{h}=0.248, \hat{w}_{1}=1.319$, and lifetime peak productivity at 1.110 .

Shutting off the Intensive Margin We also add a variant that shuts off intensive-margin reoptimization. We do so by simply solving for the optimal policies, extracting the reservation raises, and then computing alternative reservation raises that hold hours fixed at the corresponding unit raise point, such that $1+\xi_{d}=\frac{v\left(h_{d, 1+\Xi=1}^{*}\right)}{\theta_{d}\left(h_{d, 1+\Xi=1}^{*}\right) \lambda}$. 
A Short-Lived, Uncompensated Shock We simulate the labor supply response under a temporary, short, but noninstantaneous (and therefore non-Frischian) shift in the prevailing aggregate raise. As in the other models, we again study partial equilibrium, i.e., hold aggregate equilibrium variables (e.g., interest rates) fixed. We suppress calendar time subscripts in what follows. We continue to solve the model in continuous time, i.e., in the context of considering a time interval corresponding to a month-long duration, one could work for part of the period rather than having a period-long policy. Households are subject to our aggregate prevailing labor raise $1+\Xi$ for a time interval of duration $m$. After this interval, the raise returns to unity. The raise shock is unanticipated, and once occurring, the households perfectly foresee that the raise deviation will last exactly $m$ time units before returning to unity. Upon realization of the shock, households will re-optimize their planned consumption and labor supply paths.

To solve for assets, we first solve for assets at age $d$ before the raise shock. Currently held assets are determined by past earnings, government transfers (which are equal to $\tau \bar{c}$, where $\bar{c}$, taken as parametric by the household, is the equilibrium consumption level in turn equal to average income and hence $\tau \bar{c}$ is the average labor income raise payment and also government rebate), and consumption $c$ :

$$
\int_{0}^{d}\left((1-\tau) e_{\tilde{d}} y_{\tilde{d}}+\tau \bar{c}-c\right) d \tilde{d}
$$

where $e_{\tilde{d}}$ is desired employment and $y(\tilde{d})$ is potential gross earnings at age $\tilde{d}$. For $\tilde{d} \in$ [ $\left.d_{\min }, d_{\max }\right]$, where $d_{\min }$ and $d_{\max }$ are the (endogenous) entry and exit ages,

$$
\begin{aligned}
e_{\tilde{d}} y_{\tilde{d}} & =w_{\tilde{d}}\left(h_{\tilde{d}}-\bar{h}\right)=w_{\tilde{d}}\left(h_{0} \hat{w}_{0}^{-1 / \gamma} w_{\tilde{d}}^{1 / \gamma}-\bar{h}\right)=\left[h_{0} \hat{w}_{0}^{-1 / \gamma} w_{\tilde{d}}^{1+1 / \gamma}-\bar{h} w_{\tilde{d}}\right] \\
& = \begin{cases}{\left[h_{0} \hat{w}_{0}^{-1 / \gamma}\left(\hat{w}_{0}-0.5 \hat{w}_{1}+\hat{w}_{1} \tilde{d}\right)^{1+1 / \gamma}-\bar{h}\left(\hat{w}_{0}-0.5 \hat{w}_{1}+\hat{w}_{1} \tilde{d}\right)\right] \quad \text { if } \tilde{d}<0.5} \\
{\left[h_{0} e_{0}^{-1 / \gamma}\left(\hat{w}_{0}+0.5 \hat{w}_{1}-\hat{w}_{1} \tilde{d}\right)^{1+1 / \gamma}-\bar{h}\left(\hat{w}_{0}+0.5 \hat{w}_{1}-\hat{w}_{1} \tilde{d}\right)\right] \text { if } \tilde{d} \geq 0.5,}\end{cases}
\end{aligned}
$$


and 0 if $\tilde{d} \notin\left[d_{\min }, d_{\max }\right]$. The lifetime gross-of tax/raise labor income up to age $d$ is:

$$
\int_{0}^{d} e_{\tilde{d} y \tilde{d}} d \tilde{d}= \begin{cases}0 & \text { if } d<d_{\min } \\ \left.\left(\frac{h_{\tilde{d}}}{\left(2+\frac{1}{\gamma}\right) \hat{w}_{1}}-\frac{\bar{h}}{2 \hat{w}_{1}}\right) w_{\tilde{d}}^{2}\right|_{d_{\min }} ^{d} & \text { if } d_{\min } \leq d<0.5 \\ \left.\left(\frac{\tilde{d}}{\left(2+\frac{1}{\gamma}\right) \hat{w}_{1}}-\frac{\bar{h}}{2 \tilde{w}_{1}}\right) w_{\tilde{d}}^{2}\right|_{d_{\min }} ^{0.5}+\left.(1-\tau)\left(-\frac{h_{\tilde{d}}}{\left(2+(1-\tau) \frac{1}{\gamma}\right) \hat{w}_{1}}+\frac{\bar{h}}{2 \hat{w}_{1}}\right) w_{\tilde{d}}^{2}\right|_{0.5} ^{d} & \text { if } 0.5 \leq d<d_{\max } \\ \left.\left(\frac{h_{\tilde{d}}}{\left(2+\frac{1}{\gamma}\right) \hat{w}_{1}}-\frac{\bar{h}}{2 \hat{w}_{1}}\right) w_{\tilde{d}}^{2.5}\right|_{d_{\min }} ^{0.5}+\left.\left(-\frac{h_{\tilde{d}}}{\left(2+\frac{1}{\gamma}\right) \hat{w}_{1}}+\frac{\bar{h}}{2 \hat{w}_{1}}\right) w_{\tilde{d}}^{2}\right|_{0.5} ^{d_{\max }} & \text { if } d \geq d_{\max },\end{cases}
$$

from which follows lifetime net income if multiplied by $1-\tau$.

Consider an individual of age $d$. Let $m$ denote the length of the temporary raise change. One solves for optimal consumption and labor supply by finding the consumption level $c_{\Xi, d}$ that balances the income's lifetime budget constraint, subject to (a) their labor income being subjected to a multiplier and (b) the individual adjusting the remainder of their lifetime's labor supply to meet extensive and intensive-margin labor supply optimality conditions. In our experiment, for each given age level $d$, the time series of the aggregate prevailing raise will be given by

$$
1+\Xi_{\tilde{d}}=\left\{\begin{array}{l}
1+\Xi \text { if } \tilde{d} \in[d, d+m] \\
1 \text { if } \tilde{d}>d+m
\end{array}\right.
$$

For a proposed consumption level $c_{\Xi, d}$ (where subscript $d$ denotes the time at which the raise pertubation started, rather than the period during which the consumption occurs, as consumption is constant across all post-raise ages $\tilde{d}>d$ ), during the ages $\tilde{d}>d$, let $h_{\tilde{d}, d}$ be the age $\tilde{d}>d$ labor supply choice of an individual that was age $d$ when the temporary labor raise shift began.

For working ages $\tilde{d}$, intensive-margin labor supply implies that

$$
\Gamma h_{\tilde{d}, d}^{\gamma}=(1-\tau)\left(1+\Xi_{\tilde{d}}\right) u^{\prime}\left(c_{\Xi, d}\right) w_{\tilde{d}} .
$$

As in the standard setup, there will be cutoff rules that dictate extensive-margin labor supply. Under a temporary $1+\Xi$ shift, one cannot dictate age cut-offs since the benefit of working does not follow the same single-peaked shape as the original model. However, one can determine raise-productivity cutoffs in $\left(1+\Xi_{\tilde{d}}\right) w_{\tilde{d}}$.

At ages $\hat{d}$ at which the individual is indifferent to extensive-margin labor supply (con- 
ditional on optimizing on the intensive margin if working), the intensive and extensivemargin conditions imply respectively:

$$
\begin{aligned}
\Gamma h_{\hat{d}, d}^{\gamma} & =(1-\tau)\left(1+\Xi_{\hat{d}}\right) u^{\prime}\left(c_{\Xi, d}\right) w_{\tilde{d}} \\
\Gamma \frac{h_{\hat{d}, d}^{1+\gamma}}{1+\gamma} & =(1-\tau)\left(1+\Xi_{\hat{d}}\right) u^{\prime}\left(c_{\Xi}, d\right) w_{\tilde{d}}\left(h_{\hat{d}, d}-\bar{h}\right) .
\end{aligned}
$$

Combining these two implies an hours choice at the marginal age of $h_{\hat{d}, d}=\frac{(1+\gamma)}{\gamma} \bar{h}$, on the basis of which we solve for the marginal age (productivity) as follows:

$$
\Gamma\left(\frac{(1+\gamma)}{\gamma} \bar{h}\right)^{\gamma}=(1-\tau)\left(1+\Xi_{\hat{d}}\right) u^{\prime}\left(c_{\Xi, \hat{d}}\right) w_{\tilde{d}} \Longrightarrow\left(1+\Xi_{\hat{d}}\right) w_{\tilde{d}}=\frac{\Gamma\left(\frac{(1+\gamma)}{\gamma} \bar{h}\right)^{\gamma}}{(1-\tau) u^{\prime}\left(c_{\Xi, \hat{d}}\right)} .
$$

The individual will prefer working over nonworking at age $\tilde{d}$ if $\left(1+\Xi_{\tilde{d}}\right) w(\tilde{d}) \geq \Gamma\left(\frac{(1+\gamma)}{\gamma} \bar{h}\right)^{\gamma} /\left((1-\tau) u^{\prime}\left(c_{\Xi, d}\right)\right)$. From this cutoff, one can compute optimal planned extensive-margin supply for every age $\tilde{d}>d$. For a proposed candidate for the consumption level, one can then compute the balance of the individual's lifetime budget constraint given both the change in consumption and the lifetime extensive- and intensive-margin labor supply responses ${ }^{31}$ The solution to the individual's problem is the consumption level $c_{\Xi, d}$ that balances the individual's lifetime budget constraint. Repeating this for every individual in the economy (i.e., repeating this for every age $d \in[0,1])$ delivers the aggregate labor supply response. We measure the labor supply response to this temporary (but noninstantaneous) raise shift using the change in labor supply upon impact of the raise.

We set the length of the uncompensated raise shift to $1 / 240$, to represent the length of one quarter out of a 60-year adult lifespan.

\footnotetext{
${ }^{31}$ We isolate the labor supply responses, and therefore hold fixed in our partial-equilibrium experiment all aggregate variables except for the prevailing raise (i.e., government transfers and taxes, so the government budget is unbalanced in this exercise).
} 